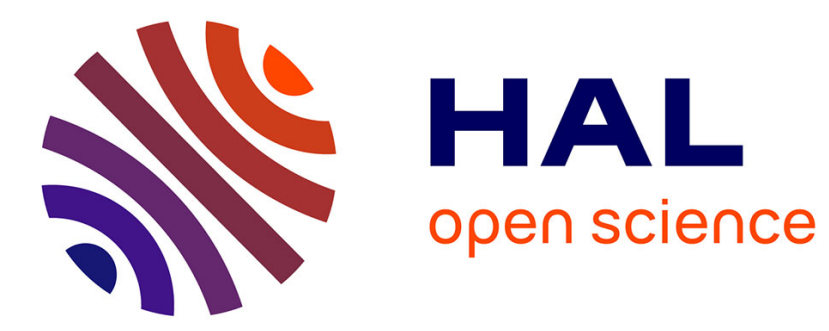

\title{
Bagues et anneaux à l'époque romaine en Gaule Hélène Guiraud
}

\section{To cite this version:}

Hélène Guiraud. Bagues et anneaux à l'époque romaine en Gaule. Gallia - Fouilles et monuments archéologiques en France métropolitaine, 1989, 46 (1), pp.173-211. hal-01939646

\section{HAL Id: hal-01939646 \\ https://hal.science/hal-01939646}

Submitted on 12 Feb 2020

HAL is a multi-disciplinary open access archive for the deposit and dissemination of scientific research documents, whether they are published or not. The documents may come from teaching and research institutions in France or abroad, or from public or private research centers.
L'archive ouverte pluridisciplinaire HAL, est destinée au dépôt et à la diffusion de documents scientifiques de niveau recherche, publiés ou non, émanant des établissements d'enseignement et de recherche français ou étrangers, des laboratoires publics ou privés.

\section{(이) $\$$}

Distributed under a Creative Commons Attribution - NonCommercial - NoDerivatives| 4.0 


\title{
BAGUES ET ANNEAUX À L'ÉPOQUE ROMAINE EN GAULE*
}

\author{
par Hélène GUIRAUD
}

Dans le cadre géographique de la Gaule à l'époque romaine, l'auteur propose une typologie des bagues et des anneaux, malgré les difficultés rencontrées avec ce genre d'objets : ce sont des pièces de création artisanale mais fabriquées selon des techniques variées; parures soumises à la mode, ce sont aussi des bijoux individuels, aus côles divers. Des cartes de répartition et des tableaux chronologiques (avec des marges assez larges) ont été éta is pour les formes les plus courantes.

Les résultats témoignent des fluctuations, dans le temps et dans l'espace, d'une clientèle au niveau de vie v.rila)le. La plupart de ces bijoux marquent l'adoption d'un instrument de la civilisation romaine, dans tout le pa: mais surtout dans des zones favorisées, axes de circulation et régions urbanisées. Nombre de formes et de decorations de la bijouterie préromaine ont disparu; ces bagues suivent une mode identique à celle du reste de l' $2 m_{\mathrm{P}}$ ire, avec, cependant, quelques formes ou types de décor privilégiés. Les ateliers sont rarement connus.

In the bounds of the Roman Gaul, the author proposes a typology of finger-rings, in spite of the difficulties in the study of these objects, producted by craftsmen bul wilh various lechniques, personal jewellery with differents functions ana following the fashion. Maps and chronological rolls (with broad limitations) are intended for usual shapes.

The following account presents the customers' fluctuations (in course of time and according to the lands and the owners' wealth). To a large degree, these rings mean the adoption of a Roman object, all over Gaul, but chiefly in improved areas, traffic axes and towns. Most pre-roman jewellery shapes and decorations have vanished and these jewels follow the fashion of the other roman countries; however, some shapes and decorations are privileged. Few of the workshops are known.

Les bagues sont des objets fragiles, souvent endommagés; relevant de la mode, elles peuvent sembler négligeables. Pourtant, nous voudrions apporter ici quelques conclusions tirées de l'étude de ces bijoux dans les provinces de la Gaule romaine,

* Le catalogue qui a servi de base à cet article est le résultat de longues années de recherches; le texte dactylographié est déposé à la Bibliothèque universitaire de Toulouse Le Mirail. Nous tenons à remercier tous ceux qui nous ont aidée dans ce travail : conservateurs des musées, fouilleurs, techniciens... Nous exprimons notre gratitude au Professeur G. Nicolini pour ses nombreux conseils. afin de montrer la place qu'avaient ces petits objets dans la civilisation gallo-romaine, dans la transmission d'un mode de vie romain. En effet, alors que l'orfèvrerie celtique est unanimement admirée pour sa richesse, elle n'a produit qu'un nombre limité de bagues, car cet objet n'avait pas la valeur sociale qu'il prit dans la société romaine. Les formes utilisées par les Gaulois sont des anneaux coudés ou hélicoïdes, des bagues ornées de spires ou d'un chaton métallique plat, de nombreux anneaux de verre multicolores; les bagues avec une pierre gravée n'apparaissent que de manière très sporadique avant le $\mathrm{I}^{\text {er }} \mathrm{s}$. avant J.-C. Avec la conquête romaine, la 
mode des bagues de type romain se développe et l'usage des sceaux se répand en même temps que la langue latine et l'écriture. En plus de leurs valeurs affective, esthétique ou financière, les bagues témoignaient du rang juridique de leur possesseur dans la société romaine ${ }^{1}$; porter un bijou de type romain pouvait traduire la volonté de s'intégrer à la société romanisée, comme l'était, pour une stèle funéraire, le choix d'un personnage tenant un volumen. La présence de bagues sur un site permet donc d'ajouter un témoignage supplémentaire de la romanisation, et aussi, parfois, d'étayer la datation d'un local, d'une tombe.

Pour cette étude, nous avons d'abord effectué le recensement (plus de 3000 objets, ce qui ne saurait être exhaustif) des bagues et des anneaux répertoriés dans les divers musées de France ou dans les comptes rendus de fouilles anciennes ou récentes; pour les zones rhénanes, l'ouvrage de F. Henkel a servi de référence, et la liste des objets rhénans a été actualisée grâce aux publications plus récentes parues en Suisse, Allemagne ${ }^{2} .$. Ensuite nous avons cherché à établir une typologie, selon une démarche

1 La codification du port de l'anneau d'or et l'évolution de la jurisprudence sont signalées dans les textes antiques: Pline L'Ancien, Naturalis Historia $(=N H)$, XXXIII, 8-36, historique de l'anneau; étude ancienne de M. Deloche, Le port des anneaux dans l'Antiquité el dans les premiers siècles du Moyen Age, MAI, 53, 1896; - A. M. DufF, Freemen in the Early Roman Empire, Cambridge, réedition 1958, p. 85 et 214220 ; - J. Gaudemet, Institutions de l'antiquité, Paris, 1967, p. 567. Voir aussi les notices "Sigillum " et "Signum * dans les encyclopédies. Pour résumer une situation assez confuse que les spécialistes n'ont pu totalement clarifier, disons qu'au début de l'Empire, l'anneau d'or est réservé aux hommes de rang sénatorial et équestre (en partie seulement), en 23, aux hommes nés de père et d'aïeul libres, sous certaines conditions financières (avoir le cens équestre : PLINE, NH, XXXIII, 32); à partir de Commode, les exigences censitaires disparaissent et, en 197, Septime Sévère accorde le droit à l'anneau d'or à tous les légionnaires.

2 F. Henkel, Die römischen Fingerringe der Rheinlande und der benachbarten Gebiete, Berlin, 1913 (= HENKEL); A. Krug, Römische Fundgemmen, Germania, 53, 1975, p. $113-125 ; 55,1977$, p. $77-84 ; 56,1978$, p. $476-503 ; 58,1980$, p. 117-135; - A. Krug, Antike Gemmen im RömischGermanischen Museum Köln, Bericht der röm.-germ. Kommission, 61, 1980, p. 151-260; - M. Guisan, Bijoux romains d'Avenches, Pro Aventico, 1975,-p. 5-39; - T. TomasevicBuck, Ein Depotfund in Augusta Raurica, Insula 2, Bayerische Vorgeschichlsblätter, 45, 1980, p. 91-117; - G. Pl.ATZHorster, Die antiken Gemmen im Rheinischen Landesmuseum Bonn, Bonn, 1984. A còté de ces publications assez importantes, il existe, comme en France, de nombreuses références dans des ouvrages moins spécialisés. Voir aussi F. H. Marshal.t, Catalogue of the Finger Rings, Greek, Etruscan and Roman, in the Department of Antiquities, British Museum, Londres, réedition 1968, pour les bagues en génèral (= MARSHaLL). que nous avons expliquée dans un précédent article de Gallia ${ }^{3}$, lors de l'étude d'un trésor de la région lyannaise. Nous ne reprendrons ce texte que pour en résumer les principaux points et ajouter quelques remarques, puisque'l'étude actuelle s'étend à toutes les parures digitales et non aux seules bagues à incrustation.

La týpologie est construite sur l'examen de l'ensemble des caractères créant une forme donnée.

C'est le volume général qui a déterminé le classement en divers types : certains se sont constitués de manière assez évidente, types 8 et 9 , type 7 , les bijoux ouverts, type 6 , les bagues-nœuds, type 5 les bagues à appendice latéral. Pour la grande masse des autres bagues, d'autres critères ont été nécessaires.

Le premier qui s'est imposé a été la présence d'un élément étranger à la forme métallique, pierre, pâte de verre, émail (Boistray, p. 221); selon la position de l'incrustation, dans le corps du bijou ou dans une capsule au-dessus de la ligne de l'anneau, nous avons distingué des types dans lesquels la bague forme un tout, avec un volume général étiré vers le haut (type 1) ou un volume disposé horizontalement (type 2) et des types où l'anneau et le chaton sont deux parties distinctes, le volume de l'anneau harmonisé avec celui du chaton (type 3) ou les volumes des deux parties dissociés (type 4).

Certaines bagues monométalliques imitent les bagues ornées de pierres en utilisant à la place une pastille de métal (fig. 1); d'autres profitent des avantages d'une forme de monture assez large pour incruster un autre genre de décor métallique : une monnaie (fig. 25, en bas); il faut donc classer ces bagues selon leur forme avec les bagues à incrustation de pierre.

En revanche, les bagues monométalliques «ordinaires", sans incrustation, se distinguent des précédentes par la faible épaisseur du dessus (fig. 2) : elles sont placées dans les types correspondant à leur aspect général (types 1 à 4), mais regroupées dans des formes autres que celles des bagues à inscrustation de pierre.

3 H. Guiraud, Les bagues d'époque romaine du trésor de Boistray (Rhône), Gallia, 39, 1981, p. 219-233 (= Boistray); - M. Amandry, conservateur au Cabinet des Médailles, Paris (que nous remercions ici) a repris l'examen des monnaies du trésor et nous a signalé que la monnaie de Maximin est celle de Maximin de Thrace (et non Maximin Daia); la composition du trésor est habituelle et s'achève avec des monnaies de Gallien, vers 260 ; la présence d'une monnaie de Magnia Urbica ne peut s'expliquer avec certitude (Boistray, p. 226 et 230 ). 




On doit ètudier les différents caractères du bijou : forme du contour, diamètre extérieur, aspect de l'anneau autour du doigt, proportions, rapport entre l'incrustation ou la zone décorée sur le dessus et le reste du bijou, profil, section (Boistray, p. 223226). Tous ces éléments permettent de distinguer dans tous les types des variantes de forme : $2 \mathrm{~b}, 2 \mathrm{c}$ par exemple ou $5 \mathrm{a}, 5 \mathrm{~b} \ldots$

Les différents types de bagues ainsi obtenus sont figurés sur les croquis ${ }^{4}$. Au fur et à mesure que se construisait la typologie, la chronologie des diverses formes et leur répartition géographique sur des cartes* prenaient corps.

4 Certains de ces croquis sont déjà parus dans Boistray et d'autres, concernant les formes portant des intailles ou des camées, dans II. Guiraud, Intailles et camées de l'époque romaine en Gaule, $48^{\mathrm{e}}$ suppl. à Gallia, 1988, p. 77 à 81 ; il faut y ajouter les formes monométalliques dans les types 2 et 4 et les types 5-9.

* Les bagues et les anneaux (reproduits grandeur nature) ont èté reportés sur des cartes, selon leur lieu de provenance. Ils sont indiqués par des symboles dont la taille correspond au nombre d'objets répertoriés.

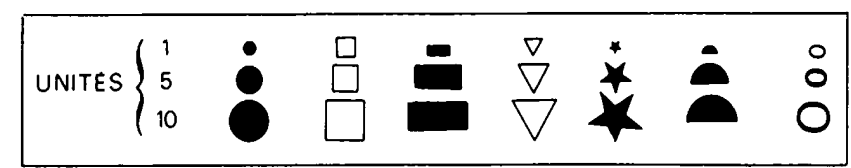

Les limites des cartes sont celles de la Gaule jusqu'au Rhin et à la région des Champs Décumates; les variations des limites des provinces de Gaule n'ont pas été prises en compte.
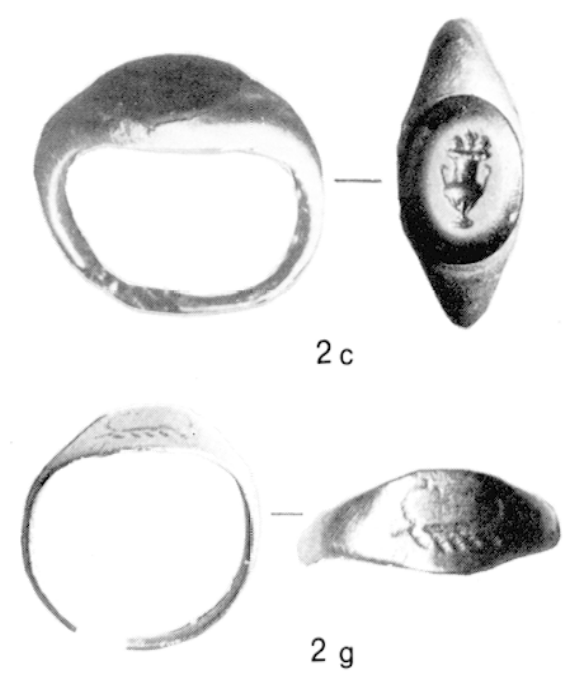

Fig. $2-$

Bague 2c;

or, nicolo; représentation d'un vase;

provenance : sanctuaire des Sources de la Seine

(Côte-d'Or); (Musée archéologique de Dijon, Côte-d'Or).

Bague 2g;

or; sur le dessus, gravure d'un bateau;

provenance : sanctuaire des Sources de la Seine

(Côte-d'Or); (Musée archéologique de Dijon, Côte-d'Or).

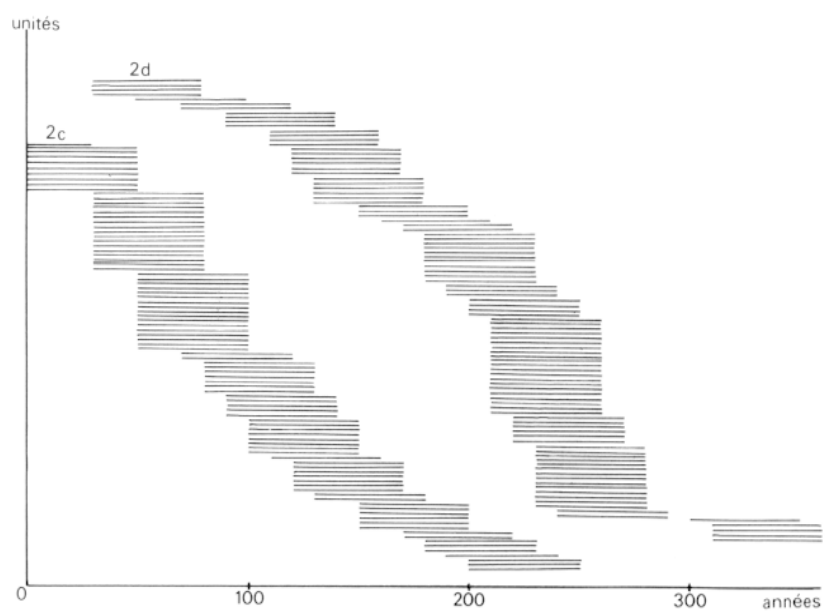

Fig. 3 - Exemple de tableau chronologique établi ici pour les formes $2 c$ et $2 \mathrm{~d}$. Pour chaque forme, chaque objet daté provenant de Gaule ou d'autres régions de l'Empire est figuré par un trait représentant 50 ans en arrière par rapport à la date d'enfouissement connue.

La chronologie (Boistray, p. 226-228) est fondée sur les datations fournies par les fouilles et avec l'aide des monnaies enchâssées dans certaines formes et de quelques rares figures, gravées sur les intailles ou les camées, exactement datables, comme les portraits impériaux. Mais la datation de bijoux appelle toujours les mèmes réserves : les bijoux sont des objets de valeur, donc thésaurisés parfois, des 
objets chargés d'une connotation affective, donc conservés longtemps, des parures mettant en valeur la beauté d'une personne, donc vite abandonnées si la mode change. Nous avons reporté sur des tableaux (fig. 3) les résultats de ces recherches chronologiques, malgré ces réserves. Pour chaque forme, chaque objet daté provenant de Gaule ou d'autres régions de l'Empire été figuré par un trait représentant 50 ans en arrière par rapport à la période d'enfouissement connue; cette durée d'utilisation attribuée au bijou est certes un procédé facilitant la lecture des tableaux, mais elle correspond à peu près à ce que des trésors ou des tombes nous laissent entrevoir sur le temps nécessaire à la constitution d'une cassette.

Pour certaines formes (2i, 3c, 3d, 4d, 4f, 4g, 4h) (souvent des bijoux très modestes), les exemplaires datés étaient trop peu nombreux pour permettre l'établissement d'une chronologie. D'autres formes, pour les mêmes raisons, ont été regroupées selon les types (types $1,5,6,7$ ). La figure 53 résume les différents tableaux que nous avons pu élaborer.

\section{LES FORMES}

\section{LES CONDITIONS}

Presque toutes les formes ont des antécédents, soit dans la bijouterie celtique (pour les anneaux hélicoïdes de type 7 et les bagues ornées de spires de type 6), soit dans la parure grecque, plus particulièrement hellénistique pour les bagues des types 1,2 et 4 . Il ne faut cependant pas s'étonner de ces ressemblances, car il n'y a guère de solutions variées dans la forme générale d'une bague, surtout si le bijou est orné d'une pierre.

Lorsqu'une forme semble satisfaisante et connaît un grand succès, les artisans l'utilisent dans des matériaux différents : les anneaux de jais ou de verre prennent la même forme que les montures d'or, certaines bagues monométalliques s'ornent d'une pastille ovale, substitut de la pierre (fig. 1). Il n'y a pratiquement pas de forme qui soit réservée à un seul matériau (fig. 4). Dans le même esprit, les artisans imitent sur les bagues des formes appréciées sur des bracelets (fig. 5.1) ou des décors à la mode sur des fibules (fig. 5.2 et 3).

Les artisans savent aussi adapter le bijou aux besoins de la clientèle. La forme de ces bagues répond à une nécessité pratique : si la bague sert de

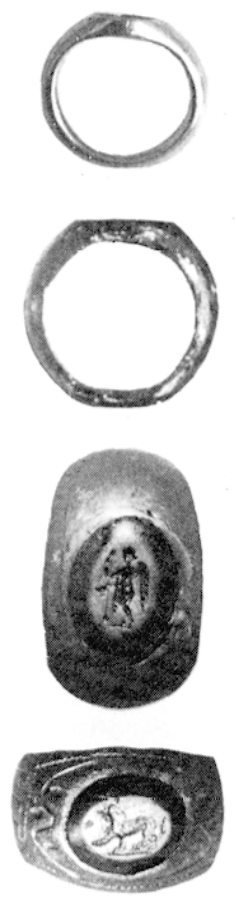

Fig. 4 - Formes

semblables.

Forme 2c.

1 , or ; provenance : Alésia (Côte-d'Or);

(Musée, Alise-Sainte-Reine, Côte-d'Or)

2 , verre jaune; provenance Alésia ;

(Musée, Alise-Sainte-

Reine).

Forme 2d.

3, argent, nicolo; figure d'Éros-Pothos; provenance : Mont-Berny, Pierrefonds (Oise); (MAN, no 29.224).

4, bronze, pâte de verre; représentation de lion; provenance : Alésia (Côte-d'Or);

(Musée, Alise-SainteReine). sceau, elle doit être solide pour supporter la pression, sur les épaules en particulier, lors de l'utilisation; si la bague est seulement un ornement, la ligne peut être plus audacieuse et le bijou plus fragile; c'est pourquoi le bijoutier préfère la forme $1 \mathrm{~b}$ ou $2 \mathrm{c}$ pour la bague-sceau, et la forme $4 a$ ou $4 \mathrm{~b}$ s'il s'agit de mettre en valeur la pierre et d'économiser le métal (fig. 6).

Des circonstances extérieures peuvent contraindre l'artisan, à utiliser l'argent par exemple parce que l'or se fait rare au III ${ }^{\mathrm{e}}$ s., à employer le fer parce que son client n'a pas le droit de porter une bague en or (voir note 1), à travailler le bronze parce que l'acheteur n'est pas très fortuné. L'artisan doit suivre aussi la mode, l'évolution de la bijouterie en général, car les bagues, les plus riches au moins, peuvent être intégrées à une parure complète. Il est également soumis parfois à des exigences religieuses ou superstitieuses.

Certaines bagues semblent difficiles à porter (fig. 7.5) ; leur extravagance peut s'expliquer par une cause de cet ordre. Il ne s'agit pas ici des bagues-clefs (type 5) dont la fonction utilitaire explique les bizarreries, mais des bagues serpentiformes ouvertes, peu pratiques sur un doigt (fig. 7.1) (type 7). Le serpent est lié aux religions orientales; il est l'animal familier d'Esculape et d'Hygie; c'est aussi un emblème d'immortalité : toutes ces raisons peuvent expliquer le choix d'une bague de ce type, même si 

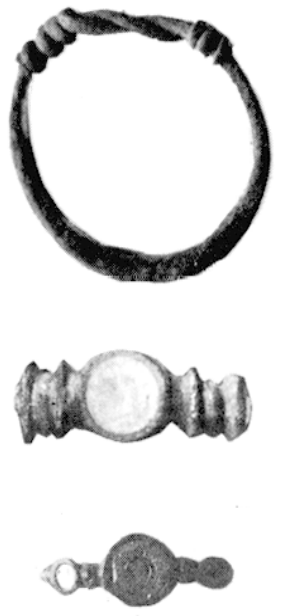

Fig. 5 -

1, Bague $6 \mathrm{~b}$;

bronze;

provenance: Sud de la

France;

(MA.V, no 30.672).

2, Bague 3d;

bronze avec émail : provenance : Nalliers

(Vendée);

lieu de conservation

inconnu.

3, Bague 4d;

bronze avec émail;

provenance : Mâlain

(Côte-d'Or);

(Musée ; Mâlain

no 1974.78). on ne peut clairement interpréter la concentration de ces bijoux dans ces zones comme le delta du Rhin et le Nord de la Gerrnanie Supérieure (fig. 44); dans la région de Genève (fig. 44 et 55.1), la présence d'un atelier (peut-être spécialisé) et les conditions d'enfouissement dans des trésors expliquent en partie le nombre des bijoux recensés. Plusieurs bagues de verre, d'ambre, de jais, de cristal de roche ont un faible diamètre intérieur et un anneau très épais (forme 2i) (fig. 7.2); elles ont, le plus souvent, été retrouvées dans des tombes et avaient un rôle funéraire. L'ambre et le jais avaient une valeur prophylactique en raison de leurs propriétés électrostatiques et le cristal de roche avait un pouvoir réfrigérant qui aidait le mort dans le passage du fleuve de feu des Enfers ${ }^{5}$. Quelques bagues d'ambre, de cristal de roche et de bronze possèdent un chaton en haut relief (fig. 7.3 et 4). Si les bagues d'ambre sont funéraires, les bagues de cristal de roche ornées de bustes d'Isis ou de femmes diadémées ${ }^{6}$ doivent, soit avoir été portées lors de cérémonies, soit avoir été offertes aux dieux.

5 Pline, NH, XXXVII, 23 (cristal de roche), 50-51 (ambre). L'usage funéraire du jais n'est pas accepté par tous les spécialistes: HeNKEL, $n^{\circ} 1660 \mathrm{sq}$. et p. 251-253; W. HaGEN, Kaiserzeitliche Gagat-Arbeiten aus dem rheinischen Germanien, Bonner Jahrbücher, 142, 1937, p. 77-144. Le cristal de roche et l'ambre sont présents dans des tombes sous forme de bague, mais aussi de petits objets zoomorphes souvent: A. van Doorset.aer, Les nécropoles d'époque romaine en Gaule septentrionale, Bruges, 1967, p. 124-125; D. Strong, Catalogue of the Carved Amber in the Department of Greek and Roman Antiquities, British Museum, Londres, 1966; - T. Biavaschi, Ambre aquileiesi nel Museo Civico di Udine, Aquileia Nostra, 22, 1951, p. 13-22.

6 Bagues en cristal de roche: M. E. Marien, L'empreinte de Rome, Belgica Antiqua, Bruxelles, 1980, p. 306 ; H. Rolland, Glanum. Saint-Rémy-de-Provence, Paris, 1960,

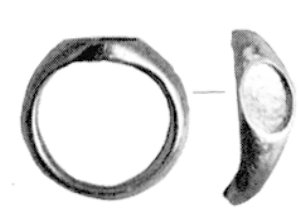

Fig. 6 -

1, Bague 2c;

or, intaille disparue;

provenance : Alésia

(Côte-d'Or);

(Musée, Alise-Sainte-

Reine).

2, Bague 4a;

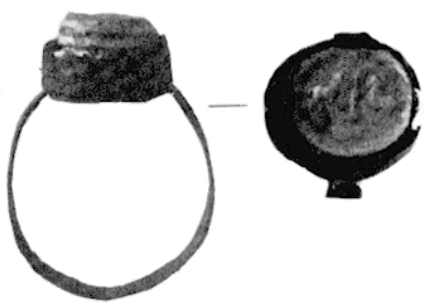

bronze, pâte de verre;

figure de déesse

danubienne :

provenance : Cimiez.

(Alpes-Maritimes)

(Musée d'Archéologie, Nice, $\mathrm{n}^{\circ} \mathrm{F}$ 60.1.4.1)

Les contraintes techniques imposées par les matériaux sont, peut-être, moins importantes qu'on ne l'imaginerait. Les tcchniques ${ }^{7}$ sont assez variées pour que l'artisan puisse choisir : une même forme de bague, 2c par exemple, peut être moulée, forgée ou martelée. Les bagues massives coulées sont les bagues de bronze (fig. 8.1) et quelques bagues ou anneaux en or ou en argent, bijoux pleins et relativement lourds. La majeure partie des bagues en or et en argent est fabriquée à partir de feuilles (fig. 8.2) ou de fils; ces bijoux creux sont remplis d'un bourrage (soufre, poix, cire) qui évite l'écrasement; ce sont des bagues légères ${ }^{8}$ (fig. 8.3). Des

p. $71 ;-$ R. Lantier, Buste en cristal de roche: Faustine l'Ancienne, Monuments et Mémoires, Académie des Inscriptions et Belles-Lettres (Fondation Piot), 38, 1941, p. 129-146; C. Barini, Ornatus Muliebris. I gioielli e le antiche romane, Turin, 1958, p. 95, bijoux consacrés aux divinités et portés lors de cérémonies. Sur une stèle d'Arlon (Belgique) (E. Espérandieu, Recueil des bas-reliefs, statues el bustes de la Gaule romaine, Paris, 1907-1981, no 4045) et de Saint-Ambroix (Cher), (E. Espérandirt, op. cit., no 7011), des femmes présentent une grosse bague à la manière des défuntes figurées sur les stèles attiques du ve s. avant J.-C.; la stèle d'Arlon date de la seconde moitié du II $^{\mathrm{e}} \mathrm{s}$. (fig. 7.5).

7 Pour les techniques, voir les chapitres qui leur sont consacrés dans R. Higins, Greek and Roman Jewellery, Londres, 1961 ; - E. Coche DE la Ferte, Les bijoux antiques, Paris, $1956 ;-J$. Ogden. Ancient Jewellery. The Materials and Techniques, Londres, 1982 ; - E. Formigl., Tecniche dell'oreficeria elrusca e romane. Originali e falsificazioni, Florence, 1985; -- Henker., p. 274-308. Ce domaine de l'archéologie connaît un manque cruel d'analyses; travail récent effectué sur les bagues du trésor d'Eauze (Gers): Le Trésor d'Eauze (Gers), ouvrage collectif, à paraître, chapitre Techniques par J. Daste, J.-P. Bernadou.

8 Poids de quelques bagues de diamètres assez proche : forme $2 f$ (diamètres 25 et $24 \mathrm{~mm}$; or), massive, 15,35 g; creuse, $4 \mathrm{~g}$; forme $2 \mathrm{~d}$ (diamètres 26 et $24 \mathrm{~mm}$; argent), massive, $26,7 \mathrm{~g}$; creuse, $6,5 \mathrm{~g}$. Sur le matériel de bourrage, Piıne, $N H$, XXXIII, 25, anneau d'or creux rempli de matière légère; - 


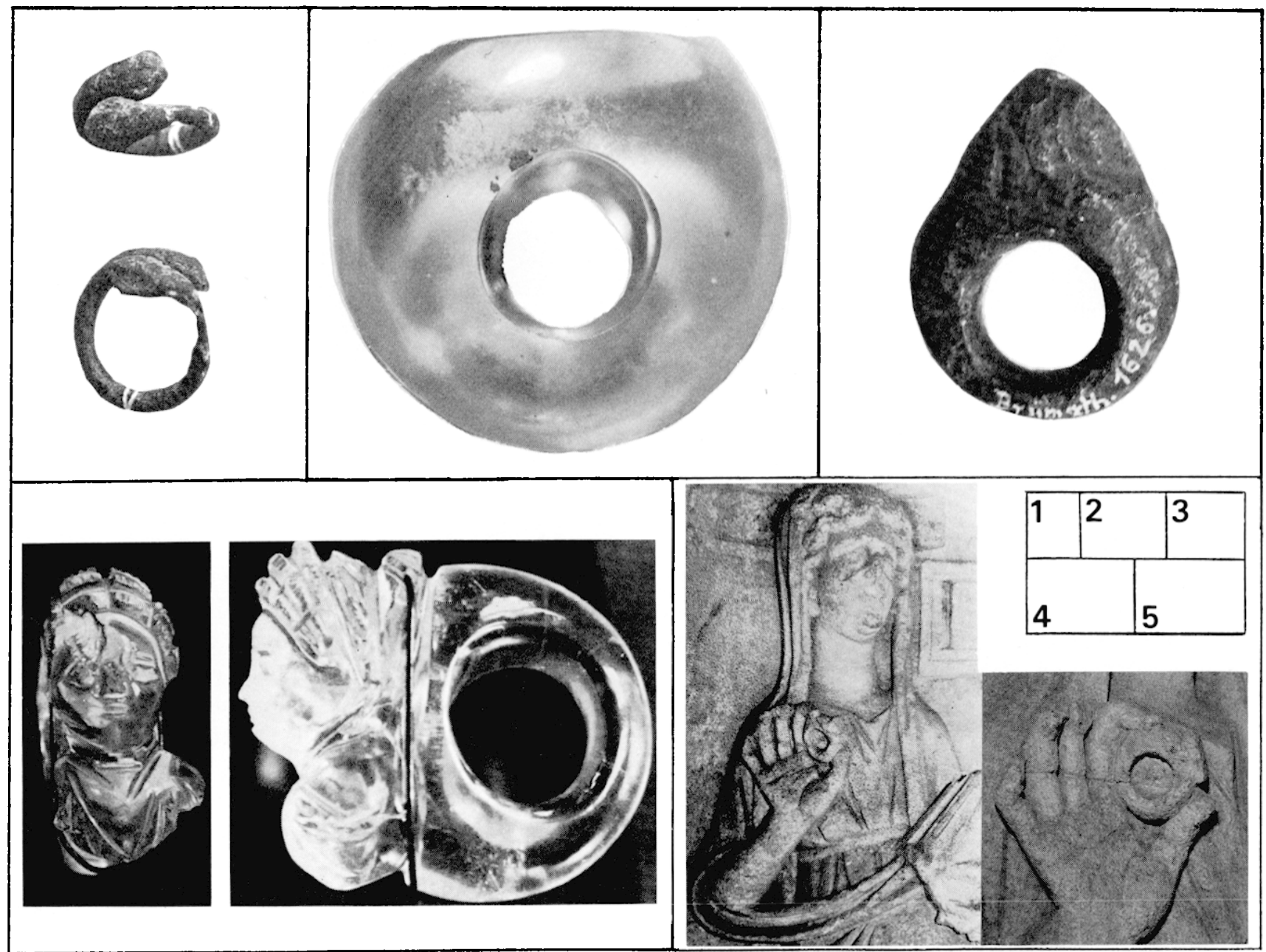

Fig. 7 -

1 , bague $7 \mathrm{a}$;

bronze;

provenance : région de Montauban (Tarn-et-Garonne);

(Musée Ingres, Montauban).

2, bague $2 \mathrm{i}$;

cristal de roche;

provenance : sépulture, Cheillé (Indre-et-Loire);

(Musée de la Société archéologique, Tours, Indre-et-Loire).

feuilles plus épaisses peuvent être utilisées, avec un travail plus important de martelage, pour des bagues de type 3 ou 4, ou des anneaux de type 7. Quelques bagues en tôle de bronze ont été retrouvées. Les fils sont employés pour les anneaux des bagues de type 4 en or ou en argent (fig. 8.4), ou pour les bagues de type 6 , en or, argent, mais aussi en bronze ${ }^{9}$. Pour la

I. Ondrejava, Les bijoux antiques du Pont-Euxin Septentrional, Prague, 1975, nos 2 et 8 (soufre); dans le trésor d'Eauze (op. cit.), on a pu analyser des fragments de soufre provenant d'un bracelet; on pouvait aussi utiliser du sable, de la poix, de la résine : R. Higgins, op. cit., p. 36.

9 Les bagues en fil de bronze $6 \mathrm{~d}$ et $6 \mathrm{e}$ ont pu être faites par étirage et martelage du fil, mais aussi avoir été coulées ; R. GARDI, Artisans africains, Berne, 1970, p. 80 (spirale de même type faite par moulage).
3 , bague $2 \mathrm{i}$;

ambre ;

provenance : Brumath (Bas-Rhin);

(Musée archéologique, Strasbourg, Bas-Rhin, no 1.626)

4 , bague $2 \mathrm{i}$; cristal de roche;

provenance : Saint-Rémy-de-Provence (Bouches-du-Rhône); (Centre archéologique, Saint-Rèmy-de-Provence).

5, stèle d'Arlon (Belgique); seconde moitiè du II $^{\mathrm{e}} \mathrm{s}$; ; (Musée d'Arlon, province du Luxembourg, Belgique).

jonction des différentes pièces d'un bijou, l'artisan de l'époque romaine emploie la brasure (fig. 8.4) ${ }^{10}$.

Les bagues de fer sont martelées à chaud; en raison des difficultés de travail du métal en si petites dimensions, ces bagues n'apparaissent que dans quelques types, 1 et 2 essentiellement. Les bagues non métalliques, en jais, cristal de roche, etc., sont obtenues par abrasion, les objets en verre à partir de bâtonnets de verre étirés et tournés à forte tempéra-

10 Brasure : utilisation d'un métal d'appoint pour réunir les deux parties à souder; chauffe de ce métal et des deux zones à réunir. Les techniques de soudure antique donnent lieu à des discussions parfois contradictoires; en l'absence d'analyses, il est difficile de se prononcer. Traces d'empâtement provoqué par une chauffe maladroite : (fig. 8.4). 


\section{1}

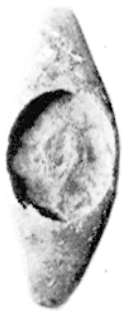

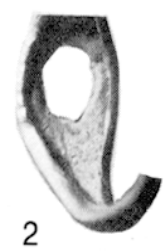

3
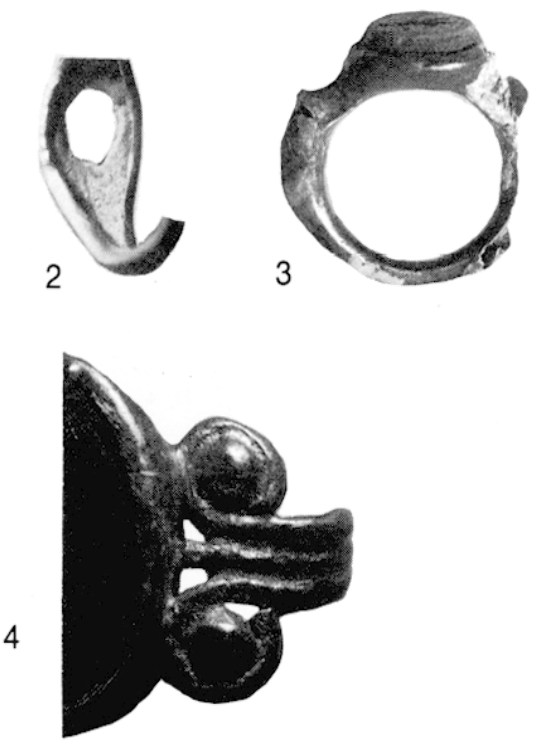

Fig. 8 - Quelques exemples de techniques de fabrication. 1 , bague 2c; bronze; bague obtenue par moulage; le fond de l'alvéole est irrégulier afin de faciliter la prise du ciment maintenant la pierre incrustée;

provenance : Mâlain (Côte-d'Or);

(Musée, Mâlain, no 1980.405).

2 , bague $2 b$;

or; bague faite d'une feuille d'or pour la partie supérieure et l'anneau; une deuxième feuille en forme de losange fermait le dessous du bijou;

provenance : Narbonne (Aude);

(Musée, .Narbonne).

3 , bague $3 \mathrm{a}$;

argent; la partie droite, endommagée, permet de voir le matériau de remplissage, sorte de poudre blanche;

provenance : Chalain-d'Uzore (Loire);

(Musée de la Diana, Montbrison, Loire, no 890.10.12).

Voir fig. 22, la bague jumelle.

4 , bague $4 \mathrm{c}$;

or; bague faite d'une feuille d'or pour le chaton et de trois fils d'or pour l'anneau; empâtement lors de la soudure entre les fils et autour des granules;

provenance : Lectoure (Gers);

(Musée archéologique, Lectoure).

ture. Tous ces procédés techniques sont connus depuis longtemps et les artisans sont habiles à choisir la meilleure manière de satisfaire leurs clients.

\section{LES RÉALISATIONS}

Nous avons essayé de présenter sous forme de croquis simple une image "moyenne" pour chaque forme : image "moyenne" car, si l'on veut classer les bijoux en groupes homogènes, il devient évident que ces objets sont des cuvres d'artisans, rarement exactement semblables; les photographies disposées à côté des croquis en sont le témoignage. Dans le

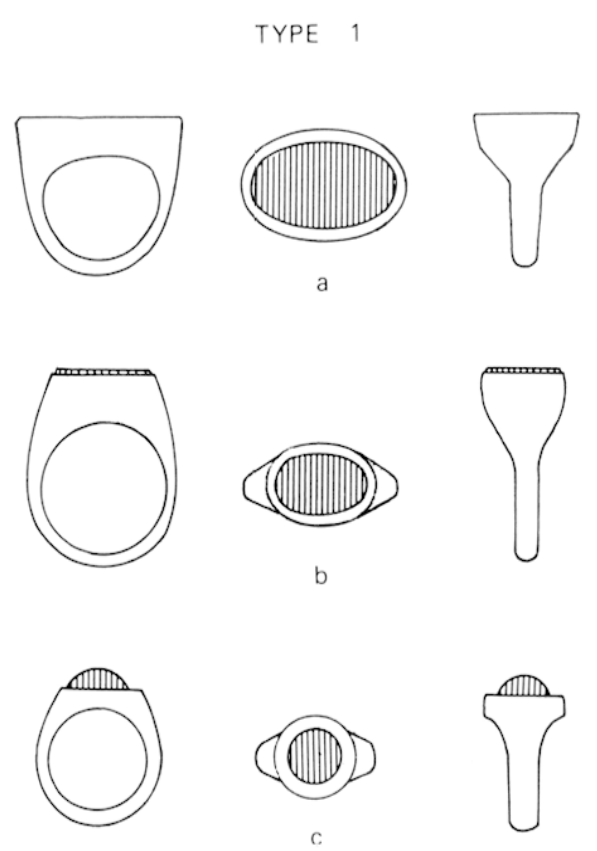

Fig. 9 - Bagues de type 1 : typologie.

texte, à la suite de l'énoncé du type, nous avons donné quelques chiffres ${ }^{11}$; le premier correspond au pourcentage de ce type par rapport à la totalité des bagues et anneaux recensés en Gaule, les autres chiffres représentent la répartition, dans le type étudié, des divers matériaux en Gaule. Tous les chiffres ont été ensuite reportés sur le tableau figure 54. Les éléments chronologiques fournis par une partie seulement de ces bijoux et ceux donnés par des bijoux provenant d'autres régions de l'Empire sont réunis dans le tableau figure 53 .

11 Les chiffres de pourcentage donnés dans le texte ou utilisés sur des croquis ont èté calculés à partir de plus de 3000 bagues et anneaux. Comme la représentation des objets sur les cartes, ces chiffres sont soumis aux aléas des découvertes et des publications; mais ils donnent une première image de la situation des bagues en Gaule. Dans ces calculs, nous n'avons cité que les pourcentages supérieurs à $1 \%$; le total peut ne pas atteindre $100 \%$, car nous n'avons pas toujours disposé, pour toutes les bagues, de tous les renseignements nécessaires; de plus certaines bagues échappent, par leur fantaisie, à une classification stricte. Abréviations concernant les matériaux : $\mathrm{Au}=$ or; $\mathrm{Ag}=$ argent; $\mathrm{Br}=$ bronze ; $\mathrm{Fe}=\mathrm{Fer} ;$ autres $:$ autres matériaux, ambre, cristal de roche, etc. 


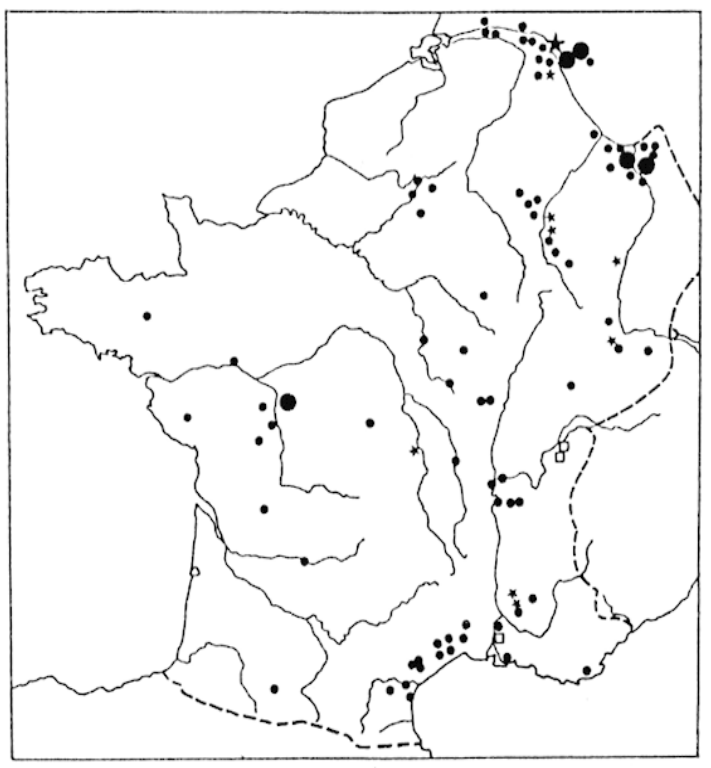

Fig. 10 - Carte de répartition des trois formes du type 1. Bague 1a;

bronze, sardonyx ; tête féminine ;

provenance : environs de Metz (Moselle);

(Römisch-germanische Museum, Cologne, RFA, n 5329).

Bague $1 \mathrm{~b}$;

bronze, pâte de verre;

provenance : Ensérune (Hérault);

(Musée archéologique, .Nissan-lès-Ensérune, n 05.455).

Bague 1c;

bronze doré, cornaline; représentation d'un chapiteau; provenance : Cruseilles (Haute-Savoie);

(MAII, n* C 1.031).

\section{LE TYPE 1}

fig. 9 et 10

$3,9 \%$

$\mathrm{Au}: 21,8 \% ; \mathrm{Ag}: 4,2 \% ; \mathrm{Br}: 41,1 \% ; \mathrm{Fe}: 29,4 \%$; autres : $3,3 \%$

L'anneau et le dessus forment un tout; l'anneau se développe verticalement; il s'élargit progressivement avec des épaules angulaires ou parfois convexes.

Ce type cst peu représenté en Gaule. Les bagues sont simples, solides, ornées le plus souvent d'incrustations en pierre ou en pâte de verre (de forme convexe, dans ce cas) utilisées comme sceau. Le type est d'origine hellénistique, venant plus précisément d'Egypte; les bijoux de Gaule sont beaucoup moins somptueux et beaucoup moins encombrants que

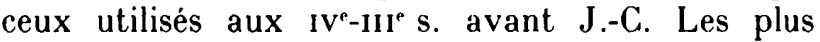
anciens exemplaires apparaissent en Narbonnaise, le long du littoral, dès la première moitié du $\mathrm{i}^{\mathrm{er}} \mathrm{s}$. avant J.-C.; si quelques bijoux ont été trouvés dans les
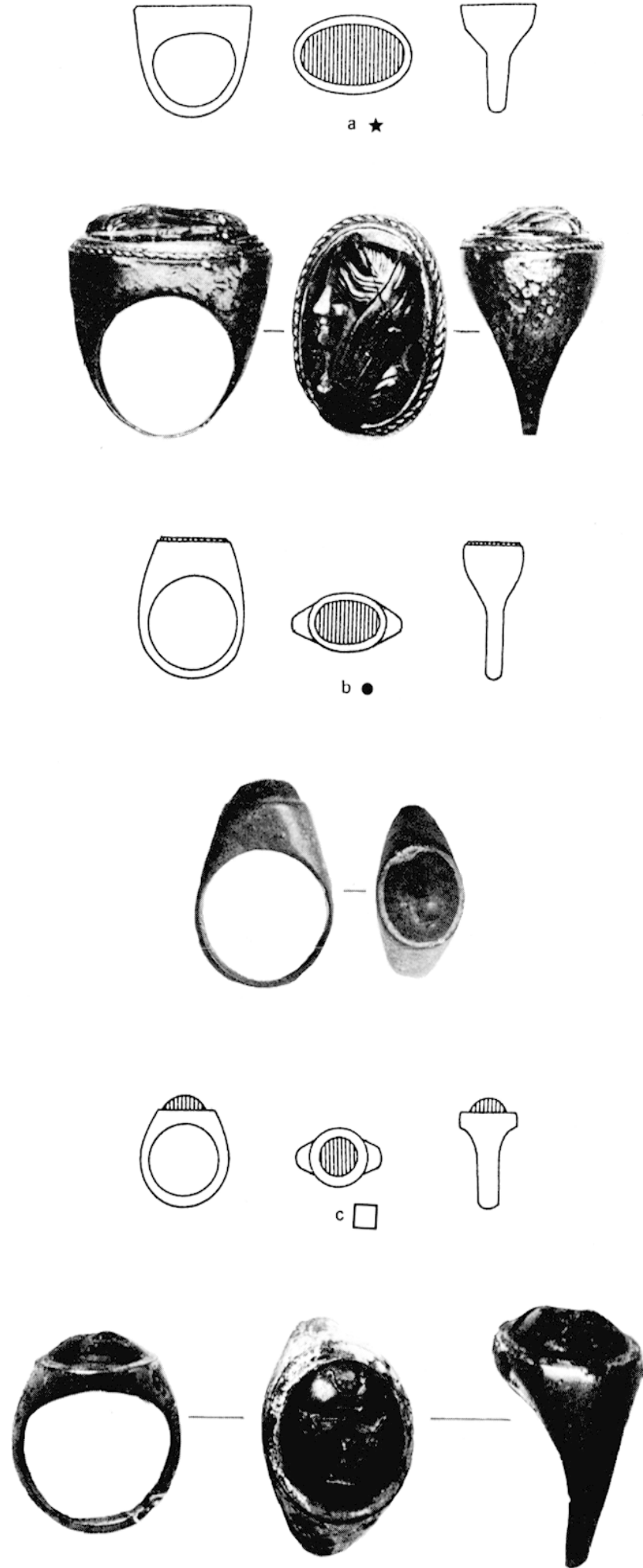

oppida et des sanctuaires fréquentés avant et après la conquête, la majorité de ces bagues est issue des zones romanisées, plus de la moitié venant des sites urbains, créations de l'occupant dans le Sud, puis en Rhénanie. Le type se maintient jusque dans la seconde moitié du $\mathrm{I}^{\text {er }} \mathrm{s}$. après $\mathrm{J}$.-C. 
fig. 11 à $20 ; 1,4,6,7.2$ à $4,8.1$ et $2,48.2$ et 3 $35,8 \%$

$\mathrm{Au}: 21,8 \% ; \mathrm{Ag}: 9,4 \% ; \mathrm{Br}: 43,5 \% ; \mathrm{Fe}: 17,1 \%$; autres : $8 \%$

L'anneau et le dessus forment un tout; l'anneau se développe horizontalement; il s'élargit progressivement, avec des épaules convexes ou parfois angulaires. C'est le type le mieux représenté en Gaule avec 1100 pièces environ répertoriées à ce jour.

Un premier groupe (2a à $2 \mathrm{f}$ ) comprend les bagues ornées d'une incrustation (pierre, pâte de verre, émail, pastille de métal imitant une intaille). Pour expliquer les variantes entre les différentes formes, on ne peut guère avancer ni la grosseur du doigt, ni les dimensions de la pierre, ni le matériau employé (sauf, en partie, pour la forme $2 \mathrm{~b}$, avec de petites incrustations et de petits diamètres). Divers éléments se combinent pour faire évoluer les formes, par exemple les variations dans la mode : dans les formes $2 \mathrm{a}, 2 \mathrm{c}$ et $2 \mathfrak{f}$, on met en valeur à la fois la pierre et le métal dans ces bijoux aux proportions assez élancées; dans les formes $2 \mathrm{~d}$ et $2 \mathrm{e}$, le bijou est plus imposant et présente une surface de métal plus large qui est parfois utilisée pour des décors secondaires (fig. 4.3 et $4 ; 48.2$ et 3 ). L'adaptation à l'anatomie joue aussi un rôle : dans les formes $2 \mathrm{a}, 2 \mathrm{c}$ et 2d, la bague entraînée par le poids de l'ornement peut tourner autour du doigt plus facilement que dans les formes $2 \mathrm{e}$ ou $2 \mathrm{f}$, formes d'ailleurs plus récentes. Ces diverses formes se développent dès le $\mathrm{I}^{\text {er }} \mathbf{s}$. après $\mathbf{J}$.-C. jusque dans la première moitié du III ${ }^{\circ}$ s., de manière parfois simultanée, parfois successive. Les exemplaires proviennent de toute la Gaule, avec des zones importantes dans le Sud, pour les $\mathbf{I}^{\text {er-II }}{ }^{\mathrm{e}}$ s., dans le Nord-Est surtout pour les II $^{e}-I^{\mathrm{e}} \mathrm{e}$ s. Les bijoux les plus luxueux, ornés de pierres rares, saphirs, émeraudes, sont issus des grands centres urbains; les petits vici, les sanctuaires ruraux, où la mode romaine se développe puisque la moitié des bagues en provient, ont le plus souvent fourni des bijoux modestes, en bronze et ornés de pâte de verre; on retrouve ces bijoux de bronze et de fer dans les forts du limes. Le fer n'apparait presque plus dans les formes les plus récentes $2 \mathrm{e}$ et $2 \mathrm{f}(53 \%$ pour les bagues $2 \mathrm{a}, 29 \%$ pour les bagues $2 \mathrm{~d}$ et $5 \%$ pour les bagues $2 \mathrm{e}$ ou $2 \mathrm{f}$ ); l'or est plus souvent utilisé pour les formes $2 \mathrm{~b}$ et $2 \mathrm{c}$ ( $30 \%$ dans les deux cas) que pour la forme $2 \mathrm{~d}(19 \%)$; les belles pierres se trouvent plutôt sur les bagues $2 \mathrm{~b}$, $2 \mathrm{c}$, ou $2 \mathrm{f}$, et les pâtes de verre sur les bagues $2 \mathrm{~d}$, souvent plus récentes.
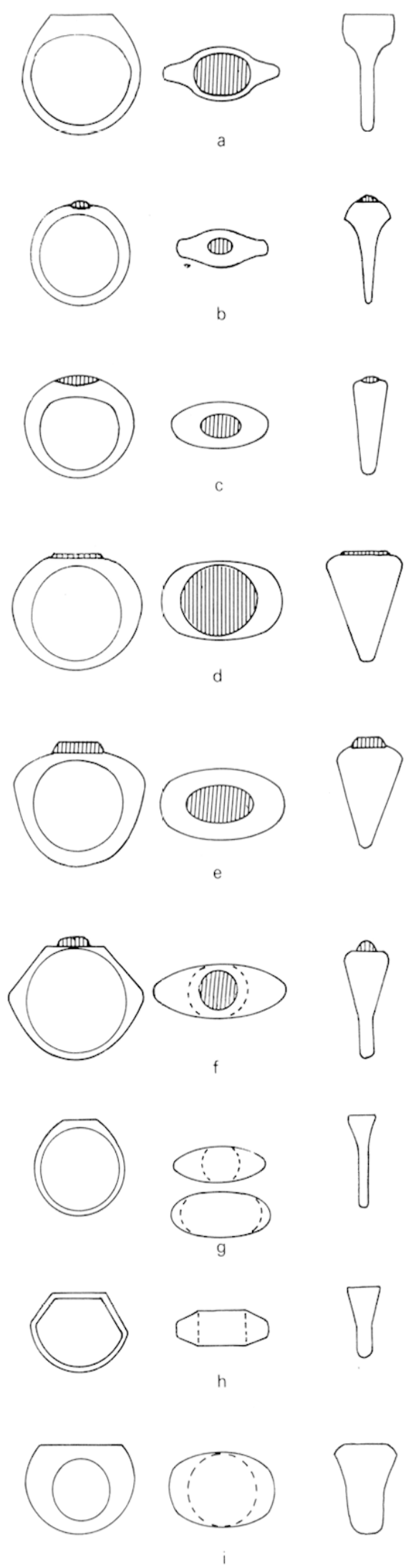

Fig. 11 - Bagues de type 2 : typologie. 

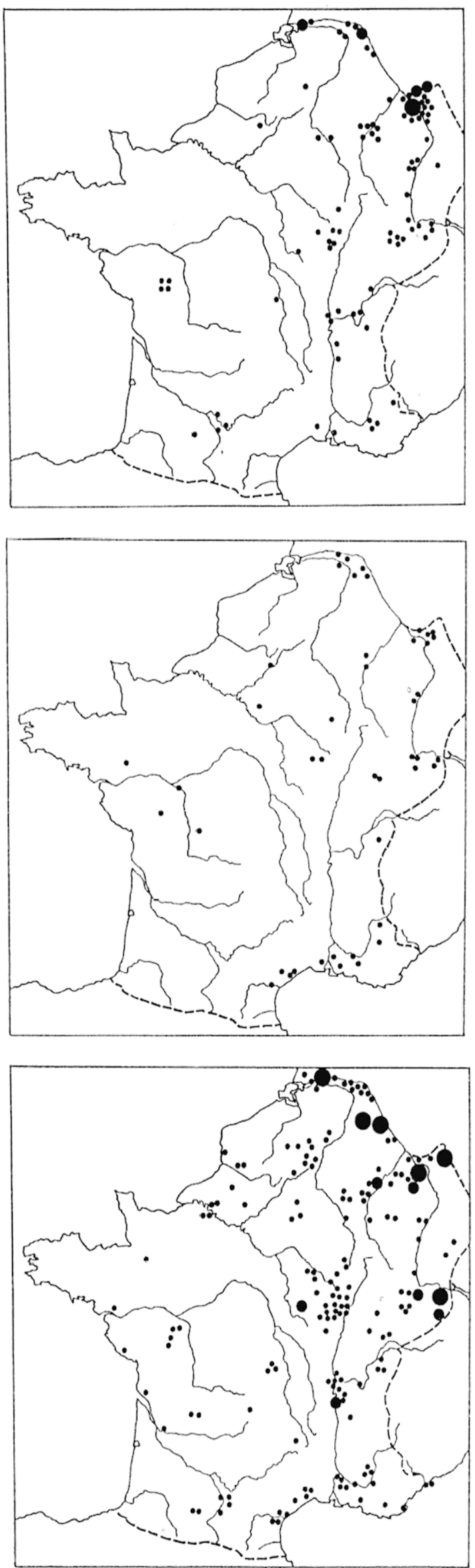
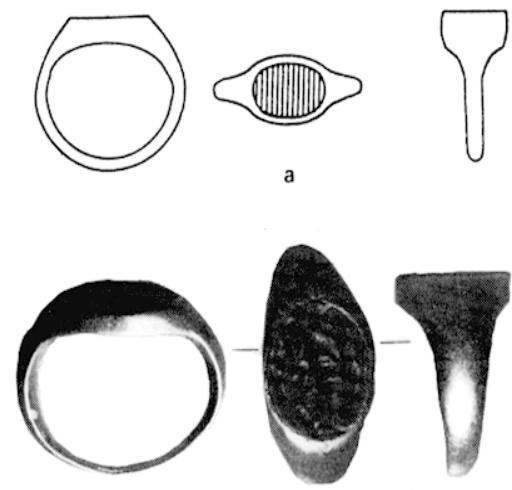

Fig. 12 - Carte de répartition des bagues de forme 2 a. Bague 2a;

or, jaspe rouge; figure de chasseur; provenance : Boistray (Rhône); (MCGR, nº 1966.7).

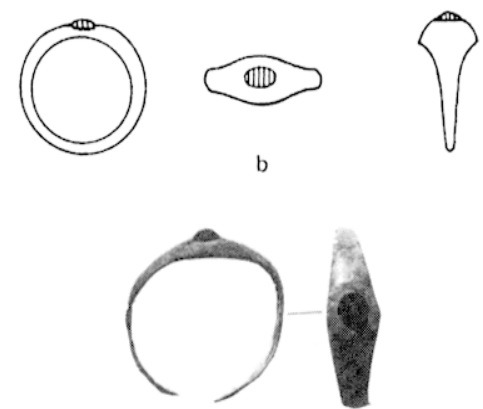

Fig. 13 - Carte de répartition des bagues de forme $2 \mathrm{~b}$. Bague $2 \mathrm{~b}$;

bronze, pâte de verre;

provenance : Vertault (Côte-d'Or);

(Musćc archéologique, Châtillon-sur-Seine, Côte-d'Or).


Fig. 14 - Carte de répartition des bagues de forme 2c. Bagues 2c:

(en haul) or, nicolo; figure de Mercure; provenance : Nissan-lèz-Ensérune (Ilérault); (collection particulière);

(en bas) or, nicolo; figure de Vènus Victrix; provenance : Arles (Bouches-du-Rhòne);

(Musée Réattu, Arles).

Voir aussi fig. 1, 4.1 et '2, 6, 8.1. 

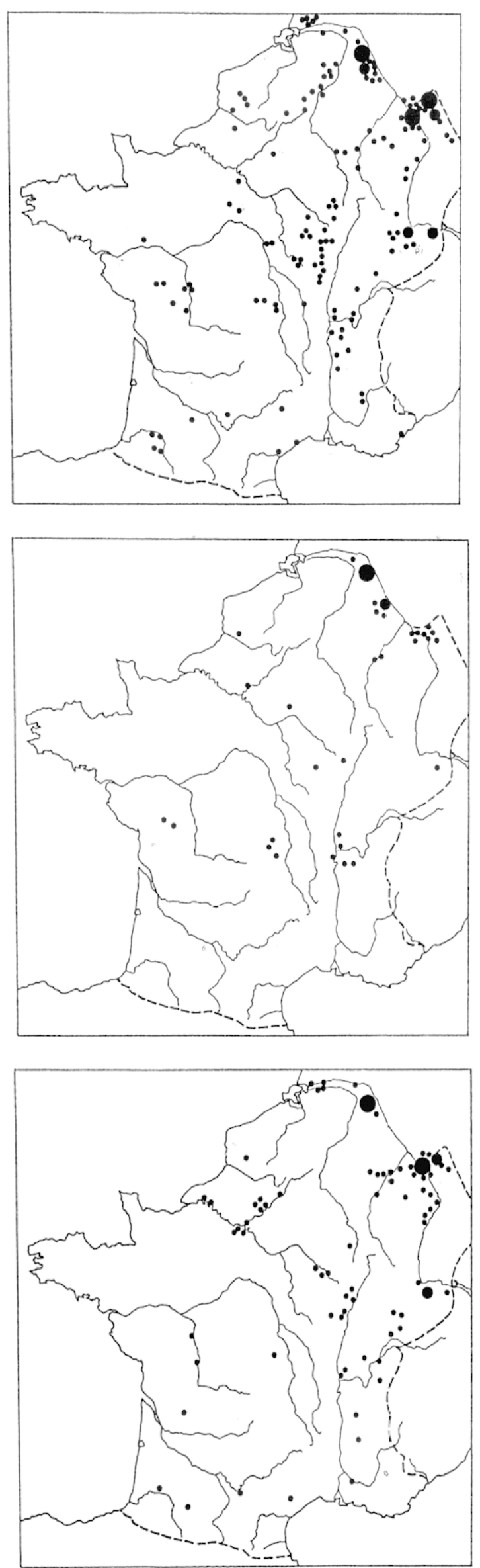
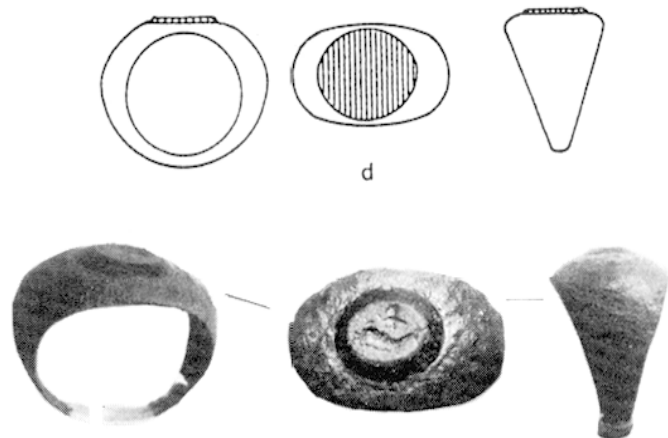

Fig. 15 - Carte de répartition des bagues de forme 2 d. Bague 2d;

bronze, pâte de verre-nicolo; Éros chevauchant un dauphin; provenance: Nord de l'Auvergne;

(MA.N, no 31878).

Voir aussi fig. $1,4.3$ et $4,48.2$ et 3 .

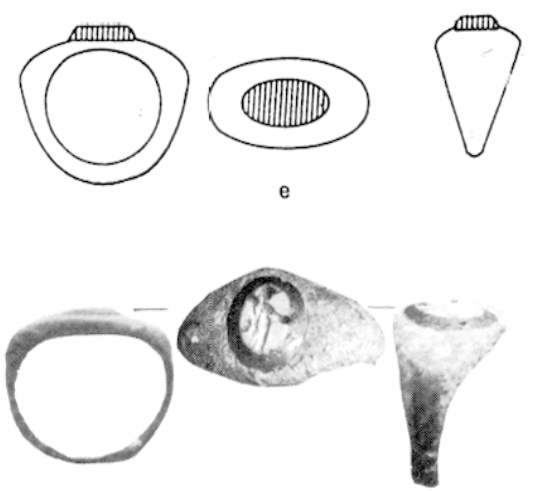

Fig. 16 - Carte de répartition des bagues de forme $2 e$. Bague 2e;

bronze, pâte de verre-nicolo; figure de Fortune; provenance : Poitiers (Vienne);

(MA.N, $n^{\circ}$ 30255).
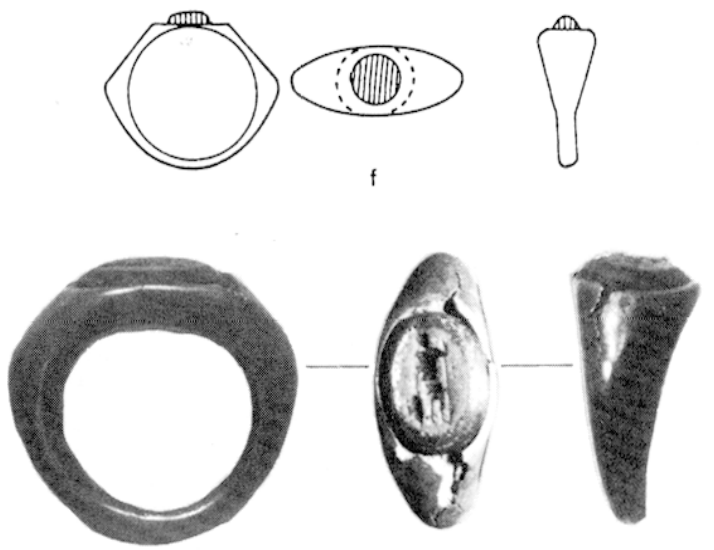

Fig. 17 - Carte de répartition des bagues de forme 2 f. Bague 2f;

argent, pàte de verre; figure de Mars Ultor; provenance : Angerville (Essonne);

(MA., no 31437). 

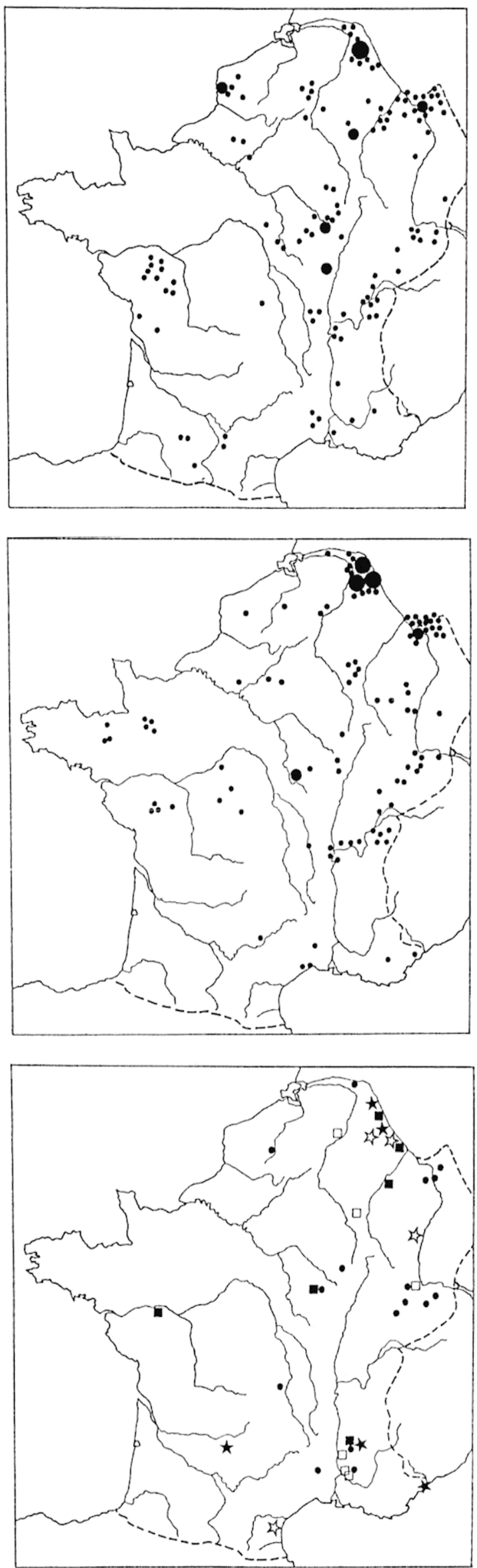
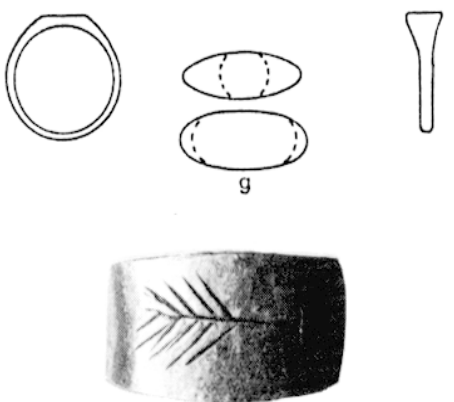

Fig. 18 - Carte de répartition des bagues de forme $2 \mathrm{~g}$. Bague 2g;

or ;

provenance : Lyon (Rhône);

(MCGR).

Voir aussi fig. 2, 55.2.
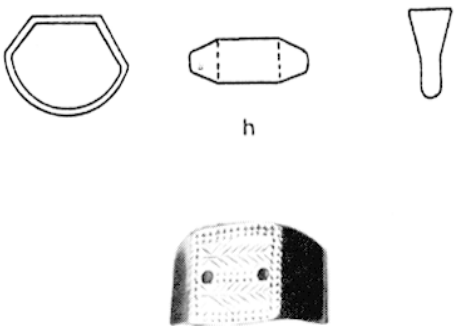

Fig. 19 - Carte de répartition des bagues de forme $2 \mathrm{~h}$. Bague 2h;

argent;

provenance : Cruseilles (Haute-Savoie); (MAH, n $\mathrm{C} 460$ ).
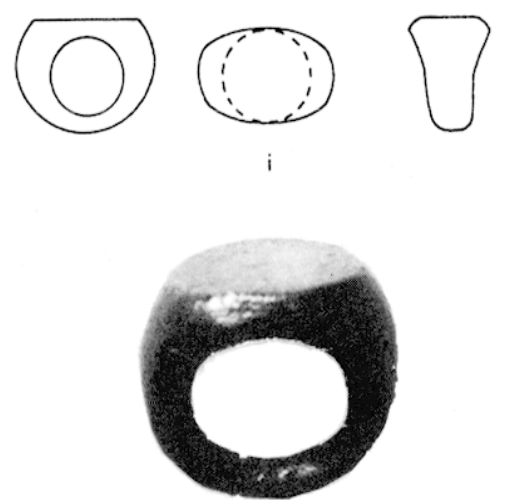

Fig. 20 - Carte de répartition des bagues de forme $2 \mathrm{i}$; rond : matériaux divers; ètoile : ambre; carré : cristal de roche; symbole noir : relief simple; symbole blanc : fort relief. Bague 2i ;

bronze ;

provenance : région de Langres (Haute-Marne);

(Musée Saint-Didier, Langres).

Voir aussi fig. $7:$ la forme simple (fig. 7.2) et la forme avec fort relief (fig. 7.3 et 4 ). 
Dans ce type 2 , on peut regrouper un second lot de bagues, de forme $2 \mathrm{~g}$ et $2 \mathrm{~h}$ (fig. 2), dans lequel sont recensés des bijoux monométalliques sans incrustation (et quelques pièces non métalliques), presque toujours ornés d'un motif (figures géométriques, animales ou humaines, inscriptions, etc.), parfois encadré, disposé sur la surface arrondie ou plane du dessus. Ces bagues sont le plus souvent simples, en bronze $(58 \%)$; l'or $(16,7 \%)$ et l'argent $(14,1 \%)$ ont été utilisés surtout pour les bijoux retrouvés en Germanie Supérieure et en Lyonnaise; il y a peu de bagues en fer et $9 \%$ de matériaux non métalliques. Elles proviennent surtout de petites villes comme Mâlain ou Alésia (Côte-d'Or), Naintré (Vienne) et des zones militaires, en Rhénanie.

Dans la forme 2i, se côtoient les bagues les plus rudimentaires et quelques-uns des bijoux les plus somptueux de Gaule, en cristal de roche (fig. 7.2 et 4).

La répartition des bagues de ce type 2 met en évidence la part prépondérante des grandes voies de circulation.

\section{LE TYPE 3}

fig. 21 à $25 ; 5.2,8.3$

$11,7 \%$

$\mathrm{Au}: 28,3 \% ; \mathrm{Ag}: 21,5 \% ; \mathrm{Br}: 42,6 \%$; autres : $6,7 \%$

Il se différencie des deux types précédents par l'usage d'un chaton placé au-dessus de la ligne de l'anneau, sans que l'unité du bijou ne soit rompue: quelle que soit la manière choisie pour dégager le dessus, les épaules, plus larges que l'anneau sous le doigt, s'harmonisent avec la taille du chaton. Ces formes apparaissent à la fin du ${ }_{1}{ }^{e}$ s. et se développent pendant la majeure partie du II $^{\mathrm{e}}$ s., jusqu'en 260-270 environ. Ce sont principalement des bijoux de prix : l'or et l'argent figurent avec un gros pourcentage dans les formes $3 \mathrm{f}$ et $3 \mathrm{~g}$ (respectivement $76 \%$ et $66,6 \%$ ); ces chiffres élevés s'expliquent en partie par le lieu de provenance de ces bijoux, des trésors monétaires ou des riches centres urbains. Bijoux de prix aussi parce que les montures de ces bagues 3 f et $3 \mathrm{~g}$ sont ornées de décors, parfois à jour, et que les incrustations sont souvent de qualité : quelques monnaies, des pierres gravées en intaille, mais aussi des pâtes de verre moins belles.

Pour l'ensemble des bagues du type 3 , on peut aussi remarquer la présence de camées, de pierres sans gravure et d'émail; dans ces cas là, les bijoux n'ont pas servi de sceau; il est vrai que la forme de la monture (3a à $3 \mathrm{~d}$ essentiellement) est fragile et ne

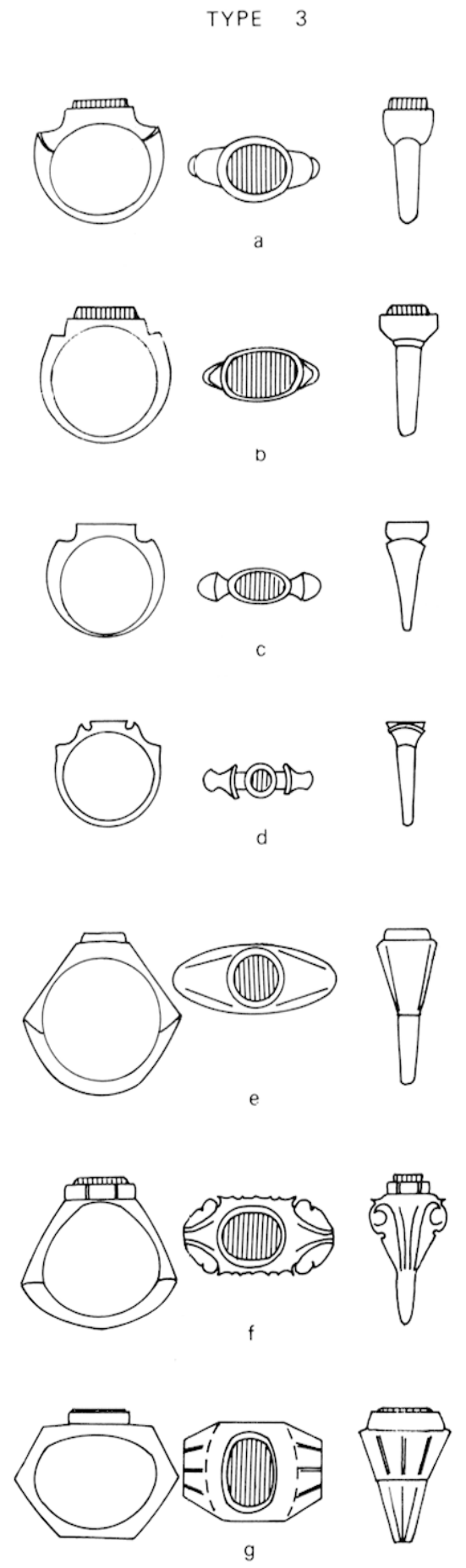

Fig. 21 - Bagues de type 3 : lypulogie.

convient guère à cet usage. Sur les cartes, le partage de la Gaule en deux zones, l'Ouest et l'Est, est encore plus net que pour les types précédents; la ligne de séparation va de l'estuaire de la Seine au sud de Vienne; cette division est très évidente sur la carte de la forme 3 f, forme préférée de ce type $(43,4 \%)$. 


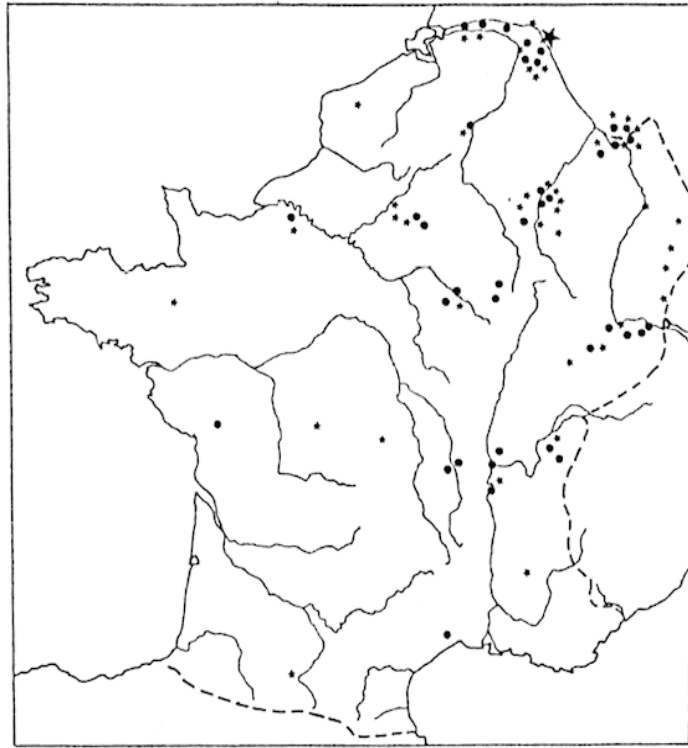

Fig. 22 - Carte de répartition des bagues de formes 3a et $3 \mathrm{~b}$.

Bague $3 a$; argent, pâte de verre;

provenance : Chalain-d'Uzore (Loire);

(Musée de la Diana, Montbrison, Loire, no 890.10.11).

Voir fig. 8.3 : la bague jumelle.

Bague $3 \mathrm{~b}$; or, incrustation faite d'une feuille d'or;

inscription : VENE/RIETTV/(T)ELEVO/TVM ;

provenance : Lyon (Rhône); (MCGR).

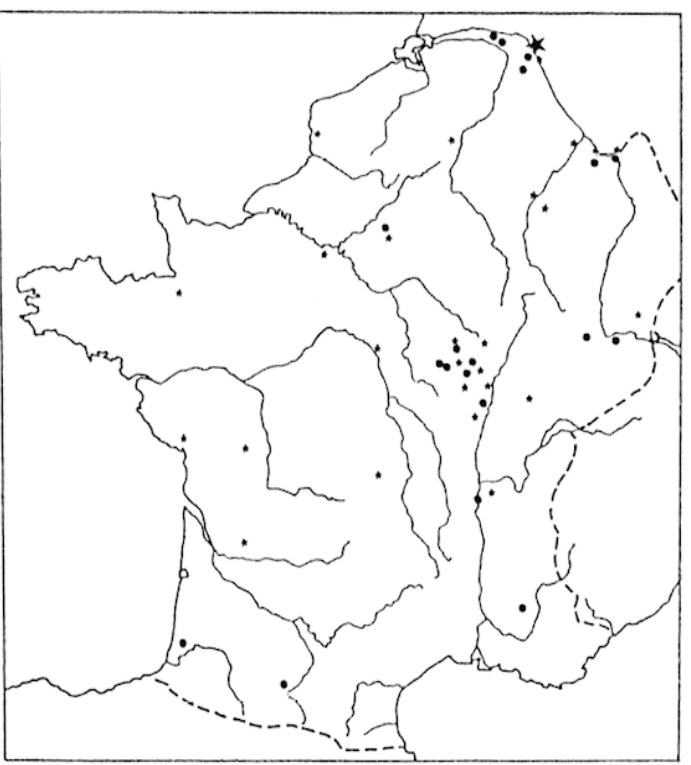

Fig. 23 - Carte de répartition des bagues de formes 3c et 3d.

Bague 3c;

bronze, émail ;

provenance : Les Bolards, Nuits-Saint-Georges (Côte-d'Or);

(Musée archéologique, Dijon, Côte-d'Or, n 7.153).

Bague 3d;

bronze, émail ;

provenance : Nalliers (Vendée);

lieu de conservation inconnu.

Voir fig. 5 : détail du dessus.
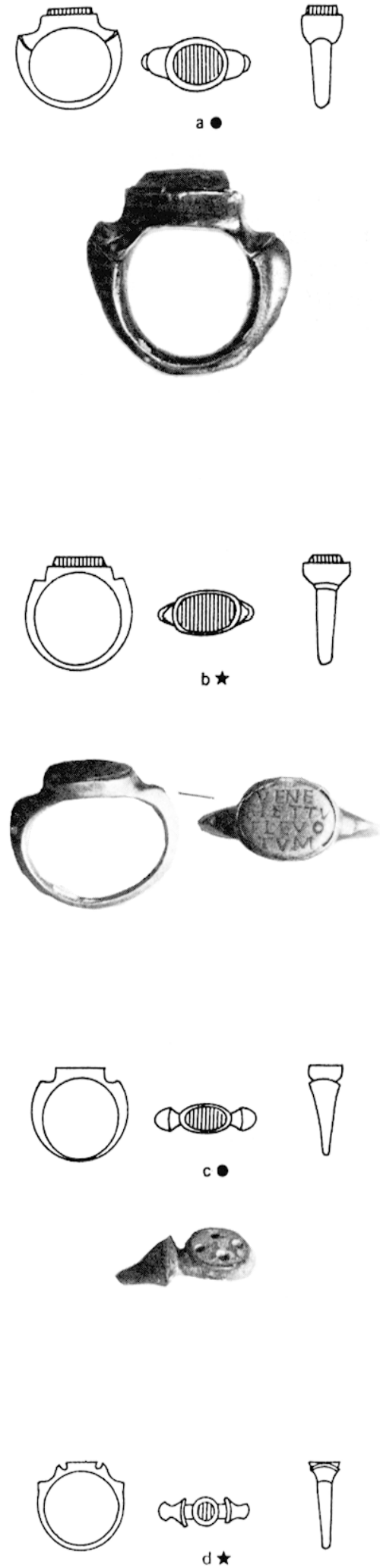

$d \star$

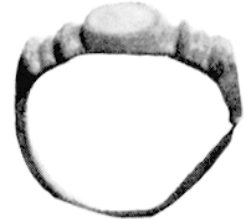




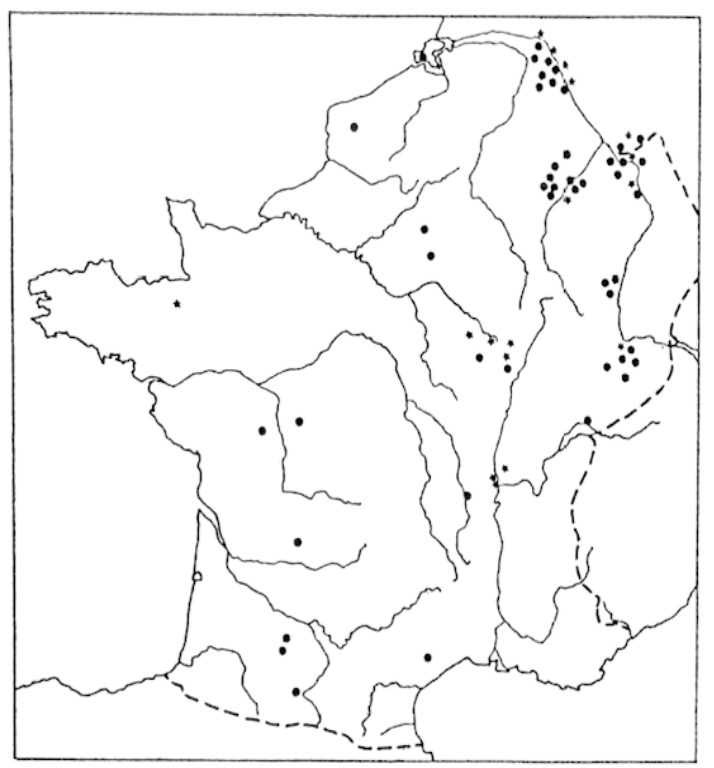

Fig. 24 - Carte de répartition des bagues de formes $3 \mathrm{e}$ et $3 \mathrm{~g}$. Bague $3 \mathrm{e}$;

bronze, chaton métallique avec inscription : LEN; provenance : Périgueux (Dordogne);

(Musée du Périgord, Périgueux, no G 181).

Bague 3g;

or, pâte de verre; Éros sur un hippocampe;

provenance : Boistray (Rhòne);

(MCGR, nº 1966.7).

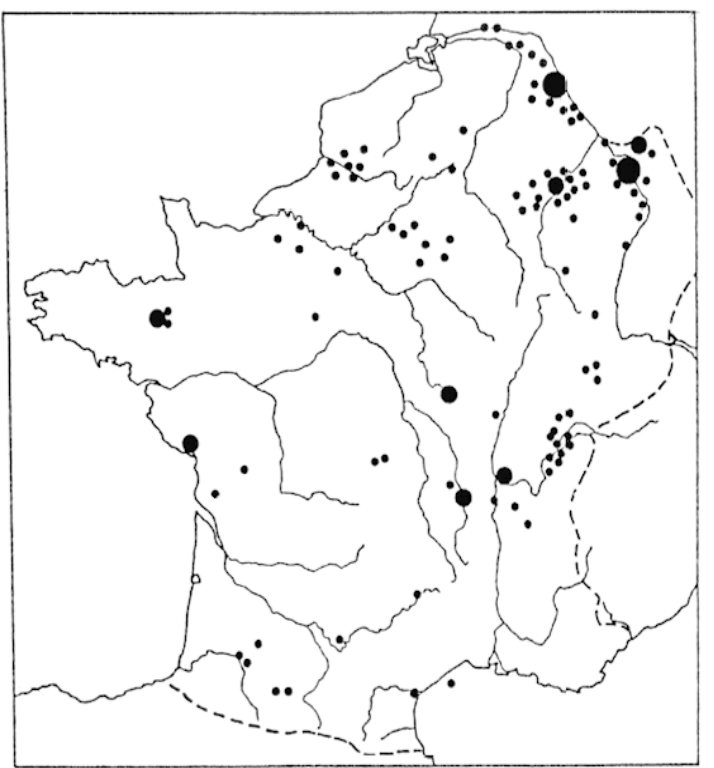

Fig. 25 - Carte de répartition des bagues de forme 3 f.

Bagues $3 \mathrm{f}$ :

(en haul, à gauche) or, cornaline; détail de l'épaule; provenance : Annecy (Haute-Savoie);

(MAII, n' 1.273);

(en haut, à droite) or, onyx; inscription en camée; détail du chaton et du haut des épaules: provenance : Eauze (Gers);

(en bas) or, incrustation, aureus de Tetricus Père; provenance : Autun (Saône-et-Loire)

(Musée Rolin, Autun).

Voir aussi fig. 48.5.
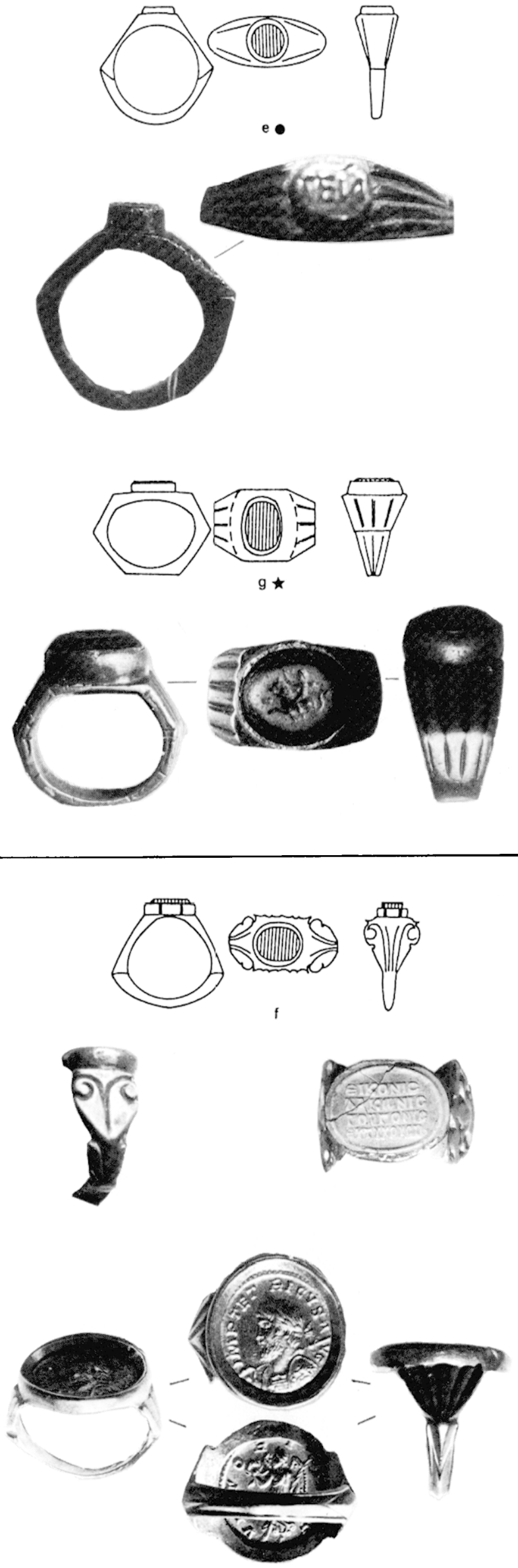
TYPE 4
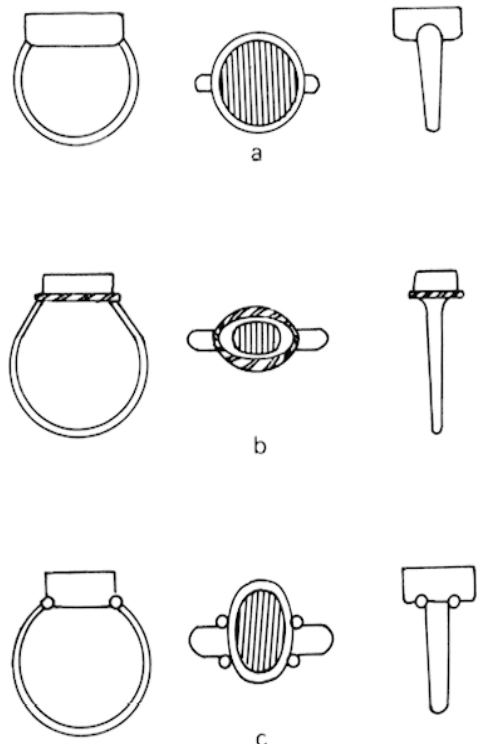<smiles>C1=CC=CC=CC=C1</smiles>
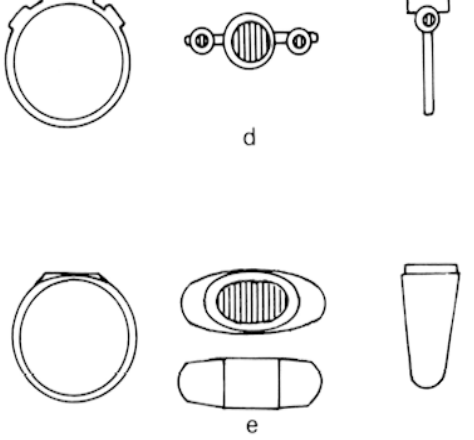<smiles></smiles><smiles>C1CCCCC1</smiles><smiles>C=C</smiles><smiles>C1=CC=COC=C1</smiles><smiles>C1CCCOCCC1</smiles>

g
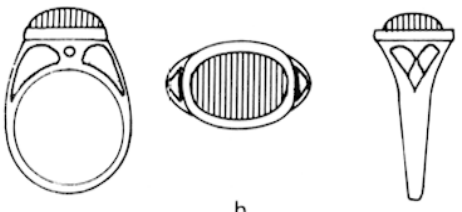

Fig. 26 - Bagues de type 4 : typologie.

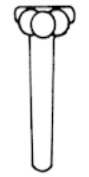

\section{LE TYPE 4}

fig. 26 à $31 ; 5.3,6.2,8.4$

$13,8 \%$

$\mathrm{Au}: 24,1 \% ; \mathrm{Ag}: 6,6 \% ; \mathrm{Br}: 62,3 \% ; \mathrm{Fe}: 2,4 \%$; autres : $4,5 \%$

Ce typc paraît plus modeste et surtout hétérogène. L'anneau est étroit et le chaton est placé au-dessus de la ligne de l'anneau; dans la forme $4 \mathrm{e}$, l'anneau est aussi large que le chaton, mais la présence du chaton sur une monture de largeur presque constante ne permet pas de rapprocher cette forme des bagues $2 \mathrm{c}$ ou $2 \mathrm{~d}$ et l'absence d'épaules distinctes du reste du bijou écarte aussi ces bagues des formes de type 3 . Dans ce type, on trouve quelques bijoux très riches, souvent un peu voyants, ornés de pierres, mais
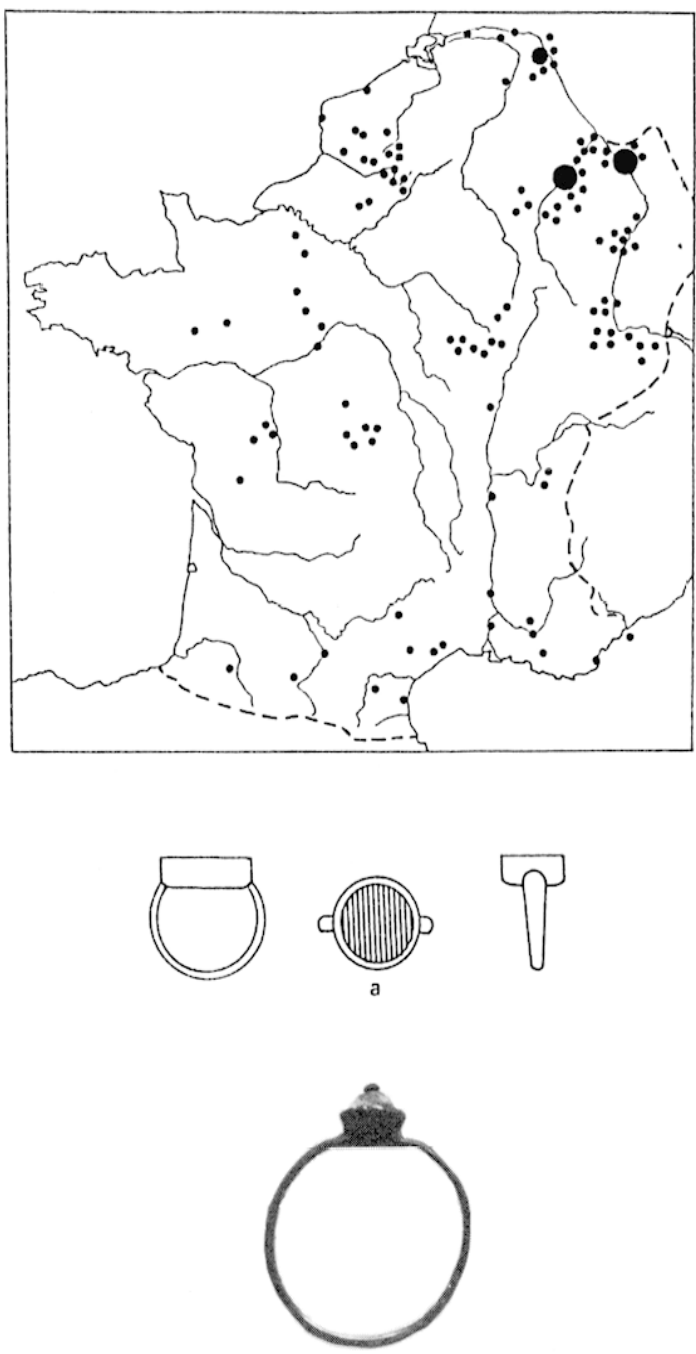

Fig. 27 - Carte de répartition des bagues de forme 4 a. Bague 4a ;

argent, pierre grège et perle d'argent;

provenance : Saint-Rémy-de-Provence (Bouches-du-Rhône); (Centre archéologique, Saint-Rémy-de-Provence).

Voir aussi fig. 6 : un autre exemplaire. 


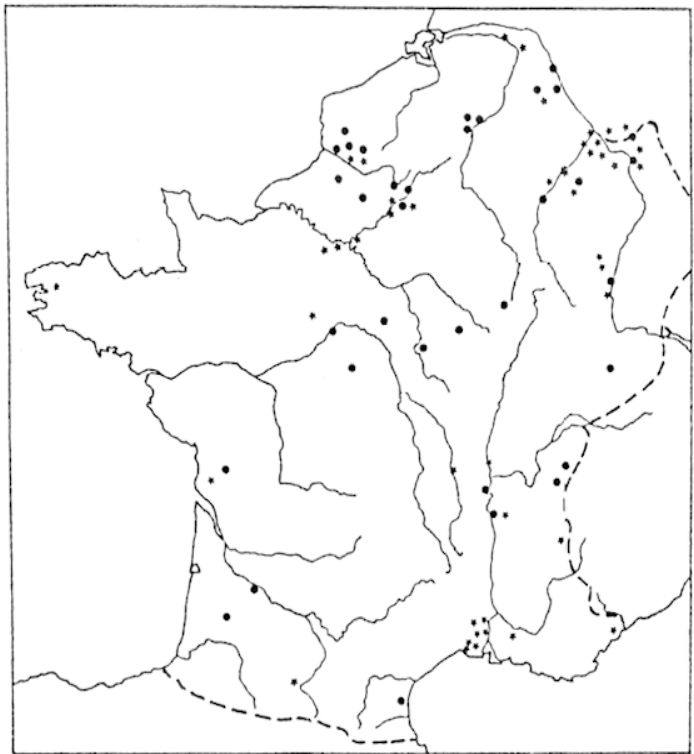

Fig. 28 - Carte de répartition des bagues de formes $4 \mathrm{~b}$ et $4 \mathrm{e}$. Bague $4 b$;

or, pâte de verre, figure de chasseur;

provenance : La Rochefoucaud (Charente-Maritime);

(Musée, Angoulême, Charente).

Bagues $4 \mathrm{e}$;

(en haut) or, cornaline; figure d'hippocampe; provenance : Cimiez (Alpes-Maritimes);

(Musée d'Archéologie, Nice, no F 67.1215).

(en bas) argent, chaton métallique (chrisme?): provenance : Lazer (Hautes-Alpes);

(Musée dauphinois, Grenoble, Isère, no 3.668).
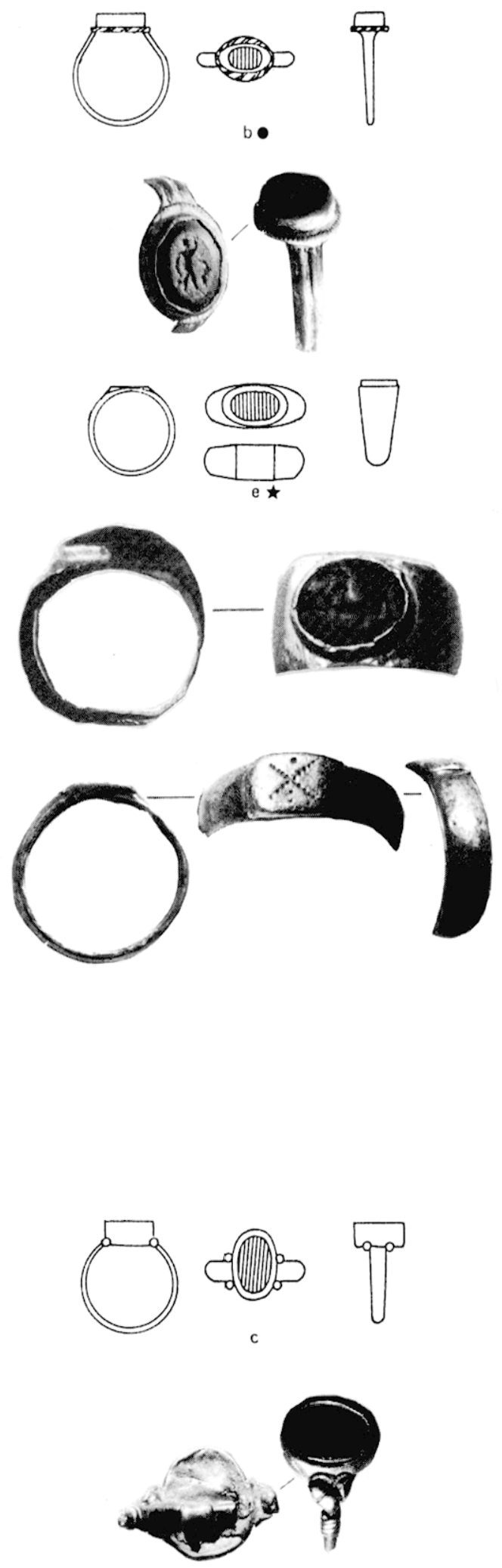

Fig. 29. - Carte de répartition des bagues de forme 4c. Bague 4c;

or;

provenance : Lyon (Rhône);

(MCGR).

Voir aussi fig. 8.4. 


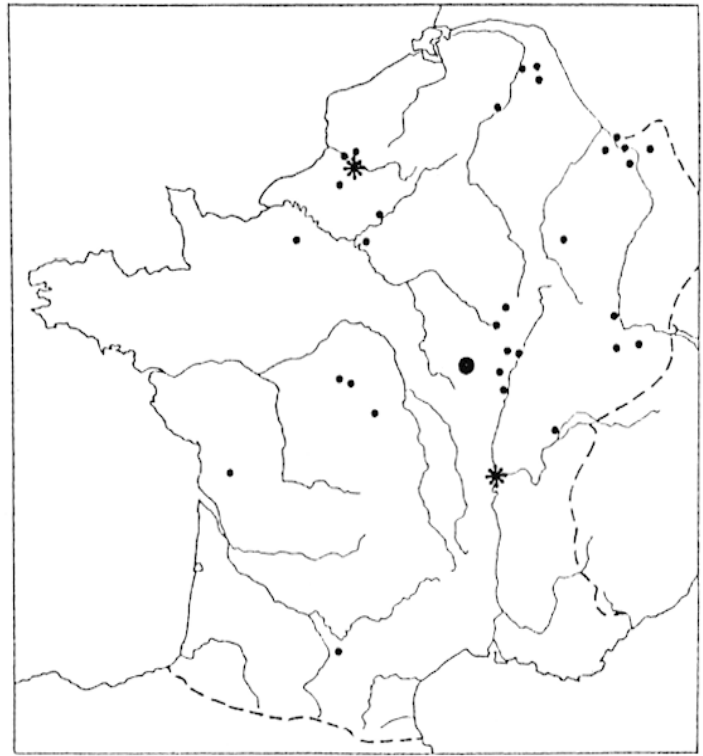

Fig. 30 - Carte de répartition des bagues de formes $4 \mathrm{~d}$ et $4 \mathrm{~h}$. Bague $4 \mathrm{~d}$;

bronze, émail ;

provenance : Mâlain (Cỏte-d'Or);

(Musée, Mâlain, n 1974.78).

Bague 4h;

or, émeraude (et deux capsules vides);

provenance : Lyon (Rhône);

(MCGR).
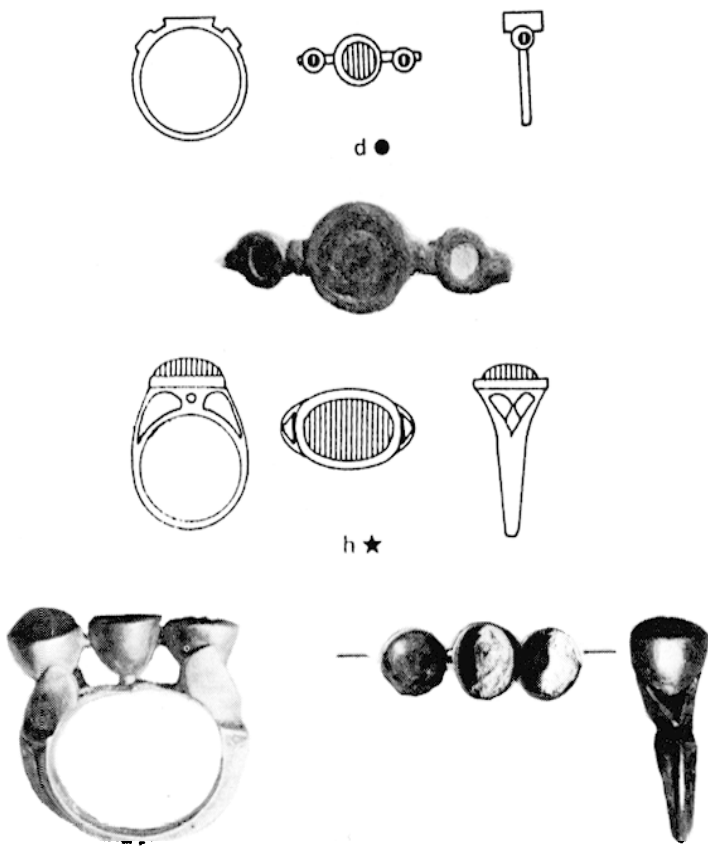
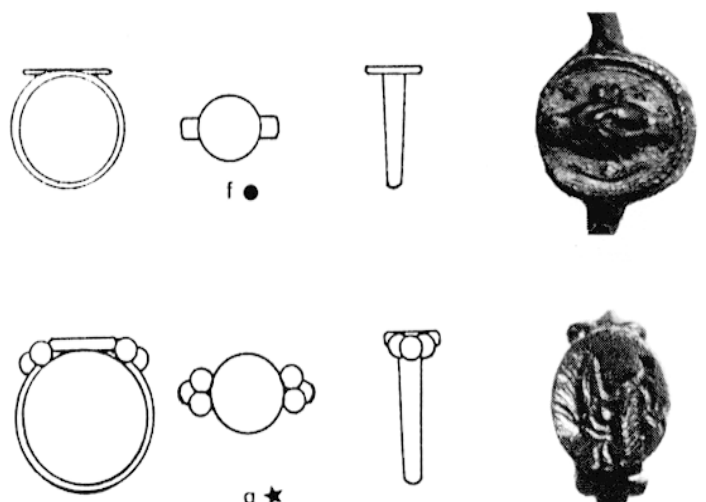

Fig. 31 - Carte de répartition des bagues de formes 4 et $4 \mathrm{~g}$. Bague 4f;

bronze, chaton métallique; représentation de deux mains jointes;

provenance : Sceaux-en-Gâtinais, Corbeilles (Loiret);

(MAN, n" 2.088).

Bague $4 \mathrm{~g}$;

bronze, chaton métallique, Moïse faisant jaillir l'eau d'un rocher;

provenance : Vaison-la-Romaine (Vaucluse);

(Musée archéologique, Vaison-la-Romaine). 
surtout de pâtes de verre sans gravure (près de $60 \%$ des incrustations non métalliques) : cela met en évidence le goût pour la couleur, accentué par l'emploi de paillons placés sous la pâte de verre pour en aviver la couleur. Quelques très belles bagues monométalliques de forme $4 \mathrm{e}(37,7 \%$ d'or pour cette forme) portent des inscriptions chrétiennes ou en faveur de l'empereur (FIDEM CONSTANTINO), ce qui permet de les dater du IV $\mathbf{s}$. Quelques exemplaires des formes $4 \mathrm{a}$ et $4 \mathrm{c}$ sont en revanche plus anciens. Un grand nombre de bagues est en bronze et les décors de la monture, trop étroite, ou du chaton sont modestes. Sur les cartes, les mêmes régions peu représentées sur les autres cartes sont à l'écart et le type est bien implanté dans le Nord-Est. La majeure partie de ces bagues provient d'agglomérations; $28 \%$ d'entre elles ont été retrouvées dans des tombes barbares du Nord.
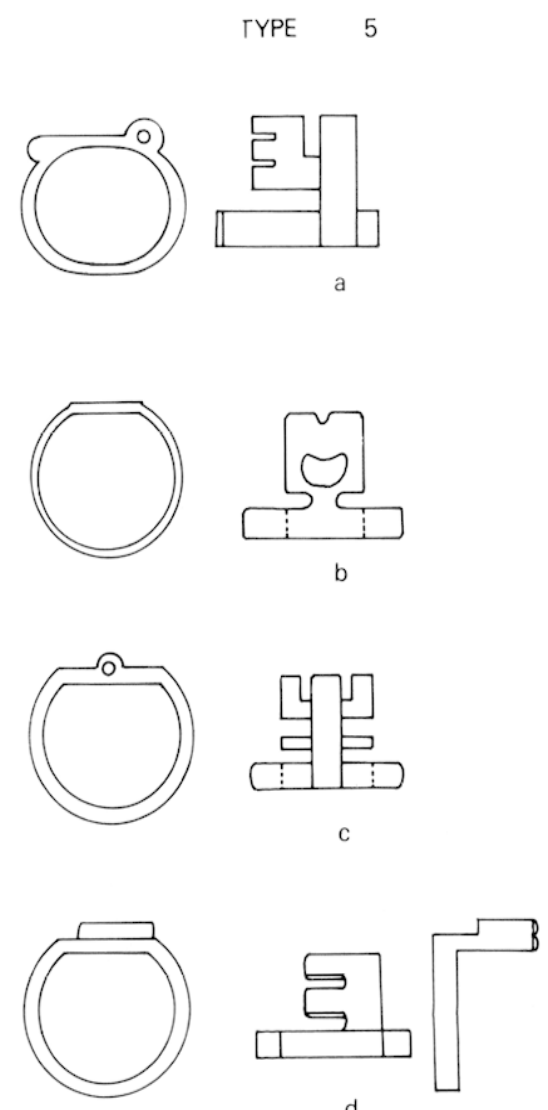

d
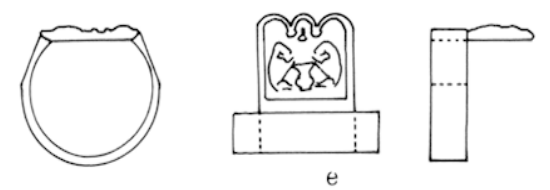

Fig. 32 - Bagues de type 5 : typologie.
LE TYPE 5

fig. 32 à $35 ; 58$

$5,7 \%$

$\mathrm{Au}: 4 \% ; \mathrm{Ag}: 2,3 \% ; \mathrm{Br}: 93 \%$

Ce type se caractérise par la présence d'un appendice latéral dans le prolongement du dessus de la bague, disposé à angle droit. L'essentiel de ce type est représenté par des bagues-clefs. Malgré leur forme peu pratique, ces bagues ont été portées au doigt; si l'anneau est trop petit, on peut imaginer la bague accrochée à une chaîne ou une ceinture. La forme 5 a est la plus courante $(55 \%)$; l'anneau porte parfois quelque motif ornemental; la forme $5 \mathrm{~b}(28 \%)$ présente des pannetons souvent décoratifs (en forme de lyre par exemple); les deux autres formes sont peu importantes et plus grossières. Les bagues-clefs existent dans la civilisation romaine avant la conquête de la Gaule; elles se propagent en Gaule du
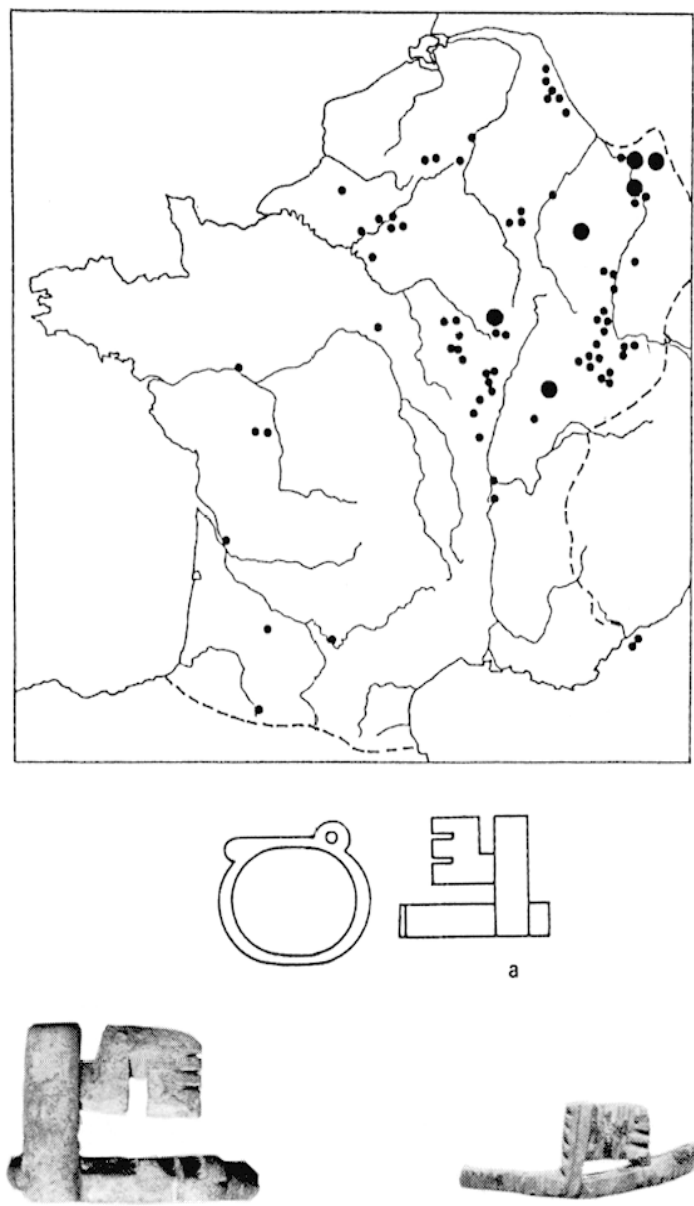

Fig. 33 - Carte de répartition des bagues de forme $5 a$.

Bagues 5a;

(à gauche) bronze;

provenance : Mâlain (Côte-d'Or);

(Musée, Mâlain, no 1973.140).

(à droile) bronze;

provenance : Mâlain;

(Musée, Mâlain, no 1980.399). 

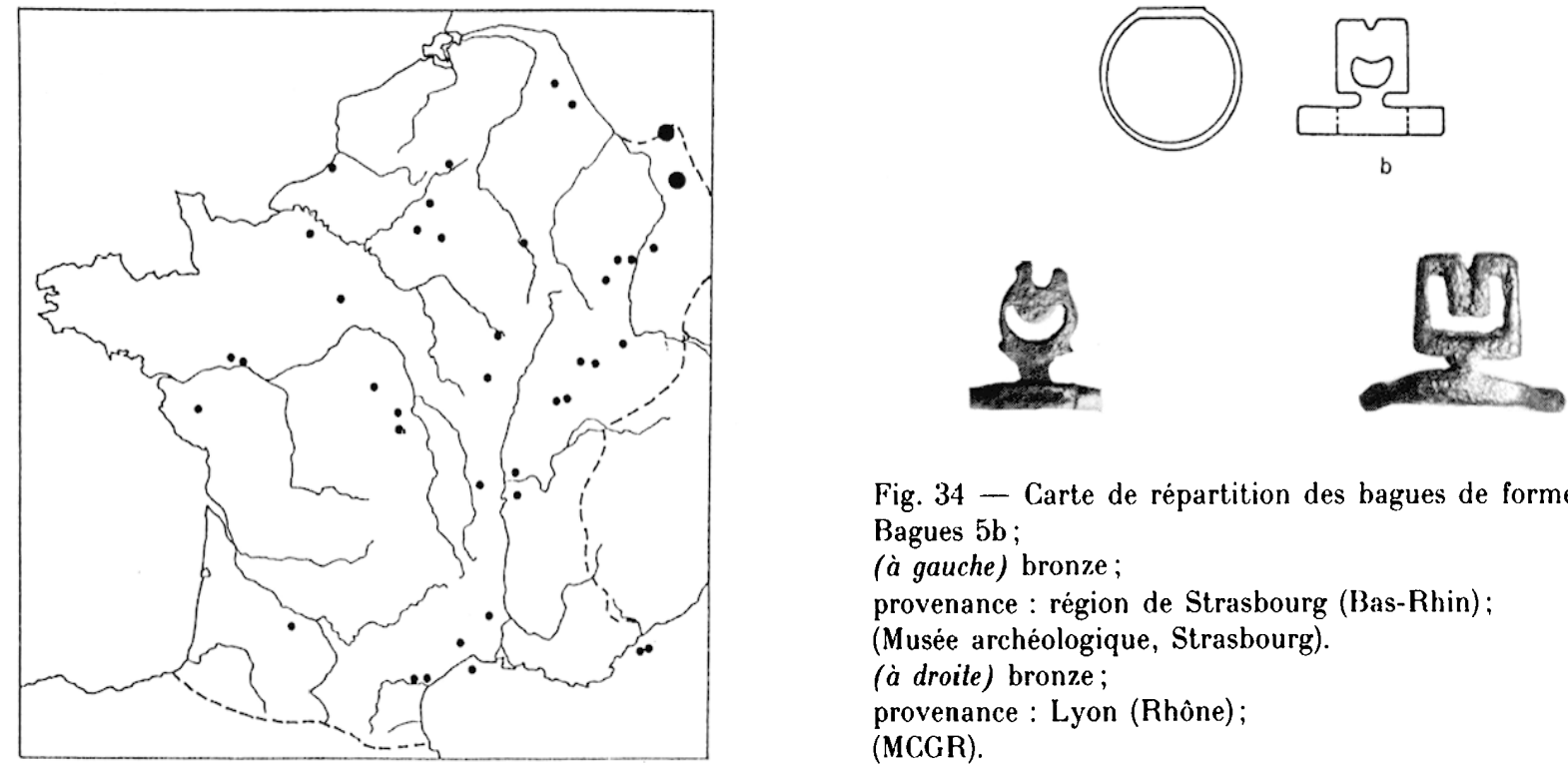

Fig. 34 - Carte de répartition des bagues de forme $5 \mathrm{~b}$. Bagues 5b;

(à gauche) bronze:

provenance : région de Strasbourg (Bas-Rhin);

(Musée archéologique, Strasbourg).

(à droite) bronze;

provenance : Lyon (Rhône);

(MCGR).
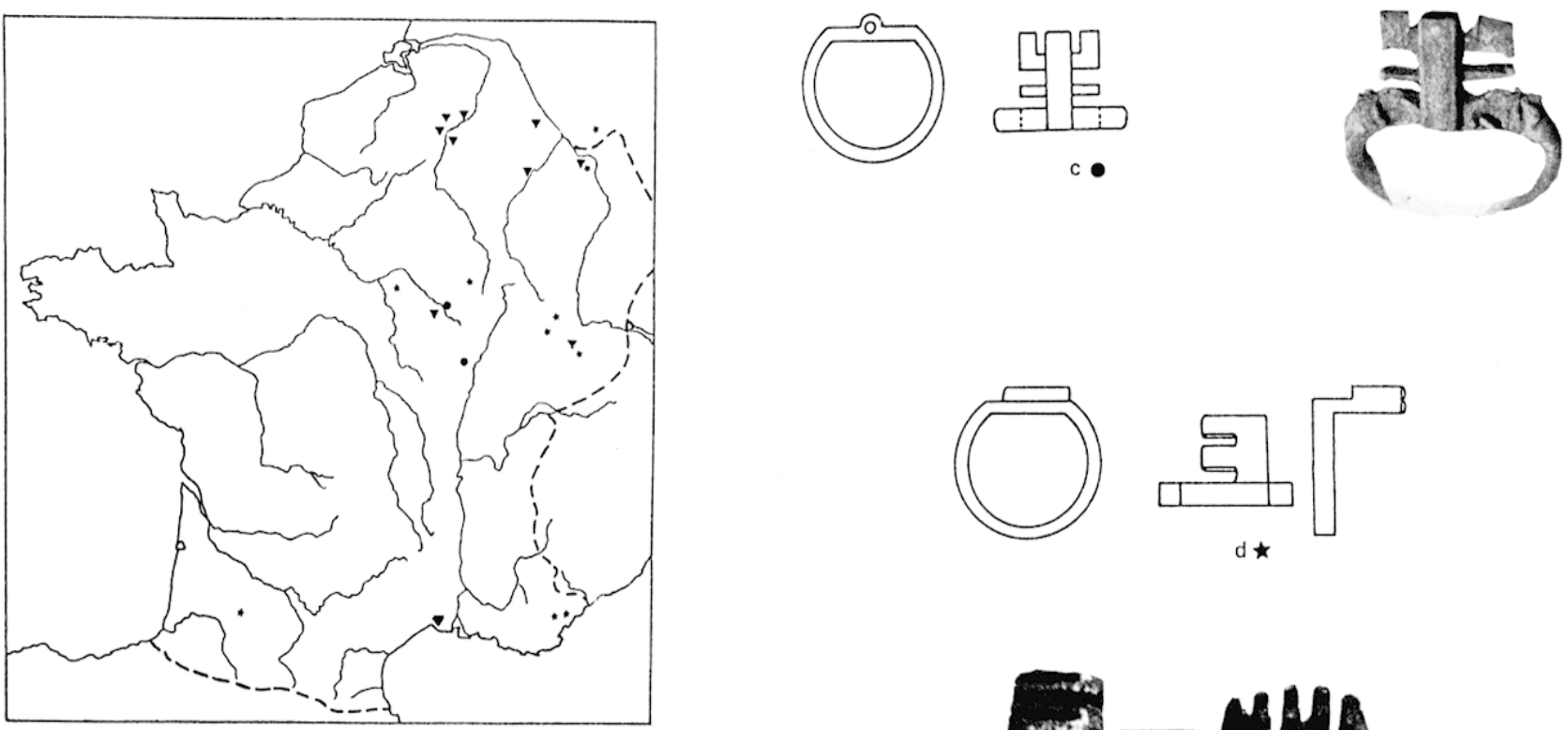

Fig. 35 - Carte de répartition des bagues de formes $5 c, 5 d$ et 5 e.

Bague 5c;

bronze;

provenance : Mâlain (Côte-d'Or);

(Musée, Mâlain, no 217).

Bague 5d;

bronze;

provenance : région de Langres (Haute-Marne);

(Musée Saint-Didier, Langres).

Bague 5e;

argent; sur l'appendice latéral, décor estampé : deux animaux (ours?) de part et d'autre d'un cratère (reconstitution moderne); provenance : Vertault (Côte-d'Or);

(Musée archéologique, Châtillon-sur-Seine, Côte-d'Or).
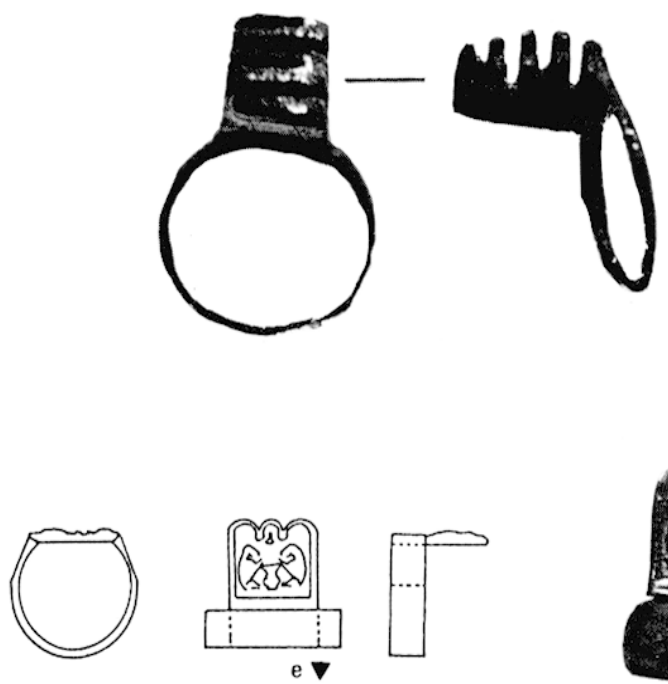
$\mathrm{I}^{\mathrm{er}} \mathrm{s}$. au IV ${ }^{\mathrm{e}} \mathrm{s}$. Ce sont presque toujours des bagues de bronze, provenant par moitié des villes petites ou grandes, et des camps du limes ou des habitats ruraux : ce sont des objets d'utilisation courante et des villes peu importantes comme Mâlain ou Alésia ont toujours fourni plusieurs bagues.

Quelques autres bijoux (5e) utilisent le même principe de construction, mais l'appendice placé dans le prolongement du dessus est soit une pierre enfilée sur une tige de métal, soit une feuille quadrangulaire aux bords découpés, ornée d'un motif en léger relief ou travaillé à jour. Ces quelques rares bagues sont en or ou en argent $(82 \%)$ et sont souvent très luxueuses; elles ont été retrouvées dans le Nord-Est, en Belgique essentiellement.

\section{LE TYPE 6}

fig. 36 à $40 ; 5.1$

$5,3 \%$

$\mathrm{Au}: 6,8 \% ; \mathrm{Ag}: 8 \% ; \mathrm{Br}: 85 \%$

Ces bijoux sont faits d'un fil de métal, arrondi autour du doigt, dont le système de fermeture s'apparente à des næuds de forme très variable. On utilise le fil seul ou multiple, uni ou quelquefois torsadé. Ce sont des bagues simples, elles ont connu un certain succès et leur répartition dans le pays est assez équilibrée; près de la moitié vient de régions rurales, plusieurs de petits sanctuaires. Ces bijoux furent à la mode dans la Gaule celtique et aussi dans tout le bassin méditerranéen avant le $\mathrm{I}^{\mathrm{er}} \mathrm{s}$. Des exemplaires sont datés du $\mathrm{I}^{\mathrm{er}} \mathrm{s}$. avant J.-C. au IV $\mathrm{s}$. et même au-delà.

Fig. 36 - Bagues de type 6 : typologie.

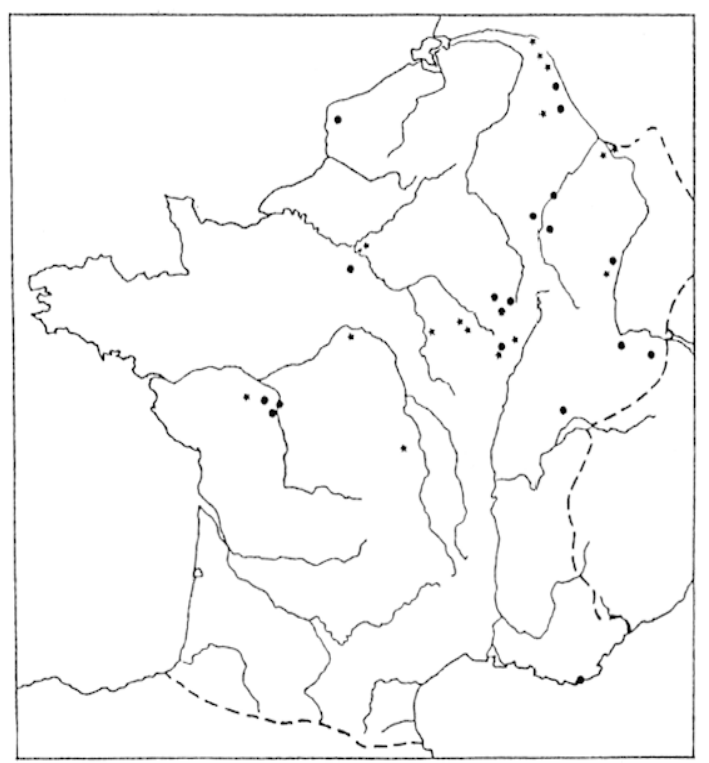

TYPE 6
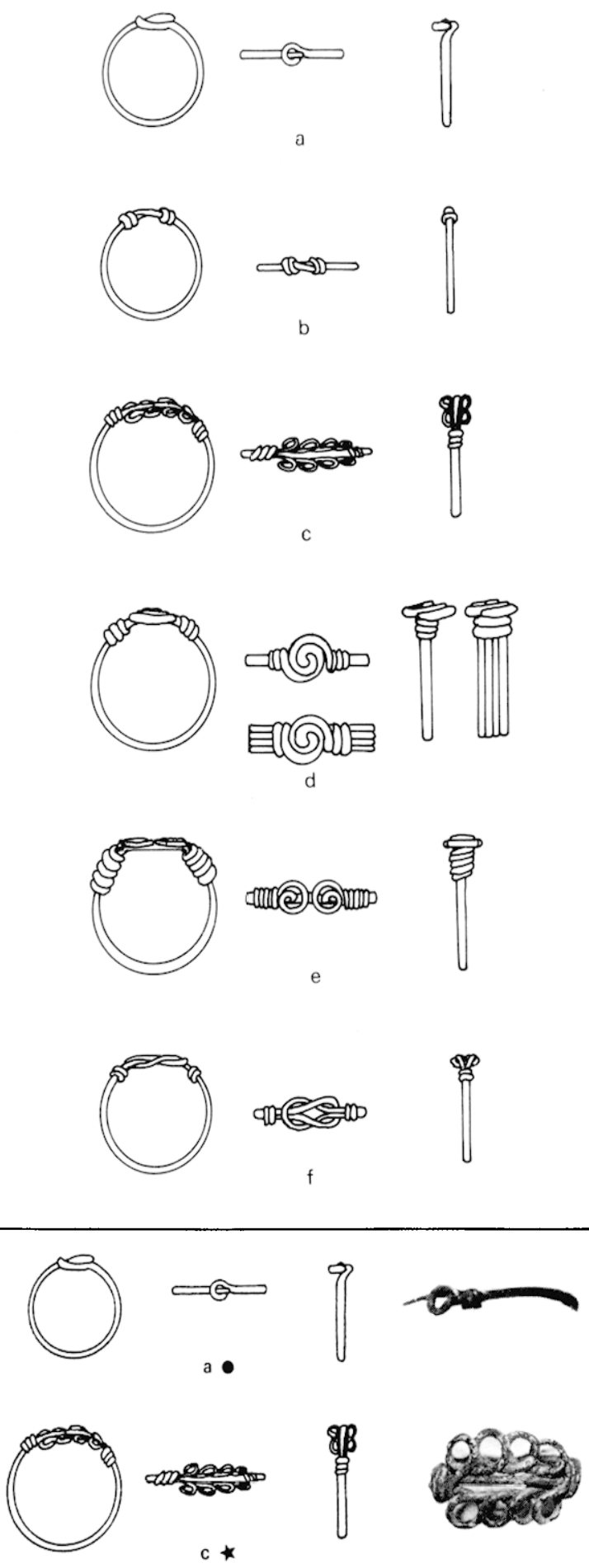

Fig. 37 - Carte de répartition des bagues de formes $6 a$ et $6 \mathrm{c}$. Bague 6a;

bronze;

provenance : région de Langres (Haute-Marne);

(Musée Saint-Didier, Langres).

Bague 6c;

bronze;

provenance : Naintré (Vienne);

(Musée archéologique, Châtellerault, Vienne). 

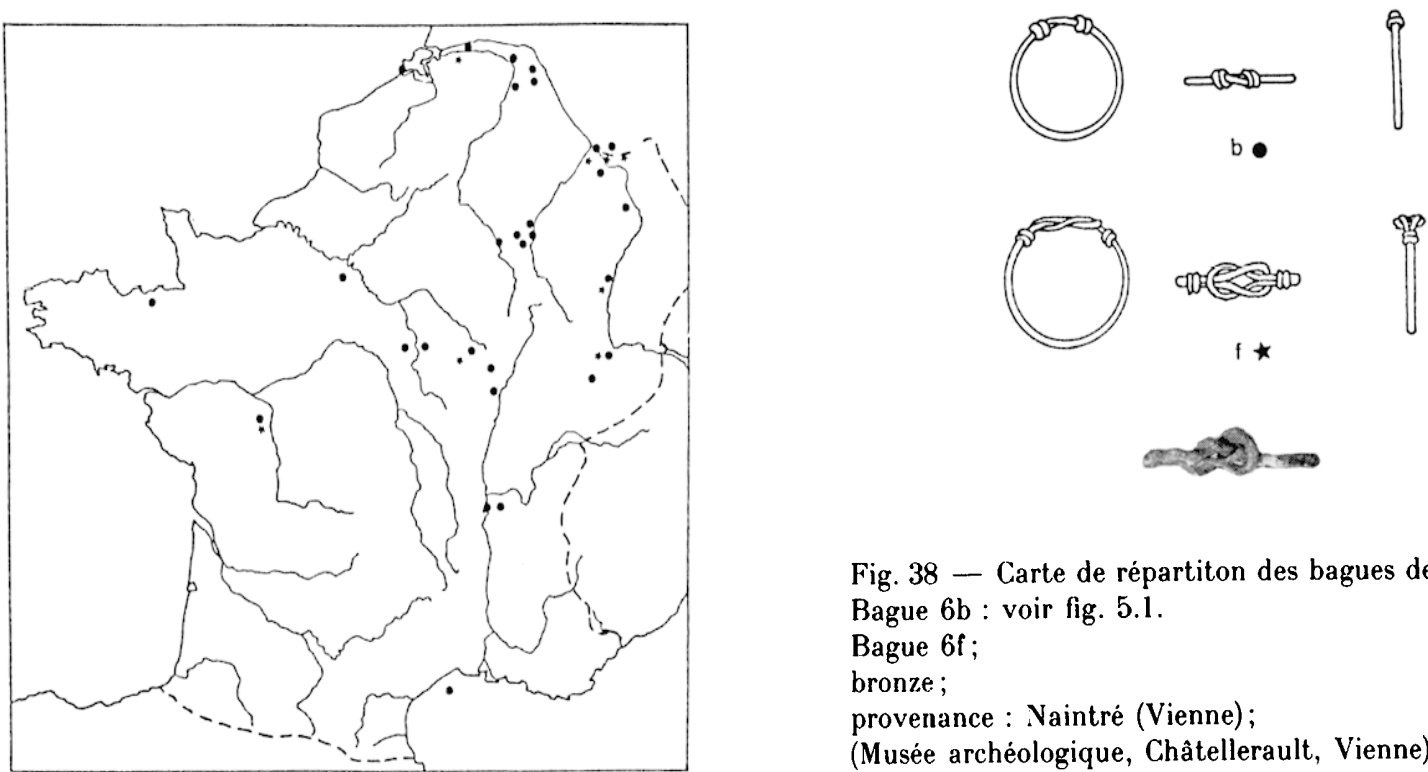

Fig. 38 - Carte de répartiton des bagues de formes $6 \mathrm{~b}$ et $6 \mathrm{f}$. Bague $6 \mathrm{~b}$ : voir fig. 5.1 .

Bague 6f;

bronze;

provenance : Naintré (Vienne);

(Musée archéologique, Châtellerault, Vienne).
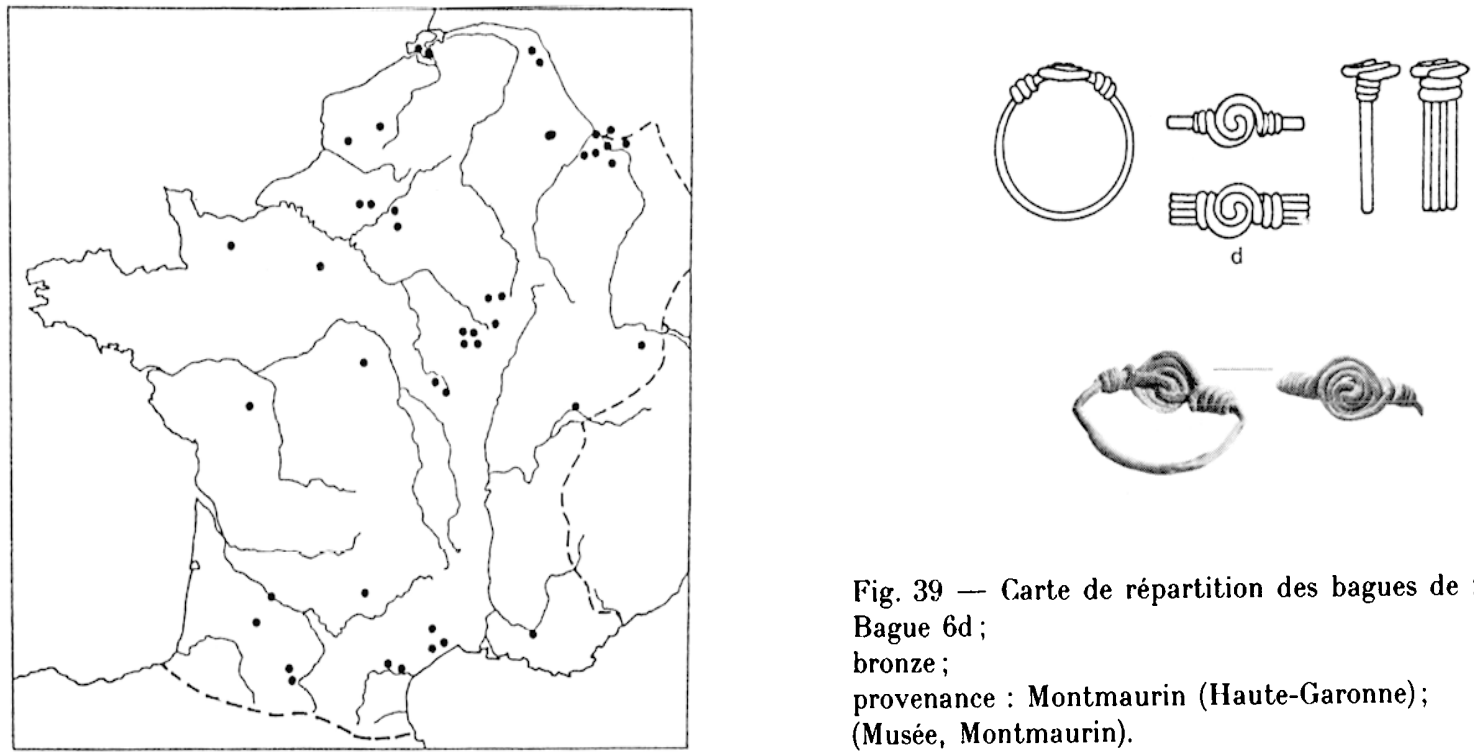

Fig. 39 - Carte de répartition des bagues de forme $6 \mathrm{~d}$. Bague 6d;

bronze;

provenance : Montmaurin (Haute-Garonne);

(Musée, Montmaurin)
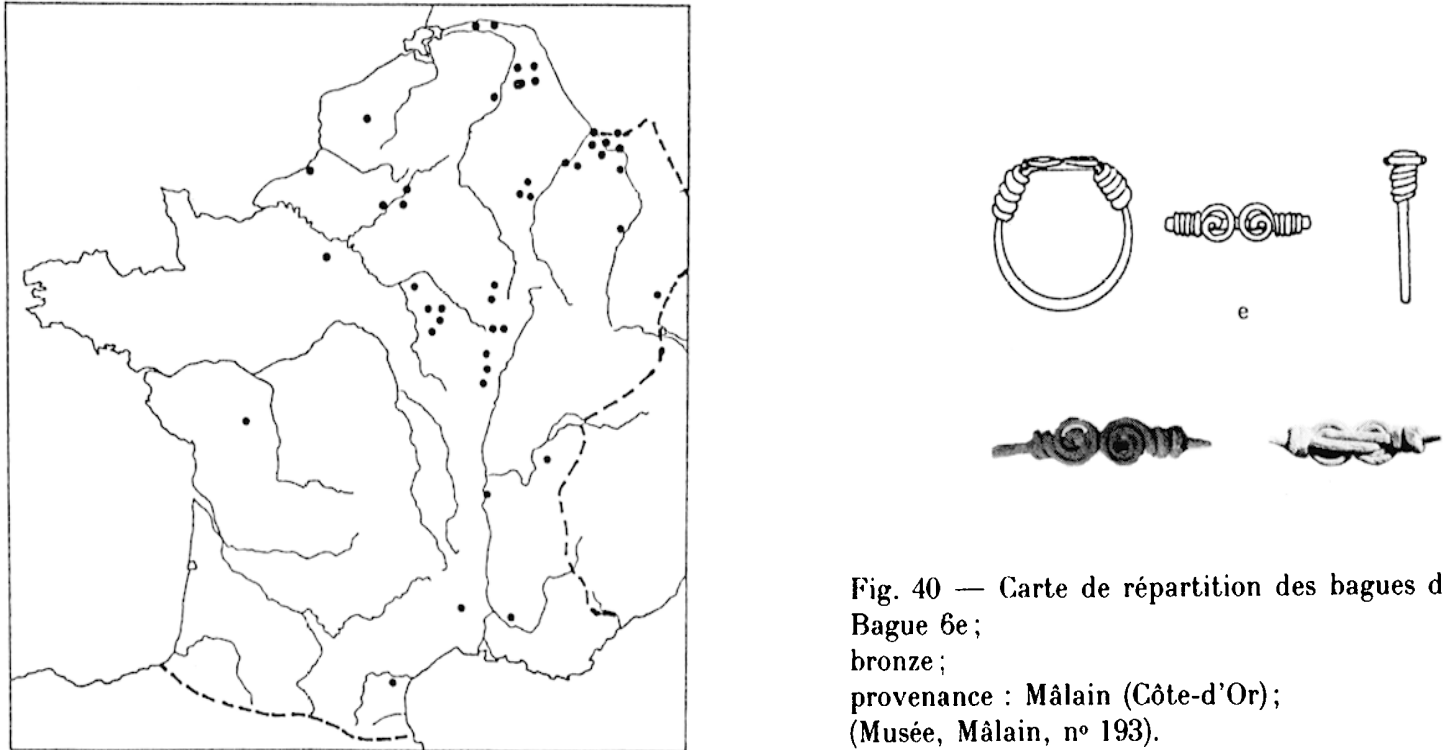

Fig. 40 - Carte de répartition des bagues de forme $6 e$. Bague 6e;

bronze;

provenance : Mâlain (Côte-d'Or);

(Musée, Mâlain, no 193). 


\section{LE TYPE 7}

fig. 41 à $44 ; 48.1$ et 4 $4 \%$

$\mathrm{Au}: 15,3 \% ; \mathrm{Ag}: 22,5 \% ; \mathrm{Br}: 60,5 \%$

Il présente des bijoux ouverts; cette ouverture est soulignée par l'ornementation des deux extrémités qui se font face ou qui sont disposées parallèlement l'une à l'autre. Ces bijoux sont faits d'un fil ou d'un ruban plus large, formant un ou plusieurs enroulements autour du doigt. La moitié de ces bijoux est serpentiforme, l'animal étant suggéré par une tête plus ou moins réaliste, des écailles faites de traits entrecroisès, d'une queue affinée; le décor est parfois très simplifié; deux exemplaires zoomorphes imitent un bélier (fig. 44 en bas) ou un cervidé (fig. 44 en haut). Ce type est un mélange de tradition celtique (bagues hélicoïdes) et de tradition hellénistique (bagues zoomorphes). Sans décor animalier, ces bagues sont en bronze; de type zoomorphe, la moitić des bagues est en or ou en argent. Ces formes ont été à la mode à toutes les époques et dans diverses régions.

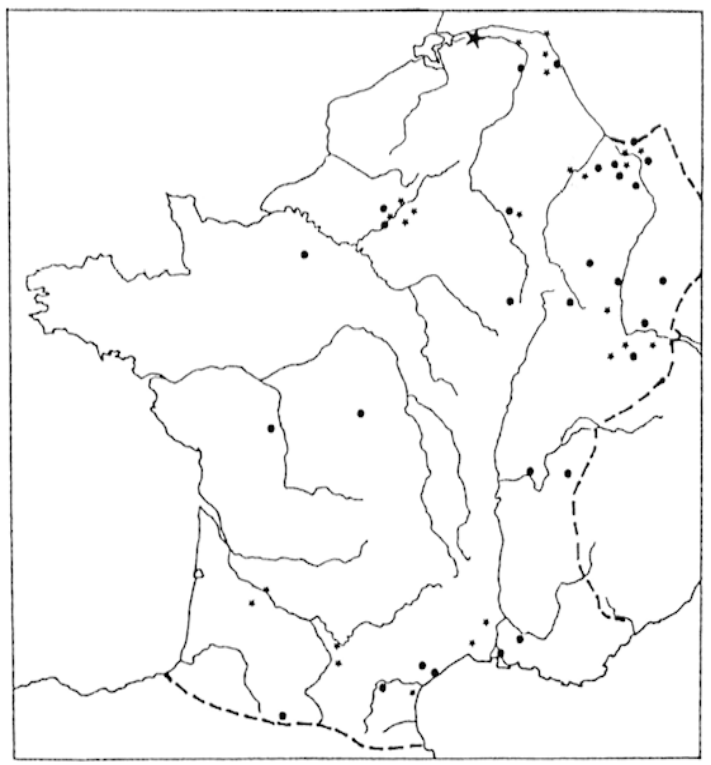

Fig. 42 - Carte de répartition des bagues de formes $7 \mathrm{a}$ et $7 \mathrm{~b}$. Bagues 7a;

(à gauche) bronze; non zoomorphe; provenance : Forêt de Compiègne (Oise);

(MAX, no 28955)

(à droile) or; serpentiforme; provenance : Ensérune (Ilérault);

(Musée archéologique, .Vissan-lèz-Ensérune, no 1963.60).

Bague $7 b$;

bronze; serpentiforme ;

provenance : Strasbourg (Bas-Rhin);

(Musée archéologique, Strasbourg, no 4.510).
TYPE 7
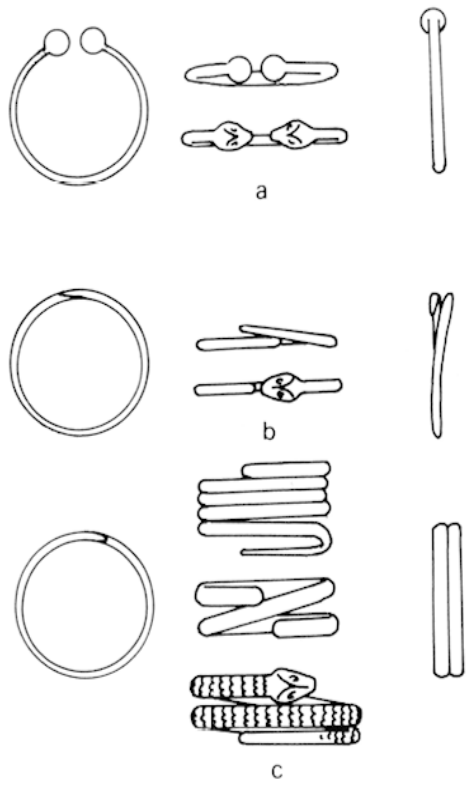

Fig. 41 - Bagues de type 7 : typologie.
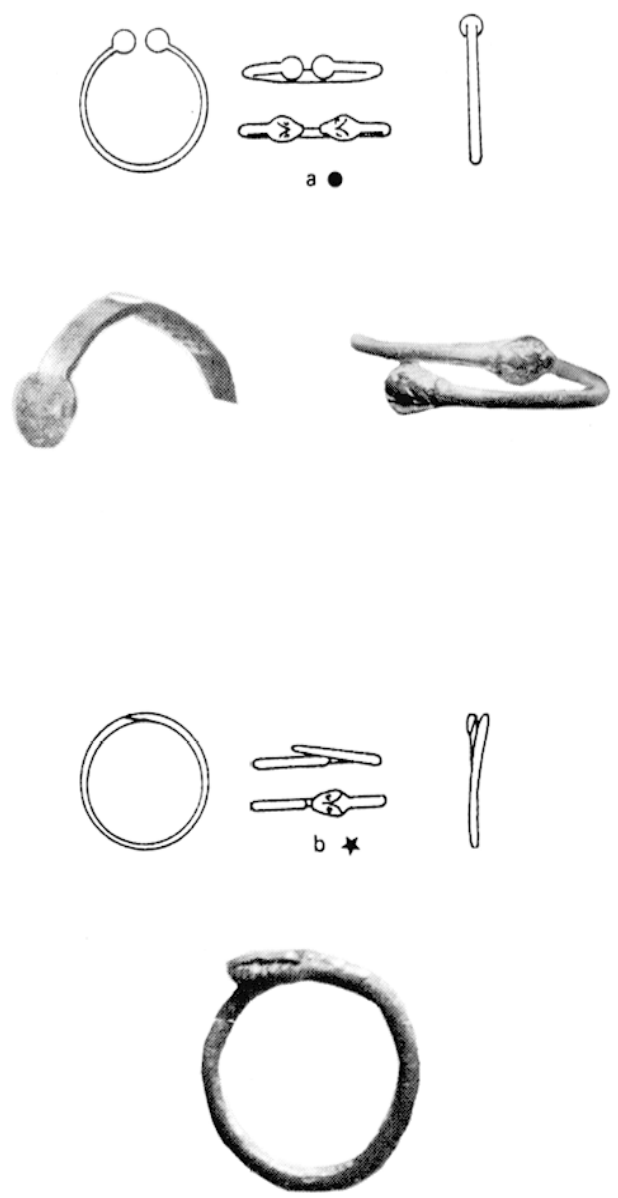

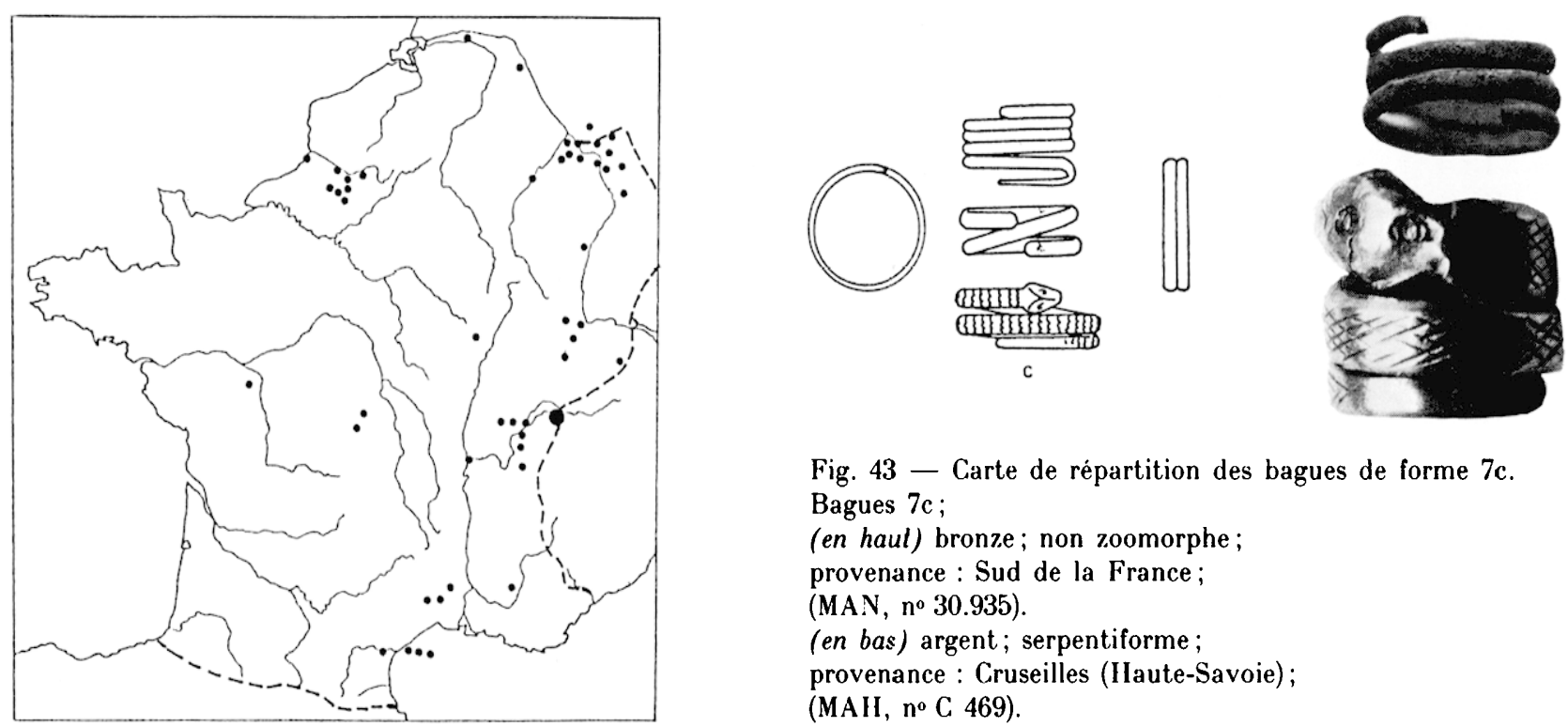

Fig. 43 - Carte de répartition des bagues de forme $7 \mathbf{c}$. Bagues $7 \mathrm{c}$;

(en haul) bronze; non zoomorphe;

provenance: Sud de la France;

(MAN, no 30.935).

(en bas) argent; serpentiforme ;

provenance : Cruseilles (Haute-Savoie);

(MAH, n० C 469).

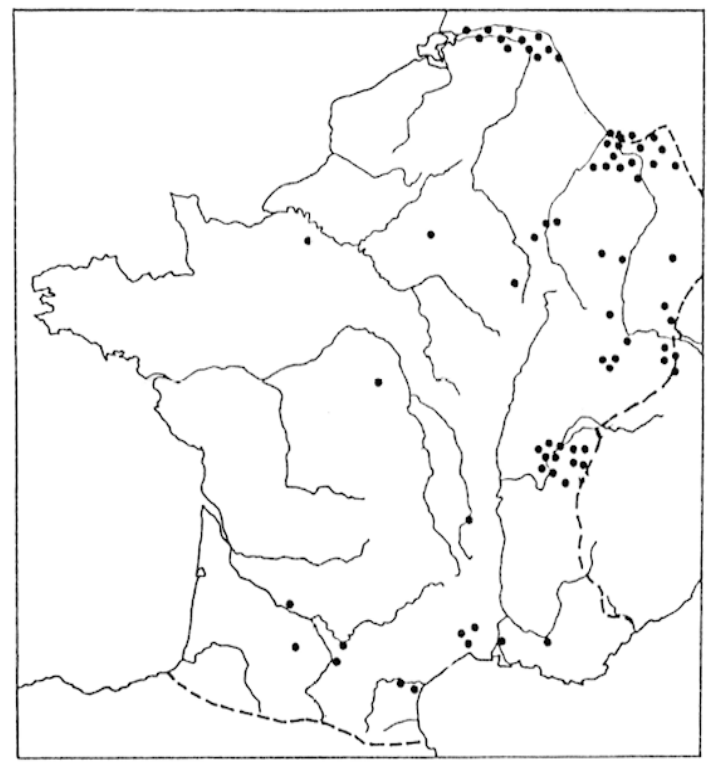

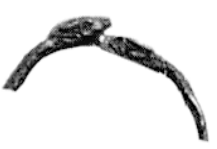
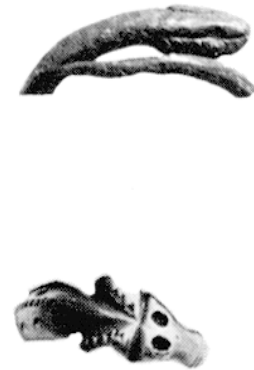

Bague $7 \mathrm{c}$;

argent; extrémités en forme de tête de bélier; provenance : Cruseilles (Haute-Savoie); (MAII, no C 459).

Fig. 44 - Carte reprenant uniquement la répartition des bagues zoomorphes.

les motifs décoratifs qui en ornent les deux tiers, décors choisis en fonction de la section le plus souvent. Les anneaux sans décor sont de toutes les époques et de toutes les régions; les anneaux décorés ont été le plus souvent datés de la fin du $\mathrm{II}^{\mathrm{e}} \mathrm{s}$. et du III" s.

Les anneaux polygonaux (type 9) ne représentent que $3,1 \%$ des bagues de Gaule; ils sont classés en anneaux simples (de section rectangulaire d) et en anneaux décorés (le décor modifiant la forme du 



Fig. 45 - Bagues-anneaux de type $8:$ typologie et carte de répartition avec les éclatements régionaux : 1, Rhin; 2, Centre; 3 , Genève.

Fig. 46 - Baguesanneaux $8 \mathrm{~g}$;

(en haul) or, grenats; inscription en opus interrasile: $\mathrm{FR} / \mathrm{V} / \mathrm{ER} / \mathrm{E} / \mathrm{M} / \mathrm{E}$; provenance :

La Haye-Malherbe (Eure); (Musée départemental des Antiquités de la Seine-

Maritime, Rouen, no 4827).

(en bas) verre noir à protubérances; provenance : Vertault (Côte-d'Or);

(Musée archéologique, Chatillon-sur-Seine Còte-d'Or). contour). Ils sont souvent luxueux : $40,4 \%$ sont en or ou en argent, surtout si des décors ornent la surface (parmi les anneaux sans décor, $24 \%$ sont en or et argent; avec décor, $58,5 \%$ sont en or et en argent). Ce type de bijou est daté de la seconde moitié du II s. et du III $s$.

Quelques très rares anneaux présentent un aspect très luxueux, par le matériau, l'or, et les décors (travail à jour, incrustations non métalliques); certains d'entre eux proviennent de trésors (fig. 46 en haut, 47 en bas, 49.2).

Tous ces anneaux de types 8 et 9 se retrouvent dans toutes les régions, surtout dans le Nord-Est, et on les trouve en particulier s'ils sont modestes dans les vici, les zones rurales, les forts du limes. 


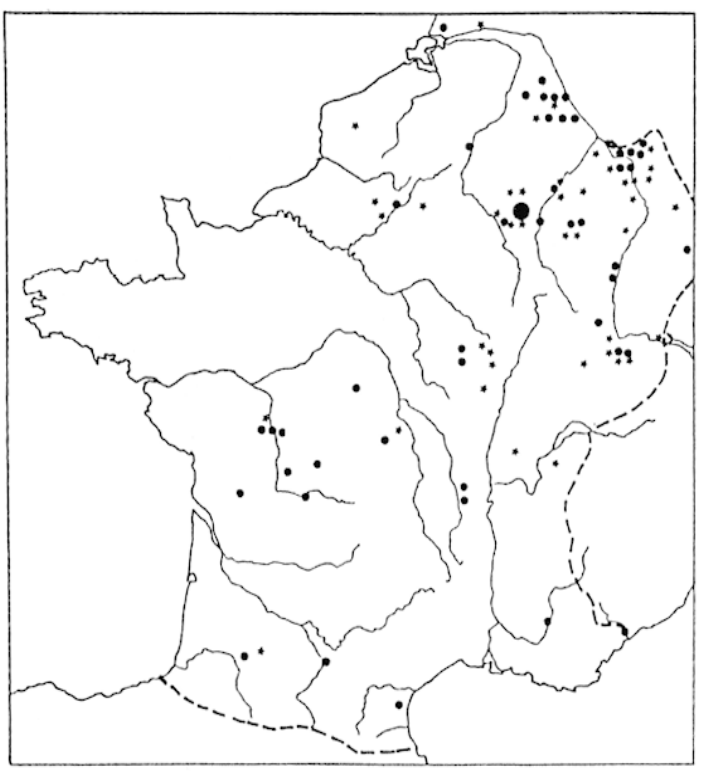

Fig. 47 - Bagues-anneaux de type 9 : typologie et carte de répartition.

Bague-anneau 9a ;

bronze; anneau non terminé;

provenance: Le Chastellard-de-Lardiers, Lardiers (Alpes-de-

Haute-Provence);

(Musée archéologique, Apt, Vaucluse).

Bagues-anneaux $9 \mathrm{~b}$;

(à gauche) argent;

provenance : Annecy (Haute-Savoie);

(MAII, no 1.276).

(à droite) or et perles;

provenance : sanctuaire des Sources de la Seine (Còte-d'Or);

(Musée archéologique, Dijon, Côte-d'Or).

\section{LES DECORS}

Il s'agit des décors qui ornent le bijou, à l'exclusion des figures disposées sur le chaton métallique ou sur l'incrustation en pierre ou pâte de verre. Pour produire un effet ornemental, les artisans ont employé une riche gamme de motifs et des techniques diverses.

\section{LES MOTIFS DÉCORATIFS INCISÉS ET AJOURÉS}

Les divers motifs peuvent être tracés en creux : les techniques utilisées sont variées et souvent mêlées sur un même bijou, comme peuvent l'être les motifs : emploi d'un ciselet pour figurer la laine du bélier (fig. 48.1) ou les traits transversaux irrégulièrement disposés entre deux lignes parallèles (fig. 48.2 et 3), emploi d'une gouge pour les cannelures longitudinales (fig. 48.2), d'un perloir pour les "fleurs" (fig. 48.3) et d'un ciselet pour reprendre le contour des grappes faites au moule (fig. 48.3), emploi d'un
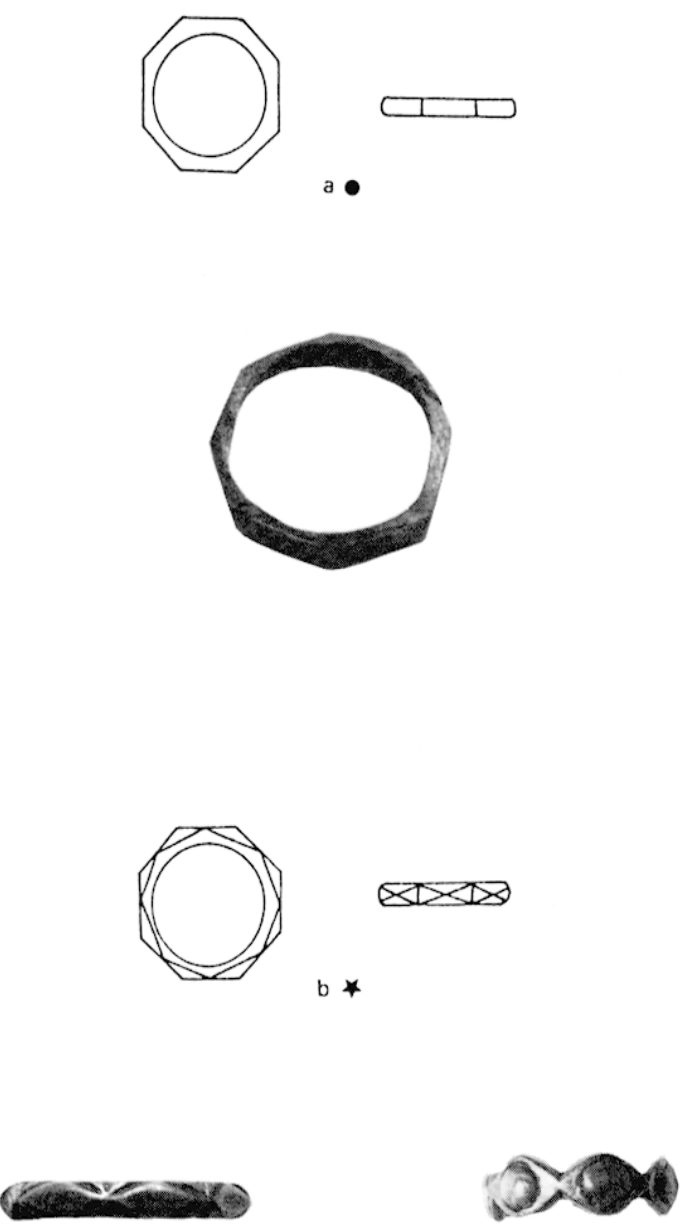

burin pour graver des inscriptions, estampage de certains décors (fig. 48.3). Sur de très beaux bijoux, surtout de forme 3 , au III $^{\mathrm{e}} \mathrm{s}$., les motifs sont ajourés : le travail à jour ou opus interrasile peut être limité (fig. 49.1) ou couvrir tout le bijou (fig. 49.2); il peut être fait avec un foret ou des limes, mais il peut être prévu aussi dès la fabrication du moule, avec la possibilité de faire des retouches après la fonte (fig. 49.2). Sur quelques bijoux du iII ${ }^{e}$ s., les motifs ont été rehaussés de nielle (sulphide d'argent, poudre noire disposée dans des sillons et solidifiée par la chaleur).

Les motifs géométriques, les plus simples, nombreux, variés dans leur aspect, leur rythme et leur répétition sont utilisés seuls ou en composition plus complexe sur les anneaux ou les montures des autres bagues (fig. $48.2,50$ ). Ils appartiennent à toutes les époques; le zigzag cependant se trouve sur des anneaux des Iur-IVe s. (fig. 50.10 et 11 ). Ces motifs géométriques ornent $66 \%$ des anneaux de type 8 et $44,5 \%$ des anneaux de type 9. 


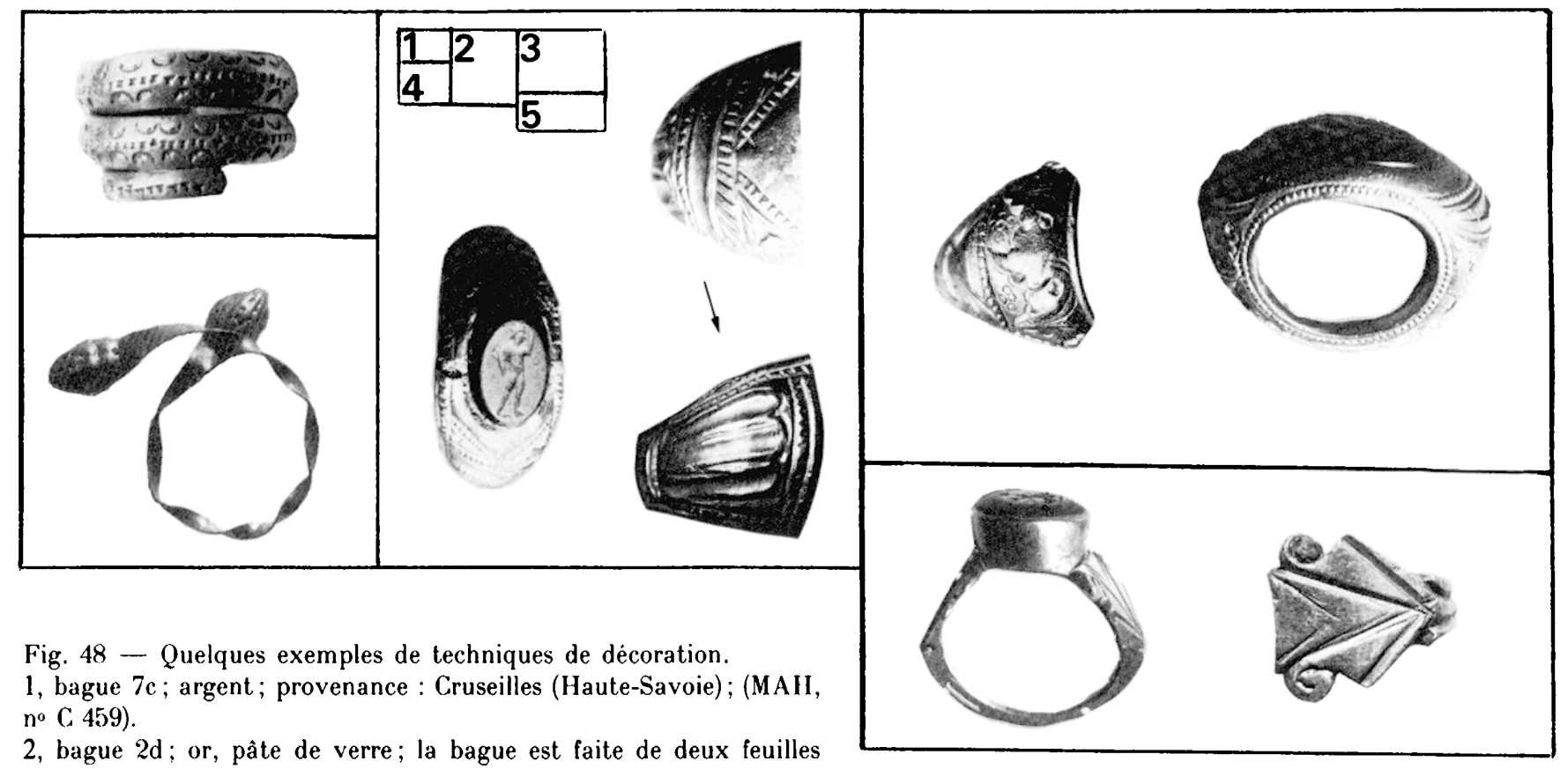

2 , bague $2 \mathrm{~d}$; or, pâte de verre; la bague est faite de deux feuilles d'or, la jonction entre les feuilles est faite le long du diamètre intérieur, vers l'extérieur; la bague est remplie d'une matière sableuse qui s'est dilatée : la feuille d'or a craqué sur le dessus et sur le côté (voir flèche). Noter le tracé irrégulier des hachures; provenance : La Celle-en-Morvan (Saône-et-Loire); (MCGR).

3, bague 2d; or, nicolo; provenance : la Saòne, Lyon (Rhône); (MCGR).

4, bague 7a; or, extrémité serpentiforme; provenance: Agen (Lot-et-Garonne); (Musée des Beaux-Arts, Agen, n³38A3).

5 , bague $3 f$; or, nicolo; on peut voir la reprise du trait oblique en bas; provenance : Chalain-d'Uzore (Loire); (Musée de la Diana, Montbrison, Loire, $\mathrm{n}^{\circ} 890.10 .36$ ).

1

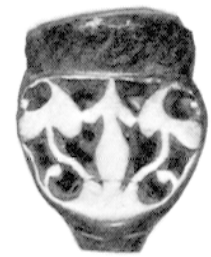

2

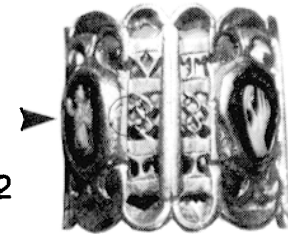

Fig. $49-$

Opus interrasile.

1 , bague $3 f$; or; détail de l'épaule; provenance : Eauze (Gers). Voir fig. 25.

2 , bague-anneau $9 \mathrm{~b}$; or, nicolo; camées : divinité, main tirant une oreille, travail à jour : inscription (ici V/T en haut, L/I en bas; UTERE FELICITER sur tout le tour de l'anneau) et décor central de chiens courants; travail fait lors de la fonte et repris avec des limes ensuite. Provenance : Eauze (Gers).

3, détail (pris sur le côté gauche) de la bague-anneau 9b (grossi 16 fois, photographie de MM. J. Daste et J.-P. Bernadou) bord des trous du décor central ct à droitc, rebord d'une des bâtes contenant un camée, mal brasé à la surface de l'anneau (flèche).

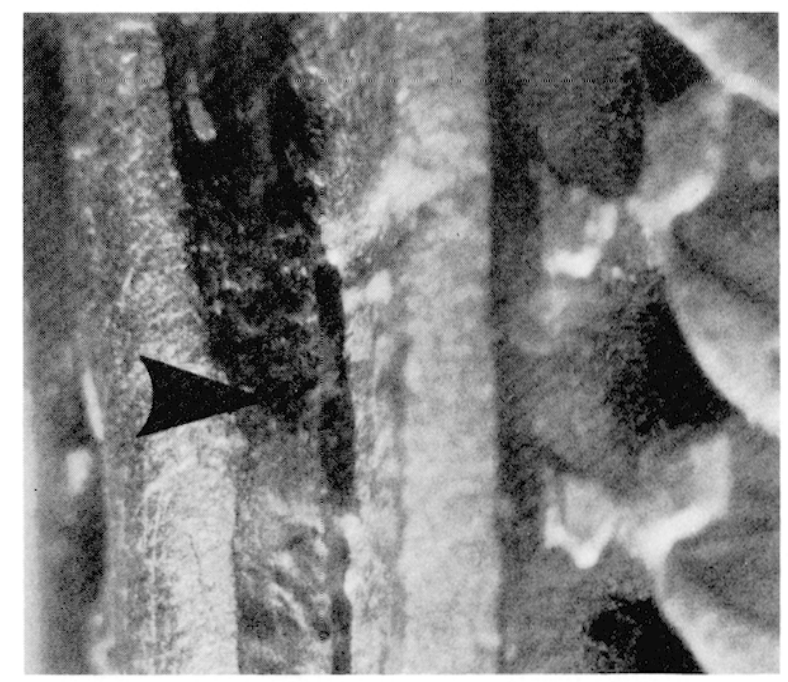

A ces décors disposés de façon linéaire et répétitive, peuvent s'ajouter sur les bagues de nombreux motifs arrangés pour mettre en valeur le dessus; ils sont donc reproduits de manière symétrique de chaque côté du chaton ou de l'incrustation. Ces motifs vont des simples figures géométriques, losanges, chevrons, à des éléments inspirés par le monde végétal, feuilles, volutes, à des cannelures, et des godrons; il y a peu de figures et peu d'inscriptions (fig. $51 ; 4,24,25,42$ à 44,48 ). La mode de l'ornementation date surtout de la fin du $\mathrm{II}^{\mathrm{e}} \mathrm{s}$. et du $\mathrm{III}^{\mathrm{e}} \mathrm{s}$.; ces motifs sont utilisés presque exclusivement sur des bagues de types 2 et 3 , lorsque les montures assez larges peuvent accueillir ces décors. On peut 

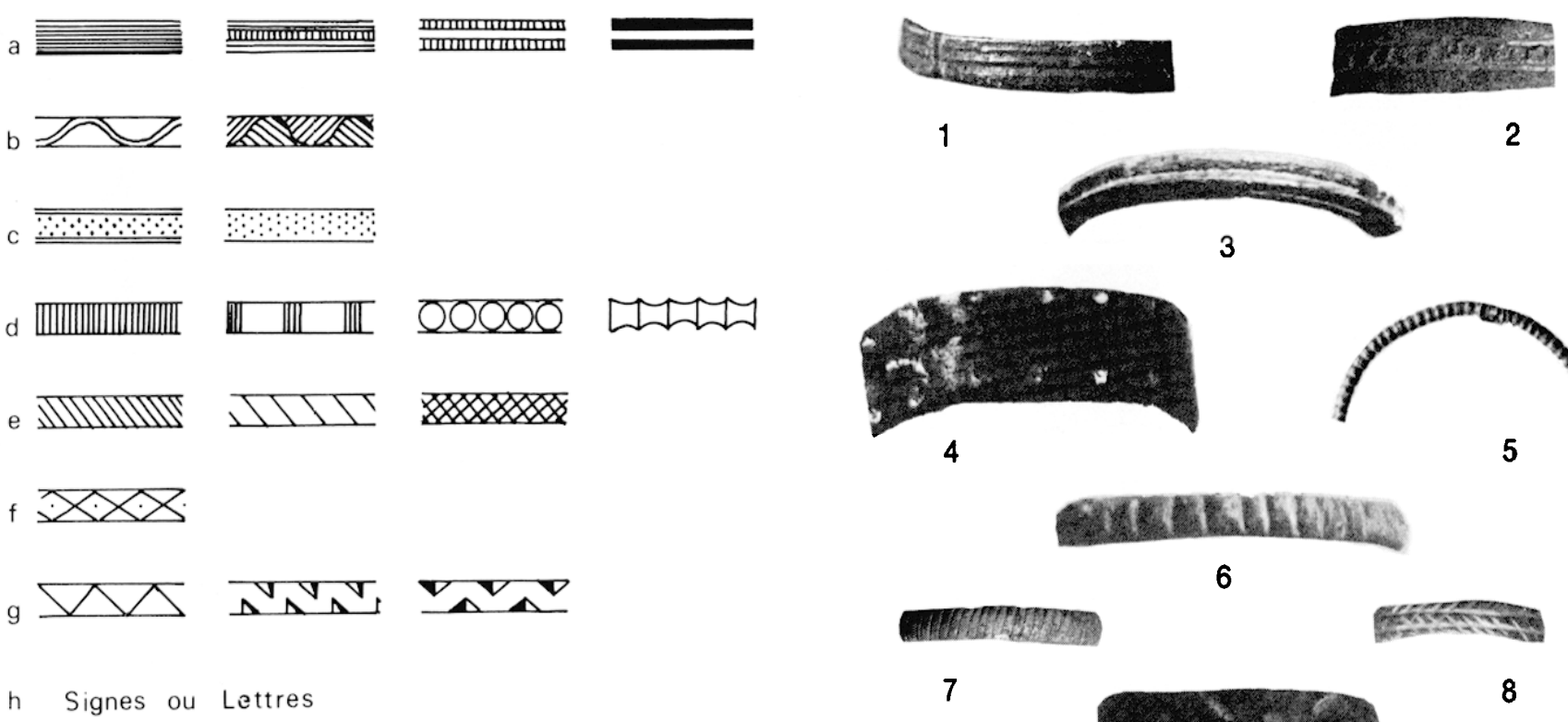

1

2

3

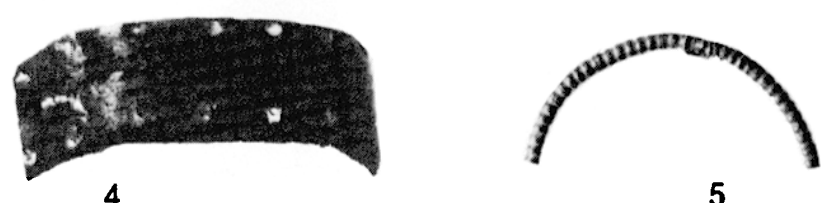

4
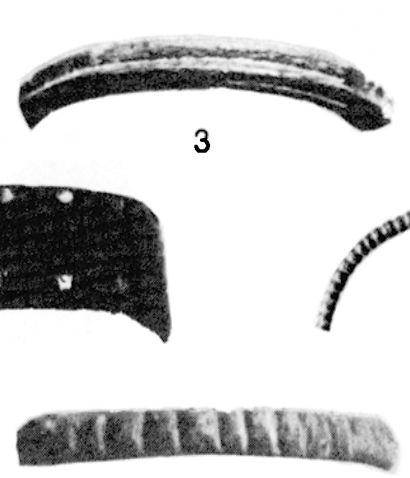

6

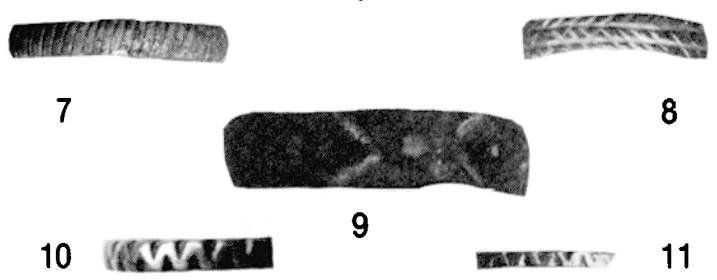

Fig. 50 - Décors incisés ou ajourés sur les anneaux. Les divers types (a à $h$ ) et quelques exemples.

a. Décor de type a.

1, anneau 8d; bronze; provenance : Mont-Chyprès, Lacroix-Saint-Ouen (Oise); (MAN no 28.883).

2, anneau 8d; bronze; provenance: Forèt de Compiègne (Oise); (MA.V, no 28.955).

3, anneau 8g; bronze; provenance: Strasbourg (Bas-Rhin); (Musée archéologique, Strasbourg, n 18.901).

c. Décor de lype $c$.

4, anneau 8d; bronze; provenance : Drevant (Cher); (Musée du Berry, Bourges).

d. Décor de type $d$.

5 , anneau $8 \mathrm{a}$; or; provenance : Saint-Genis, Pouilly (Ain); (MAII, $\left.n^{\circ} \mathrm{C} 1360\right)$.

6 , anneau 8a; bronze; provenance : Vienne (Isère); (Musée des Beaux-Arts, Vienne).

e. Décor de lype e.

7 , anneau 8c; bronze; provenance : Mâlain (Côte-d'Or); (Musée, Mâlain).

8, anneau 8d; bronze; provenance: Naintré (Vienne); (Musée archéologique, Chatellerault, Vienne).

f. Décor de lype $f$.

9, anneau 8d; bronze; provenance: Tresques (Gard); (collection particulière).

g. Décor de lype $g$.

10, anneau 8d; argent; provenance: Annecy (Haute-Savoie); (MAH, no 1.272).

11, anneau 8e; argent; provenance : Rennes (Ille-et-Vilaine); (Musée de Bretagne, Rennes, no 2247).

chercher la filiation de ces motifs aussi bien dans la bijouterie hellénistique que dans l'art celtique ${ }^{12}$. Il faut noter une excellente adaptation entre la forme et le décor : non seulement le genre du motif mais aussi la technique de réalisation sont choisis en fonction de la forme de la bague et dans le but de

12 Il n'est pas sùr que les motifs curvilignes, si appréciés dans l'art laténien, aient été choisis plus tôt dans les provinces "celtiques" de la Rhénanie ou de la Pannonie que dans le reste de l'Empire; - I. SEL.tyf, Recueil des bronzes ajourés de Pannonie faits par les maitres celtiques à l'époque de l'Empire romain, Ilommages à $M$. Renard, coll. Latomus, 103, Bruxelles, 1969, III, p. 518-541; on trouve le même type de décor en Orient: T. G. Frisch, Pierced Bronzes, in : Excavations at Doura Europos. Final Report, IV, 1 The Bronze conduire le regard vers le dessus : godrons faits au repoussé sur les bijoux d'or (fig. 48.2), les cannelures en gravure profonde sur le bronze des bagues $3 \mathrm{~g}$ ou $2 f$, les traits longitudinaux en stries fines sur les épaules des bagues $3 \mathrm{e}$ ou $3 \mathrm{f}$ (fig. 48.5), les volutes en travail à jour sur les épaules des bagues $3 \mathrm{f}$ en métal

Objects, New IIaven, 1949, p. 1 sq. Les motifs, à l'époque romaine, ne se présentent plus en composition enchainee et dynamique comme dans le style curviligne celtique, mais ils sont statiques, organisés de manière symétrique pour mettre en valeur le "centre" du bijou. Pour l'art, celtique, P.M. Duval, Les Celles, Paris, 1977, fig. 440, 443-445; V. Kruta, L'arl celtique en Bohême. Les parures métalliques du ve au Ite siècle avant notre ère, Paris, 1973. 
Fig. 51 - Décors incisés ou ajourés sur les bagues.

a, pourcentages des trois groupes de motifs :

1, motifs géométriques variés : croix, chevrons, hachures, lignes ondées, végétaux, vases, inscriptions;

2 , traits incisés simples, parallèles, obliques, ..., cannelures, godrons :

3 , traits courbes, volutes, peltes, esses, vrilles, rinceaux.

Dans ces trois groupes, pourcentage des divers matériaux ( $\mathrm{Au}$ : or; $\mathrm{Ag}$ : argent; $\mathrm{Br}$ : bronze)

$\mathrm{b}$, répartition des trois groupes de motifs dans les principales formes (en \%).

Les pourcentages sont calculés par rapport à la totalité des motifs recensés (environ 250) et non des bagues ornées, car des motifs différents peuvent décorer le même bijou.

assez épais. On doit constater aussi que les artisans n'ont pas cherché à créer de forme originale pour un motif et une technique donnés ${ }^{13}$.

LES MOTIFS ORTFNUS PAR LE FILIGRANE ET LA GRANULATION

Ces deux techniques sont employées essentiellement sur les bagues de type 4 . Le filigrane utilise les fils d'or soudés sur les montures ou entre eux; le fil est lisse, perlé ou tordu sur lui-même pour imiter une tresse. L'anneau peut être fait d'un ou de plusieurs fils conjoints (fig. 8.4), ou bien de fils formant un châssis dans lequel un autre fil dessine des volutes, des spires, etc. Fil perlé, il orne le bord du chaton ou entoure l'incrustation (fig. 52).

La granulation emploie de petites boules d'or soudées à la surface de la monture, disposées en couronne autour de la pierre, ou réunies en motifs, triangles, grappes, rosettes, autour du chaton (fig. 52).

Ces deux techniques et les motifs choisis ne sont qu'une pâle imitation des fines et élégantes décorations de l'époque hellénistique. Presque toutes les bagues (ornements et non sceaux) concernées sont datées du IV's.; quelques beaux bijoux sont plus anciens. Ces deux types de décor n'ont guère eu la faveur de la clientèle: quelque soixante bagues seulement en sont ornées; les capacités pratiques que demandent ces techniques expliquent en partie ce faible chiffre, et aussi la mode du temps qui

13 C. Lepage, Les bracelets de luxe romains et byzantins du $\mathrm{II}^{\mathrm{e}}$ au $\mathrm{vi}^{\mathrm{e}}$ siècle. Etude de la forme et de la structure, Cahiers Archéologiques, 21, 1971, p. 1-23; l'auteur constate l'absence de création par rapport à une nouvelle technique ou un nouveau motif (p. 8-9); ce n'est que dans les dernières années du $u^{e} s$. que les bijoutiers créeront des formes adaptées à la fragilité du métal percé par les décors.

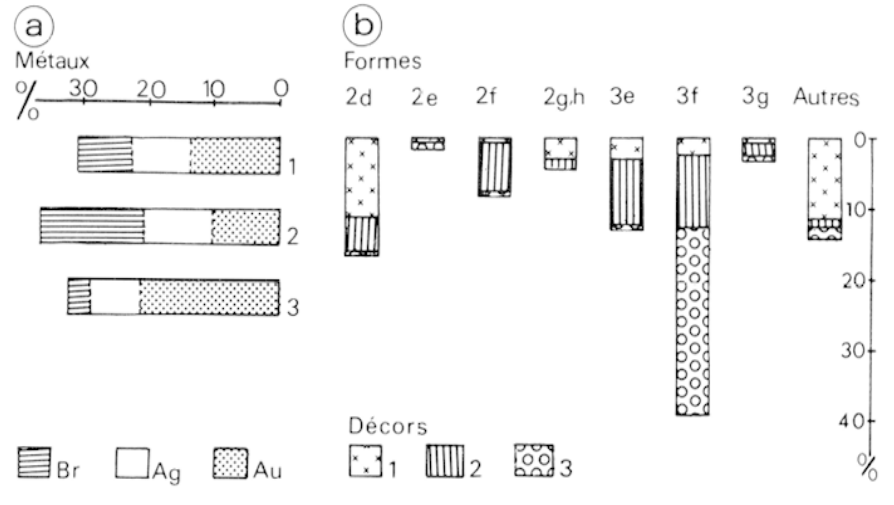

Fig. 52 -- Filigrane et granulation.

Bague 4e;

or, filigrane et granulation; provenance : région de Langres (Ilaute-Marne); (Musée Saint-Didier, Langres).

sélectionne plutôt des bijoux très polychromes; le style de bijoux lourdement chargés de gros filigranes et de grosses granulations apprécié par les Barbares des $\mathrm{V}^{e}-\mathrm{VI}^{\mathrm{r}} \mathrm{s}$. n'en est qu'à ses débuts.

\section{EMPLOI D'ÉLÉMENTS COLORÉS}

Il s'agit d'ornements ajoutés à la monture pour former le décor principal sur le dessus de l'anneau ou dans le chaton, pierre, pâte de verre, émail (et quelques rares emplois de métal de nature différente de la monture). La pose de ces décors implique une forme adaptée et on a noté la liberté offerte aux artisans dans les différentes méthodes d'insertion de la pierre. A la différence des autres moyens de décoration, l'emploi d'une incrustation a incité les artisans à créer ou à transformer des formes de montures. Les orfèvres ont rarement utilisé les jeux de réfraction des matériaux (tels ceux obtenus par la taille moderne des pierres) et, pour maintenir la pierre, ils ont rarement choisi des montants fins (4h) qui se rapprocheraient des griffes utilisées aujourd'hui. Les bagues offrent une polychromie simple, moins brillante que celles des pendants d'oreille ou des colliers, même aux III $\mathrm{e}^{\mathrm{e}} \mathrm{IV} \mathrm{V}^{\mathrm{e}} \mathrm{s}$., lorsque la couleur prend davantage d'importance. Le mélange de pierres de couleurs différentes n'existe en Gaule que sur de très rares bagues; cette lacune est liée peutêtre à des difficultés d'approvisionnement en pierres précieuses venues d'Orient (mais l'émeraude arrive 
jusqu'en Gaule); et autre fait plus étonnant : si les fibules émaillées très colorées se multiplient en Gaule, les bagues ornées d'émail sont peu nombreuses (3c et $3 \mathrm{~d}, 4 \mathrm{~d} ; 4 \%$ seulement des bagues portant des incrustations). Les bagues de verre elles-mêmes sont de couleur terne et rien ne semble survivre de la belle tradition celtique en ce domaine. Le ròle de la couleur est donc sur les bagues de Gaule discret, plus discret que sur d'autres bijoux ou dans d'autres régions de l'Empire.

\section{DISTRIBUTION DES BAGUES ET DES ANNEAUX DANS LE TEMPS ET DANS $L^{\prime} E S P A C E$}

Les indications sur la chronologie et la localisation des divers types de bagues sont formulées avec les réserves habituelles concernant la datation des bijoux (voir supra, p. 175) et les réserves attachées à tout catalogue régional, fatalement non exhaustif. Les événements historiques modifient aussi, bien entendu, les conditions habituelles, en intensifiant par exemple l'enfouissement des bijoux.

Ainsi, à la suite de l'évolution monétaire et de troubles divers, de nombreux trésors ont été enterrés au III" s. en Gaule. Ils donnent ainsi une proportion élevée de bagues $3 \mathrm{f}$, alors que les formes à la mode au II" s. n'ont pas connu de conditions d'enfouissement aussi favorables. Les bagues ornées de monnaies (peu nombreuses en réalité) datent du III $^{\circ} \mathrm{s}$. grâce à la conjonction de deux éléments, l'existence d'une forme 3a ou 3f susceptible de porter un chaton d'aussi grand diamètre et la politique monétaire des empereurs entraînant la thésaurisation, et par làmème, l'usage plus répandu de sertir les monnaies en bijoux (en pendentif surtout) ${ }^{14}$. Le hasard des fouilles peut s'ajouter aux conditions historiques pour changer la fourchette chronologique que l'on avait proposée. Ainsi, les anneaux de jais semblent très à la mode dans la première moitié du III" s.; or, les deux tiers de ces bagues ont èté trouvés dans les fouilles de la Neue Klinik à Bonn, zone de canabae détruites par des raids barbares en 259-260. Le même site a fourni un grand nombre de bagues en verre, publiées par F. Henkel en 1913; la découverte

14 Pour les trésors, voir Boistray, p. 231-233 et Le trésor d'Eauze, op. cil.; - pour la politique monétaire, J.-P. CAI.LU, La politique monélaire des empereurs romains de 238 a 311, Paris, 1969, p. 417, 424-430; - J. LAFAURIE, L'Empire gaulois. Apport de la numismatique, $A N R W$, II, 2, p. 853-1012 (trésors, p. 967-985). en 1922 à Trèves d'un atelier de verrier a transformé les pourcentages, les cartes et les datations (l'atelier est daté de la seconde moitié du III-IV"s.) que l'on avait pu faire en 1913. En revanche, rien, sinon un phénomène de mode, ne permet, aujourd'hui, d'expliquer la vogue des bagues en cristal de roche et en ambre dans la première moitié du II $^{\prime} \mathbf{s} .^{15}$.

\section{Évolution des formes, des matérialix ET DES DÉCORS DANS IE TEMPS}

Les formes et les décors offrent un éventail plus ou moins riche selon les siècles (fig. 53). Le II' s. et la première moitié du III"s. sont les plus belles périodes, celles où l'échantillonnage des formes est le plus complet et la variété des décors la plus grande. Les formes des bagues à la mode en Gaule ont une assez grande longévité : un siècle et demi pour les formes $2 \mathrm{c}$ et $2 \mathrm{~d}$; d'autres ont traversé les siècles, comme les formes $6 \mathrm{~d}$ et $6 \mathrm{e}$; à l'opposé, la période de fabrication des bagues $3 \mathrm{e}$, 3f et $3 \mathrm{~g}$ est limitée aux années 190-260 environ. Les changements de goût, l'évolution économique et le rôle attribué à la bague expliquent ces variations.

Les bagues et les anneaux peuvent être divisés en trois catégories : bagues et anneaux monomètalliques (53\% environ), bagues et anneaux ornés d'incrustation non métallique $(40 \%)$, bagues et anneaux non métalliques ( $7 \%$ environ).

La proportion des bijoux monométalliques passe de $23 \%$ dans le type 1 , à 30 et $31,5 \%$ pour les types 2 et 3 , a $42 \%$ dans le type 4 . Le chiffre est faible dans le type 1 parce que l'importation de bijoux "romains" porte davantage sur des bagues ornées de pierre, pour une société encore faiblement romanisée, où se développent l'emploi des baguessceaux et le goût pour les pierres. Le fort pourcentage dans le type 4 traduit, à l'inverse, le déclin de la glyptique (d'autant plus que moins de la moitié seulement des incrustations est décorée d'une intaille), les difficultés de circulation dans les régions orientales où passent les routes des pierres semiprécieuses, les embarras financiers d'une partie de la

15) Fouilles de la Neue Klinik: II:Nkel., p. 81 et n" $1623 \mathrm{sq}$.: -- W. HAgren, op. cit., p. 77-144. Atelier de Trèves : La rivilisation romaine de la Moselle à la Sarre, catalogue d'exposition (Paris, 1983) Mayence, 1983, p. 352-353 (bibliographie) et $n^{\prime \prime} 320$ ( $f, g, h$ : bagues du Iv"s.). Commerce de l'ambre: un calme relatif dans les pays de Cermanie Libre a pu favoriser le commerce de l'ambre, au début du II" s., à travers l'Allemagne jusqu'à Aquilée; et l'on sait que les mouvements de populations barbares reprennent dans la seconde moitie du II's. bloquant ainsi les routes de l'ambre. 


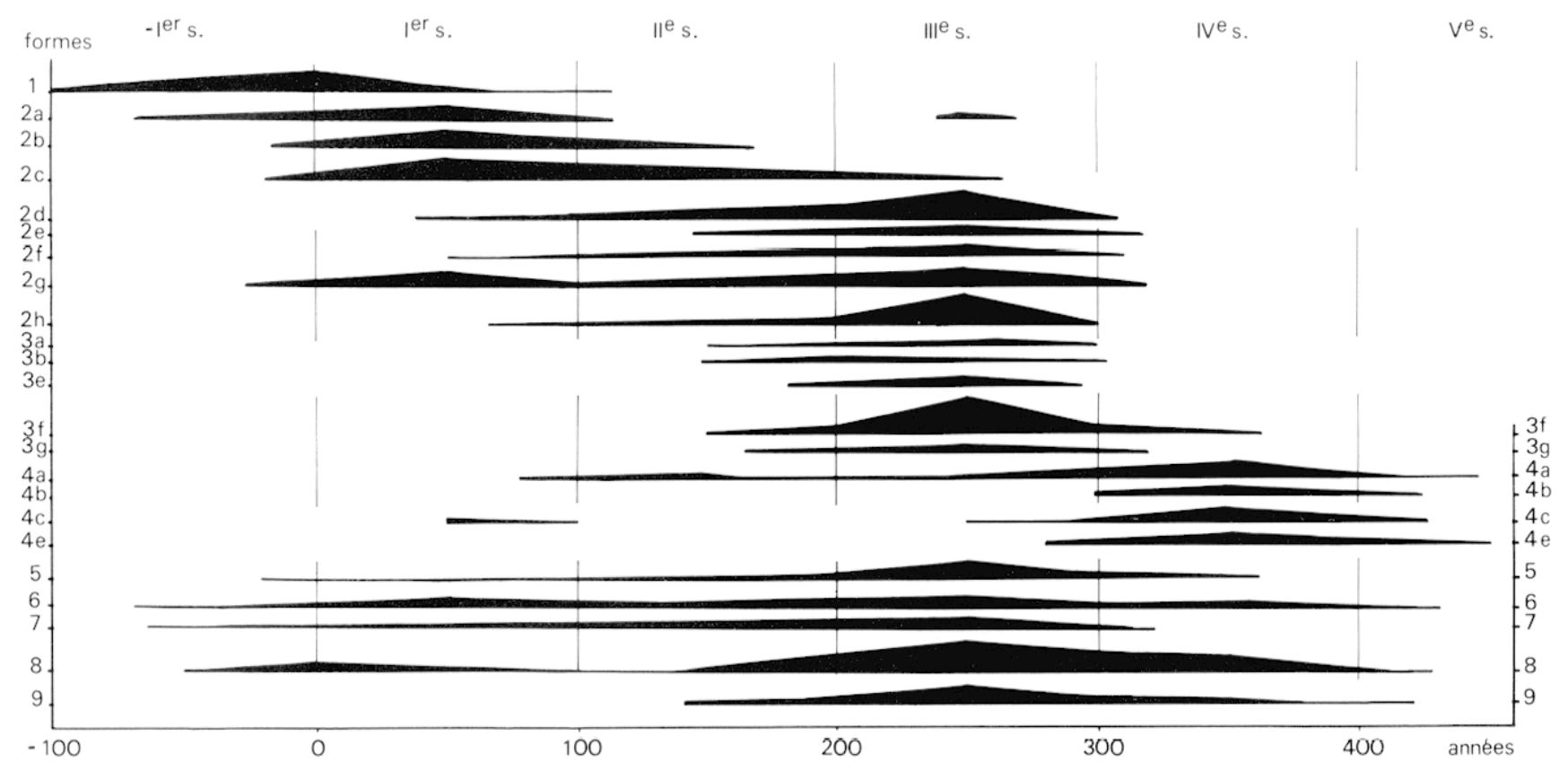

Fig. 53 - Chronologie des principales formes de bagues et anneaux. L'épaisseur du trait est fonction de la quantité de bijoux datés, de Craule et de l'ouest de l'Empire, que nous avons répertoriés.

clientèle, les changements de goût aussi. La proportion élevée des bijoux monométalliques suggère la vogue des bagues dans des couches sociales variées, certaines peu fortunées, car, si cette catégorie offre de beaux bijoux comme les bagues $4 \mathrm{e}$ ou $3 \mathrm{e}$ en métaux précieux, ornés parfois de nielle, le matériau (le bronze) et le décor sont souvent bien médiocres pour la majorité des bagues.

La distribution des bagues selon les matériaux (fig. 54, b et c) témoigne aussi de cette expansion dans les diverses couches de la société gallo-romaine. Les bijoux en matériaux précieux, or et argent, représentent seulement le quart des objets catalogués; le type le plus riche est le type 3 , les moins riches les types 5 et 8 ; pour les bagues-clefs, une raison pratique explique ce choix, le bronze étant plus résistant que les métaux précieux pour un usage fréquent de la bague. La provenance des bagues du type 3 issues souvent de trésors où seuls des objets de prix étaient conservés, explique en partie cette richesse; les difficultés économiques ont dû creuser l'écart entre les riches clients qui peuvent encore acheter le bijou à la mode et en métal précieux, et les autres; le prix des bijoux précieux est monté aussi à cause de la pénurie de l'or sur le marché. Cette difficulté d'approvisionnement en or pour la bijouterie explique le choix de l'argent pour des bagues luxueuses au III $^{\text {e }}$ s. (type $3: 21,5 \%$; type $9: 20,2 \%$; pourcentage de l'argent sur le chiffre total des

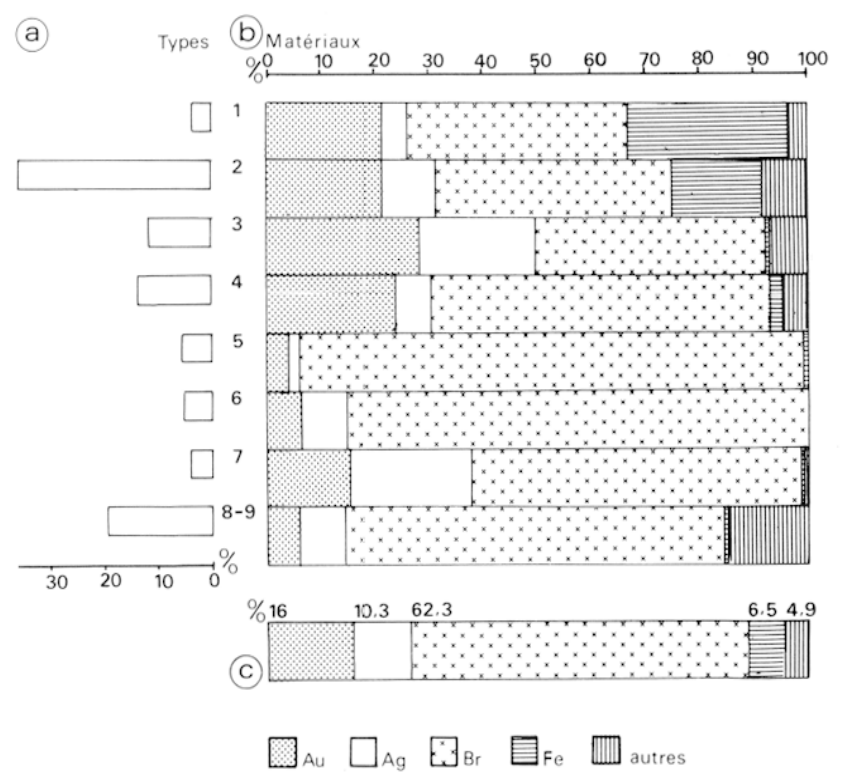

Fig. 54 - Les divers types de bagues et anneaux.

a, pourcentages de chaque type par rapport à la totalité des bagues et anneaux recensés en Gaule;

b, pourcentages des divers matériaux dans chaque type $(\mathrm{Au}=$ or $; \mathrm{Ag}=$ argent, $\mathrm{Br}=$ bronze; $\mathrm{Fe}=\mathrm{fer}$ );

c, pourcentage des divers matériaux par rapport à la totalité des bagues et anneaux recensés en Gaule.

bagues et anneaux : 10,3\%). A l'opposé, les baguesclefs (type 5), les bagues à spires (type 6), les anneaux (type 8 ) sont "pauvres" (de 72 à $93 \%$ de bagues en bronze); ils mettent en valeur l'existence 
d'une clientèle modeste, même si dans de somptueux trésors, comme celui d'Eauze (Gers), il y a parfois une bague-clef en bronze. Le fer n'est véritablement utilisé que pour les types 1 et 2 , la forme simple de ces bagues permettant le travail du métal; il est employé pour des bagues à incrustation : les acheteurs qui avaient besoin d'utiliser un sceau n'avaient peut-être pas le droit de porter une bague en or. Les matériaux non métalliques apparaissent peu, dans quelques formes particulières et rares (2i) ou dans un type simple, les anneaux 8 : leur plus grande vogue se situe dans les années 80-250. Pour chaque type, la répartition entre les différents métaux varie selon la catégorie du bijou; en généralisant, on peut dire que les bagues ornées d'une incrustation sont plus riches que les bagues monométalliques; c'est particulièrement le cas dans les types 2 et 4 .

La répartition en pourcentage entre les différents types 1 à 4 (fig. 54a) montre la progression de la mode romaine et ensuite le déclin économique de l'Empire. Le type 1 qui apparaît le premier en Gaule est peu important, parce que la romanisation en profondeur est lente à se répandre ${ }^{16}$; le type 2 , en vogue pendant deux siècles, est le témoin de l'essor économique et de celui de la civilisation romaine : les bagues-sceaux sont des objets de la civilisation conquérante, étrangère aux Gaulois. Le type 3 et le type 4 représentent deux parts à peu près identiques, marquant un certain déclin économique. Les autres types sont moins spécifiques de la bijouterie et de la civilisation romaines.

\section{RÉPARTITION RÉgionale}

Selon les régions, les divers types sont plus ou moins bien représentés. En Narbonnaise, seules la zone côtière et la vallée du Rhône connaissent une distribution de ces bijoux; le type 1 (fig. 10) y est fortement représenté, preuve du développement de l'influence romaine; le type 2 est présent surtout dans les formes $2 \mathrm{a}, 2 \mathrm{~b}$ et 2c (fig. 12 à 14), c'est-à-dire pour les bagues des $\mathrm{I}^{\mathrm{er}}-\mathrm{II}^{\mathrm{e}} \mathrm{s}$.; pour les formes les plus récentes ( $2 \mathrm{~d}, 2 \mathrm{e}$ et $2 \mathrm{f})$ (fig. 15 à 17 ), la province perd beaucoup de son inporlance; elle voil ses aclivités se ralentir, comme le montre plus clairement le déplacement des centres fabriquant la sigillée. Elle ne retrouve pas au $111^{*} \mathrm{~s}$. pour les bagues de type 3

16 On peut comparer la diffusion de ce type 1 avec celle des sigillées italiques; - B. Hofmann, Diffusion en Gaule romaine des marques sur sigillée italique depuis l'époque de César jusqu'au règne de Tibère, Actes du colloque le vicus gallo-romain, juin 1975, Caesarodunum, 11, 1976, p. 39-49. (fig. 22 à 25) la vitalité des premiers temps. Sur les cartes de répartition du type 4 des points réapparaissent, autour de Narbonne et du Bas-Rhône (fig. 27 à 31). L'Aquitaine et l'ouest de la Lyonnaise font figure de parents pauvres, quels que soient le type ou la forme étudiès. Seules paraissent vraiment représentées la zone bordant, au nord, le massif Central, et quelques vallées pénétrant dans le massif ; la Loire inférieure et la vallée de la Garonne semblent moins actives. On peut constater ensuite le grand blanc recouvrant la Normandie et la Bretagne, et, dans une moindre mesure, le bassin Aquitain; même sur les cartes figurant les bagues $6 \mathrm{~d}, 6 \mathrm{e}$ et $7 \mathrm{c}$ (fig. 39, 40 et 43 ), les plus proches de la tradition celtique, ces régions sont faiblement représentées. Sont négligées de la même manière les zones montagneuses de l'Est, les Alpes et le Jura, à l'exception de quelques points dans les vallées ${ }^{17}$. Une carte comme celle des anneaux de type 8 (fig. 45 ) révèle bien les zones vides et le semis léger dans l'Ouest de la France.

Les zones de passage de la Lyonnaise, de la Belgique et des Germanies, le Nord-Est, sont notées sur toutes les cartes, vallées de la Saône, de la Moselle ou de la Meuse et du Rhin, plateau de Langres ou plaines du Nord. Et cela, dès le début de l'occupation romaine. En effet, sur la carte de répartition du type 1 (fig. 10), la vallée du Rhin est déjà soulignée par plusieurs points, marques de l'arrivée de Romains et des expéditions rhénanes. Pour le type 2 (fig. 12 à 20 ), la primauté de la vallée du Rhin est évidente; on peut y noter l'importance de Cologne, du delta du Rhin et de Mayence; et, dans cette zone, on peut suivre l'extension romaine au-delà du fleuve, dans les Champs Décumates, en comparant la répartition des formes $2 \mathrm{c}$ et $2 \mathrm{~d}$ (fig. 14, 15). Les deux grandes cités rhénanes, auxquelles onpeut ajouter Trèves, ont fourni la même quantité de bagues $2 \mathrm{a}$ à $2 \mathrm{f}$ que toutes les autres villes et camps du limes; pour les formes $2 \mathrm{~g}$ à $2 \mathrm{i}$, ces trois villes ne représentent plus que le tiers des bagues. Des bagues en bronze $2 \mathrm{~g}$ et $2 \mathrm{~h}$ (fig. 18 et 19), les anneaux de

17 Les zones blanches se retrouvent sur d'autres cartes représentant d'autres produits romains. L'aspect physique de certaines de ces régions explique peut-être une résistance plus grande à la romanisation; mais il faut aussi tenir compte de faits matériels "extérieurs", la politique de fouilles et la destruction des musées lors de la guerre de 1939-1945. La publication de bagues dans des comptes rendus de fouilles n'offre pas toujours les renseignements nécessaires pour classer le bijou. Voir les remarques de F. Braemer, Bronzes romains. Problèmes de géographie, Actes du congrès, Toreulik und figürliche Bronzen römischer Zeit, mai 1980, Berlin, 1984, p. 6386. 
type 8 (fig. 45) ont été découverts en grande quantité dans les zones militaires où une population subalterne n'avait guère les moyens d'acheter et d'offrir qu'un bijou modeste, par exemple les nombreuses bagues portant des inscriptions amoureuses provenant de la zone des canabae du camp de Bonn. Les zones de passage sont à nouveau les plus riches sur les cartes du type 3 (fig. 22 à 25) et du type 9 (fig. 47); les trois grandes cités de Rhénanie sont nettement signalées, mais on peut noter aussi les régions lyonnaise et genevoise; le delta du Rhin est à peu près vide. Sur les cartes du type 4 (fig. 27 à 31 ), qui correspond à peu près au Ive s., si Cologne, Mayence et surtout Trèves sont toujours les centres les plus importants, les bijoux se dispersent dans l'ensemble de ce grand Nord-Est, en particulier dans les régions entre la Meuse et la Seine, ce qui correspond essentiellement aux fouilles des nécropoles barbares; la zone à l'est du Rhin et celle près de l'embouchure sont vides. Pour les autres types de bagues, à toutes les époques, cette zone du Nord-Est est aussi marquée, avec toujours une prédilection pour les voies fluviales ou le plateau bourguignon.

On peut donc lire sur ces cartes (avec peut-être moins de précision que sur les cartes d'autres objets, car les bijoux, nous l'avons dit, sont datés de manière moins sûre que la céramique ou la verrerie) l'empreinte de la civilisation romaine dans des régions privilégiées, soit des axes économiques, soit des zones fortement urbanisées, où les conditions étaient favorables à un commerce de luxe. Les cartes et les schémas de pourcentages des divers types de bagues montrent aussi que la clientèle a évolué; les remarques faites pour les intailles sont valables pour les bagues et les anneaux : au début ( $\mathrm{I}^{\mathrm{er}} \mathrm{s}$. avant $\mathbf{J}$.C. - $\mathrm{I}^{\mathrm{er}} \mathrm{s}$. après J.-C.), la clientèle est limitée, elle est de condition sociale élevée et un second groupe, moins riche, de moins haute condition juridique, se romanise. Dans le courant du $\mathrm{I}^{\mathrm{er}} \mathrm{s}$. et surtout pendant le $\mathrm{II}^{\mathrm{e}} \mathrm{s}$., la clientèle se diversifie et est dispersée sur tout le territoire. A la fin du III' s. et au $\mathrm{IV}^{\mathrm{e}} \mathrm{s}$., la situation s'inverse, la clientèle se raréfie, une partie restant cependant d'un niveau financier assez élevé pour posséder des bijoux de prestige.

\section{Évolution STYLISTIQUe}

On peut essayer de résumer l'évolution stylistique des bagues et des anneaux, à partir de l'examen de ces groupes assez homogènes que représentent les formes et les types 1 à 4 .

Aux Ir-II $^{e}$ s., l'ensemble des bagues donne une impression d'équilibre, de pureté des lignes; pierre et métal sont conjugués en un bijou harmonieux. Dans le courant du $\mathrm{II}^{\mathrm{e}} \mathrm{s}$., apparaissent des formes plus anguleuses, le volume de certains bijoux augmente trop et le décor transforme la surface de quelques bagues dans un rythme le plus souvent régulier; la pierre prend davantage d'importance, dépassant parfois de la ligne de l'anneau. A la fin du II $^{e} s$. et au III $^{\mathrm{e}} \mathrm{s}$., ces tendances se précisent : angles aigus des montures, aspect géométrique des bijoux où les jeux de couleurs s'accentuent, grâce aux décors gravés sur les anneaux ou les épaules, grâce aux trous d'ombre de l'opus interrasile. Au ive s., les bagues $4 \mathrm{e}$ redonnent la même impression de simplicité que celle des bagues $d u \mathrm{I}^{\mathrm{er}} \mathrm{s}$.; les autres bijoux offrent un aspect plus déséquilibré à cause des dimensions différentes de la monture et du chaton, la couleur de la pierre comptant plus que celle du métal.

En cela, les bagues suivent l'évolution générale de la bijouterie romain ${ }^{n}$ entre le $\mathrm{I}^{\mathrm{er}}$ et le $\mathrm{IV}^{\mathrm{e}} \mathbf{s}$., avec la progression de la poly romie, la recherche de l'effet, la géométrisation des iormes; et en même temps, à travers les siècles, cette bijouterie continue à utiliser des formes appréciées pour leur beauté, leur valeur prophylactique ou leur simplicité d'exécution. Les ressemblances avec les autres bijoux se manifestent dans les techniques décoratives (travail à jour en particulier), les motifs décoratifs (volutes, peltes, etc.), le type d'incrustation (usage de monnaies, pierres non gravées comme l'émeraude). A cause de leur forme circulaire, les bracelets et les bagues ont des rapports assez précis ${ }^{18}$. Il est cependant difficile de dire quel est le type de bijou qui a influencé l'autre: l'opus interrasile se développe conjointement autour des médaillons monétaires et sur les épaules des bagues, dès le début du $\mathrm{II}^{\mathrm{e}} \mathrm{s}$. sinon la fin du II $^{e} \mathrm{~s}$., mais l'emploi de lettres en réserve et de "dentelles" de métal est peut-être antérieur sur les anneaux à leur usage sur des bracelets ${ }^{19}$. L'emploi de l'émail et la forme de l'arc découpé par des éperons sont antérieurs sur les fibules à leur utilisation sur les

18 Rapports entre les bagues et les bracelets : type serpentiforme, C. LePage, op. cit.; bagues et bracelets de forme $6 \mathrm{~b}, \mathrm{C}$. Lepage, op. cit.; bagues et bracelets de jais, W. Hagen, op. cit.; anneau 9b (fig. 47 en bas) et bracelet de même forme : P. La Baume, E. Nuber, Das Achatgefass von Köln, Kölner Jahrbuch für Vor-und Frühgeschichte, 12, 1971, p. 80-93, tombe 1 ( $\left.\mathrm{n}^{\circ} 3\right)$.

19 C. Lepage, op. cil., p. 8-12, 14; - Le trésor d'Eauze (Gers), op. cit., Les bijoux (anneau 4); - M. Henig, Continuity and Change in the Design of Roman Jewellery in: The Roman West in the Third Century, Oxford, ed. A. King, M. Henig, 1981, p. 127-143 (p. 129). 
bagues ${ }^{20}$. Les parures complètes retrouvées en Gaule proviennent le plus souvent de trésors du $\mathrm{II}^{\mathrm{e}} \mathrm{s}$. (il est rare de trouver dans une tombe un assortiment assez important de bijoux); ces parures présentent un choix de bijoux très variables en quantité et parfois en qualité (même si les bagues ou les autres bijoux en bronze sont rares dans les trésors). Les bagues sont assez bien représentées dans ces trésors; elles semblent avoir été choisies sans que l'on tienne compte des autres bijoux, même si l'on a respecté la tonalité or ou argent de la parure complète. Plus rare est la recherche d'harmonie entre les pierres ornant une bague et celles des colliers ou des pendants d'oreille ${ }^{21}$; c'est lors de l'achat du bijou par le client que, pour des raisons personnelles, se produit le désaccord entre les bijoux.

Il est délicat de se prononcer sur les rapports entre les bagues de Gaule et celles des autres provinces de l'Empire. En effet, dans le domaine des matériaux, le jugement est partial, car les collections des musées ou les collections privées publiées renferment surtout des objets en métaux précieux ${ }^{22}$. Les études récentes faites en Pannonie, en Mésie ou en Lusitanie $^{23}$ présentent un aspect de la bijouterie

20 Fibules à éperons: L. Lerat, Calalogue des collections archéologiques de Besançon, II, Les fibules, Besançon, 1956, pl. 11 ( no $243 s q$. ; seconde moitié du I I $^{\text {er }}$ s.-début du II' s.); - E. Ettingrer, Die römischen Fibeln in der Schweiz, Berne, $1973\left(n^{\circ} 32\right.$, I $^{e r} \mathrm{~s}$.). On peut noter un décalage de près d'un siècle entre le début de la mode de ces fibules et celui des bagues $3 \mathrm{~d}$.

21 Il y a parfois harmonie entre les bagues et les autres bijoux d'un trésor : bague, pendants d'oreille et collier ornés d'émeraudes à Eauze (Le trésor d'Eauze, (Gers), op. cil.), à Lyon (A. Comarmond, Descriplion de l'écrin d'une dame romaine trouvé à Lyon, Paris-Lyon, 1844); à Sissy (Aisne), parure monométallique, collier, pendants d'oreille et bague (fig. 44) : J.-M. Dessordes, La Picardie antique, Archéologia, 80,1975 , p. $44-60$ (p. 60).

22 La publication de A. DF Rindre, Collection de Clercq, I, Les bijoux, Paris, 1911, montre l'extraordinaire richesse de bijoux provenant de Syrie, mais en fonction d'une collection personnelle et non d'un relevé de fouilles; à l'opposé, les bagues de verre du Musée de Damas ressemblent à celles de Gaule: B. Zounhı, Bracelets et bagues de verre du Musée National de Damas, Annales du Congrès international, Élude historique du Verre, Cologne, 1973, p. 85-99. Le catalogue des bijoux de Naples (R. Sivifro, Gli ori e le ambre del Museo nazionale di Napoli, Florence, 1954) peut être comparé au catalogue de Gaule pour une partie seulement des bagues; la forme $2 b$, assez fréquente dans les villes de Campanie avant l'éruption du Vésuve, se présente ornée de pierres précieuses comme l'émeraude; la même forme en Gaule est beaucoup moins somptueuse.

23 A. Jovanovic, Nakit u Rimskij Dardaniji, coll. Dissertationes et Monographiae, 21, Belgrade, 1978, (Jewelry in Roman Dardania, résumé anglais, p. 109-119); - assez concordant avec celui des bijoux de Gaule, mélange de quelques belles pièces et de nombreuses bagues ordinaires, en bronze surtout et en fer. Au point de vue des formes et des décors, on peut observer une identité assez remarquable entre la Gaule et les provinces du limes danubien : on y retrouve des proportions voisines pour plusieurs formes des types 2 et 4 ; dans le type $3 e$, il y a, des deux côtés, des bagues surtout monométalliques.

Cependant des différences existent, dans les formes, les décors et la chronologie, entre la Gaule et les autres régions de l'Empire. La forme $2 \mathrm{c}$ disparait plus tôt des trésors de Gaule que de ceux des autres provinces; peut-être parce qu'au début du III' s., les artisans de Gaule ont d'autres formes à proposer à leurs clients, les bagues de type 3 . Les bagues du type 1 sont peu représentées en Gaule; elles sont très nombreuses en Orient, pratiquement absentes en Bretagne et sur le limes danubien : la chronologie de ce type hellénistique explique facilement sa faible quantité en Occident ${ }^{24}$, comme s'explique, pour les mèmes raisons, la quasi-absence de grenats comme décor.

Manquent ou presque à la liste des bagues de Gaule, quelques formes: les bagues à double ou triple anneau, prenant deux-trois doigts, certes peu courantes en général, existent en plusieurs exemplaires en Syrie. Les bagues doubles associées (fig. 52), deux ou trois sur le même doigt, réunies par la soudure, sont peu nombreuses en Occident et beaucoup plus fréquentes en Orient, en Égypte en particulier. Les bagues $4 \mathrm{~h}$, à la pierre surélevée, les anneaux faits d'un chapelet de pierres (fig. $30 ; 47$ en bas) sont surtout des bijoux de l'est de l'Empire. On a parlé d'influence de la bijouterie orientale où seraient nées des formes nouvelles, des techniques comme l'opus interrasile, sur l'Occident. En réalité,

K. Mıнovit.sc, Anelli ed orecchini de epoca romana in Slovenia, Arheoloski Vestnik. Acta Archaeologica, 30, 1979, p. 223-242; - E. Avita Franca, Anéis, braceletes e brincos de Conimbriga, Conimbriga, 8, 1969, p. 17-64; - J. A I.ARCAO, R. Étifnne, Fouilles de Conimbriga, VII, Trouvailles diverses. Conclusions générales, Paris, 1979, pl. 31-32.

24 Cinq exemplaires en Bretagne, M. IIENig, A Corpus of Roman Engraved Gemslones from British Siles, Oxford, 1978; sur le limes danubien, une dizaine d'exemplaires. Cette forme est proportionnellement assez bien représentée au Hradischt : J.-L. PIc, Le Iradischt de Stradonilz, Leipzig, 1906, p. 52-53 (site de Bohème occupé jusqu'en 20 après J.-C. environ); en Germanie Libre, Ilenkli., nos 1436, 1445 (lors de l'avancée des Romains au-delà du Rhin, à l'èpoque augustéenne, à Haltern, Westphalie); - C. M. ВескмамN, Melallfingerringe der römischen Kaiserzeil im freien (iermanien, Berlin, 1969, n*5 651 et 704 . 
une communauté de formes et de décors s'est maintenue dans toutes les régions où le style de vie "romain" était diffusé; elle a même débordé les frontières puisque des bijoux de la Russie du Sud ou de la Germanie Libre ont servi d'agents de transmission. Dans le cadre de cette unité, déterminer l'origine d'un type de bijou n'est possible que si le nombre d'exemplaires connus est limité à une région (comme c'est le cas pour les bagues à double anneau) ou s'il y a un net caractère local (les bagues ornées d'un buste en relief de divinité égyptienne). La même incertitude apparaît quand il s'agit de déterminer l'origine d'un motif ou d'une technique de décoration. L'opus interrasile passe pour être une création orientale, syrienne, mais des bijoux bien datés permettent d'en voir l'éclosion, assez tôt, en Gaule ou dans les régions danubiennes, sur des bagues 3f par exemple ou sur des anneaux comme celui du trésor d'Eauze (fig. 49) ${ }^{25}$. I.e développement de la polychromie au Bas-Empire, en Occident, n'est pas exclusivement lié à l'influence des Barbares, car les bijoux syriens ou égyptiens se parent de couleurs variées et les lourds bijoux rutilants de la période des invasions n'ont guère de rapport avec ceux de Gaule au IV" s. Dans ces deux cas, des éléments trop variés se conjugent pour que l'on puisse trancher. Fn revanche, le nielle renait en Occident assez tôt, fréquemment utilisé sur la vaisselle d'argent mais aussi sur les fibules et quelques bagues ${ }^{26}$; la granulation, elle, revient à la mode d'abord en Orient ${ }^{27}$.

Si quelques types de bagues absents ou presque de Gaule peuvent avoir été "inventés» en Syrie, à l'opposé, il est vraisemblable que les formes $3 e$ et $3 f$ sont des créations occidentales, sinon rhénanes ${ }^{28}$. On

25 M. E. MARIEN, Bagues en or en opus interrasile. Notes d'inventaire, Bulletin des Musées royaux d'Art et d'llistoire, Bruxelles, 52, 1980-1, p. 175-180; anneau du trésor d'Eauze enfoui dans les années 260, bagues de Belgique, première moitiè du $1 I^{\mathrm{F}} \mathrm{s}$.

26 Fibules ornées de nielle : F. Etruinger, op. cit., type 43(1), 50-100 après J.-C.; - F. Barattr, Remarques à propos de quelques objets gallo-romains en argent à décor niellé, Antike Kunst, 1978, p. 40-45 (objets provenant de trésors du milieu ou de la fin du $\omega^{\circ}$ s.); - IEnket, no 72 (forme 3e); - de Lyon, forme 3b (fig. 22), A. Comarmond, op. cit., n" 4 (début du $\omega^{\circ} \mathrm{s}$.).

27 O. Picard, J.-P. Sodoni el alii, Collection $H$. Stathatos, IV, Bijoux et petits objets, Athènes, 1971, p. 61 (objets syriens).

28 . Nous avons pu recenser trois fois plus de bagues de forme $3 f$ en Gaule que dans les autres provinces de l'Empire réunies; si la Gaule n'a pas "inventé" cette forme (et rien ne le prouve ou ne le contredit), elle l'a particulièrement appréciée ; cf. Boistray, p. 229. peut aussi mettre à l'actif des bijoutiers de Gaule les bagues ornées d'émail. les bagues décorées d'éperons $3 \mathrm{~d}$, les bagues dont le dessus porte un losange de petits picots (fig. 5̄.4) ${ }^{29}$. Les bagues $6 \mathrm{~d}$ et $6 \mathrm{e}$ connaissent, en Gaule mais aussi le long du limes danubien, beaucoup plus de succès qu'en Orient. Enfin, les bagues de jais sont nombreuses dans les zones rhénanes et les bagues je monométalliques dans la province de Belgique.

Il existe bien dans tout l'Empire une bijouterie assez homogène; cela est dù à l'unification créée par Rome et à l'attrait de ses modes de vie; entre l'Orient et l'Occident, la différence qui apparaît dans les catalogues, ou entre les stèles de Palmyre, les sarcophages de momies égyptiens où s'étalent la profusion et la richesse de leurs bijoux, et les simples stèles funéraires d'Italie ou de Gaule, traduit plus la richesse d'une région. la différence d'état d'esprit que des dissemblances de formes ou de décors. On peut rapprocher la Gaule de la Bretagne et des pays celtiques romanisés, le long du Danube ; la similitude est due peut-être au substrat celtique (mais il faudrait retrouver en Gaule ou en Bretagne, quelques exemplaires de bagues utilisées par les Germains libres ${ }^{30}$ ou des formes celtiques disparues comme les bagues coudées et moins de bagues "romaines»); la ressemblance vient aussi du niveau de développement économique et d'essor de la romanité voisins.

\section{***}

Dans ces conditions, l'originalité des bagues de Gaule n'apparaît guère. Cette absence d'originalité ne signifie pas que seuls quelques centres de fabrication aient pu fonctionner. Certes, la Gaule a pu importer des bijoux d'Orient, les bagues en cristal de roche peut-être, mais rien ne permet de l'affirmer ${ }^{31}$. Elle a dû acheter les bagues d'ambre à Aquilée qui

29 On trouve quelques exemplaires de ces bagues ornées d'émail, d'éperons ou de picots le long du Danube (voir bibliographie, note 23) et en Bretagne: D). D)(Dd.ry, Excavations on Nor'nour in the Isles of Scilly, The Antiquaries Journal, 124, 1967, p. 1-64.

30 C. M. BeckManN, op. cit., formes $17 \mathrm{~b}, 18,39,40,41$, 42 , formes qui n'apparaissent pas en Gaule.

31 La fabrication de bagues en cornaline (le travail est. de mème ordre pour des bagues en (ristal de roche) est active au III' s., dans l'est de l'Empire:-M. MaAskant-Ki.fibrink, The Laocoon Group of Gems, Bulletin antieke Beschaving. 1972, p. 135-146; mais, Henkel, $n^{\prime *} 1793$, 1794, ébauches de bagues en calcédoine provenant de Trèves: travail des pierres semiprécieuses comme l'agate à Cologne: P. I. B Batims, op. cil. 


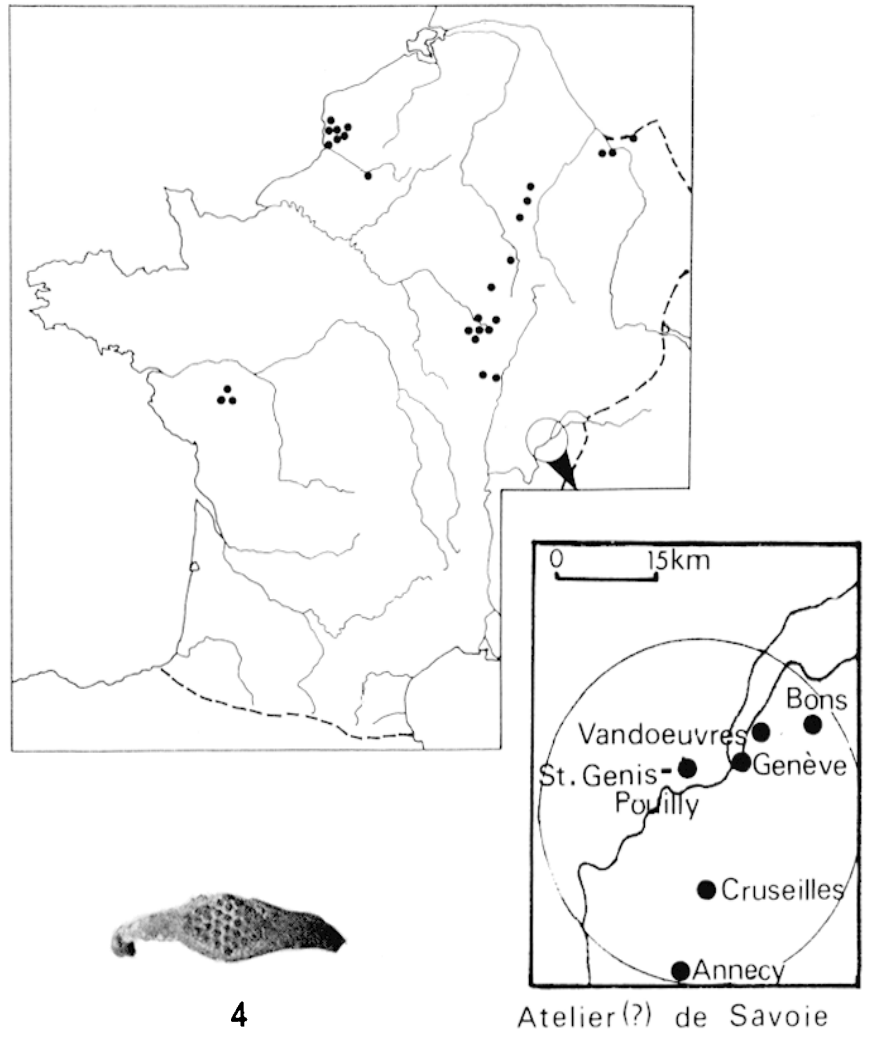

semble avoir été le centre de fabrication à la charnière entre le $\mathrm{I}^{\mathrm{er}}$ et le $\mathrm{II}^{\mathrm{e}} \mathrm{s}$. Mais l'essentiel de ces bagues a dû être fabriqué sur place; cela semble plus particulièrement exact pour les bijoux de pacotille.

Les témoignages archéologiques concernant les artisans, les ateliers, sont rares. On connaît seulement deux inscriptions d'anularii ${ }^{32}$, cinq en l'honneur d'aurifices qui ont pu fabriquer des bagues ${ }^{33}$. Ces inscriptions ne fournissent aucun détail sur les activités des personnages. Les représentations de ces artisans sont peu nombreuses sur les stèles funéraires

32 CIL XII, 4456, Narbonne et XIII, 7249, Mayence; on ne sait si l'anularius est le fabricant ou le marchand de bagues; il existe un faber anularius; le collège d'anularii à Rome est très ancien (CIL VI, 9144); pour ces références, II. Gummfrus, Die römische Industrie. Wirtschaftsgeschichtliche Untersuchungen, Klio, 14, 1915, p. 129-189 et 15, 1918, p. 256-302; - Enciclopedia dell'arte antica $e$ orientale, I, p. $449-450$.

33 CIL XII, 4391, 4464, 4465, Narbonne, 5908, Nîmes et XIII, 5154, Avenches; on en recense une trentaine à Rome et huit en Italie (II. Gummerus, op. cit.; EAA, I, p. 930-932). Rien ne permet d'exclure ou d'inclure d'une liste d'artisans les inscriptions des autres ouvriers métallurgistes, argentarius, aerarius, ferrarius, cela d'autant plus que le rapport entre le terme et les fonctions exactes des personnages n'est pas précisément défini et prête à de nombreuses discussions. Par prudence devant ces imprécisions, nous arrêterons la liste aux seules mentions des anularii et aurifices.

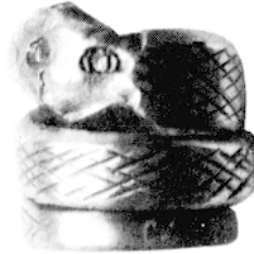

a

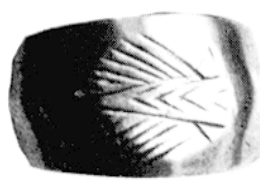

2

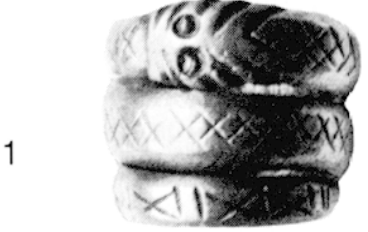

b

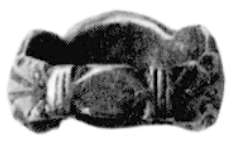

3
Fig. 55 - Localisation d'éventuels ateliers métallurgiques. 1 , bagues $7 \mathrm{c}$-argent, serpentiformes; provenance : Cruseilles (llaute-Savoie);

a, un des modèles de l'atelier (MAH, no $\mathrm{C} 469)$;

b, un autre modèle simplifié (MAH, no 1078$)$;

2, bague $2 \mathrm{~g}$-argent, décor incisé; provenance: Cruseilles (Haute-Savoie); (MAN, no C 468).

3 , bague $3 \mathrm{f}$ - cf. supra, fig. 25 (en haut, à gauche). Même bague, vue de dessous. Provenance: Annecy.

4 , bague $2 \mathrm{~g}$-bronze; provenance : sanctuaire des Sources de Seine (Côte-d'Or); (Musée archéologique, Dijon).

ou les reliefs dans une région de l'Empire qui privilégie pourtant les figurations de métiers; peutêtre peut-on reconnaitre trois familles d'orfèvres ${ }^{34}$. Les fouilleurs ont pu repérer des ateliers métallurgiques grâce à la présence de déchets d'or ou d'argent, des perles ou des pierres semi-précieuses, à Angers ou Rouen $^{35}$ ou des produits semi-finis associés à du matériel métallurgique, à Mâlain (Côte-d'Or), Dalheim (Luxembourg), ou Trèves ${ }^{36}$.

Ces résultats sont minimes, non seulement par rapport à la superficie de la Gaule ou l'espace de

34 E. Espérandieu, op. cit., IX, 6992 (Saint-Ambroix, Cher), IV, 3333 (Langres, Haute-Marne); Gallia, 21, 1963, p. 381 (Alléan, Cher); - P.-M. Duval, Vulcain ou les métiers du métal, Gallia, 10, 1952, p. 43-55; - M. Redde, Les scènes de métier dans la sculpture funéraire gallo-romaine, Gallia, 36 , 1978 , p. 44-63.

35 Angers (Maine-et-Loire) : Gallia, 39, 1981, p. 352; Rouen (Seine-Maritime) : Gallia, 40, 1982, p. 300 et Rouen gallo-romain. Fouilles el recherches archéologiques, catalogue d'exposition, Rouen, 1982, p. 85-88.

36 Mâlain (Côte-d'Or) : L. Rousser. el alii. Mediolanum, une bourgade gallo-romaine. 20 ans de recherches archèologiques, catalogue d'exposition, Dijon, 1988, p. 211-219; travail du bronze, n० 694 (marteau), no 688, b, e, f (creusets tapissés de gouttes d'or) : bronziers-orfèvres; no 696 : bague en cours de réalisation (voir, ici, fig. 56.1 et $2 \mathrm{~b}$ ). Atelier de verrerie de Trèves: voir note 15. Pour les ateliers de Rhénanie, voir Henkfl, p. 306-308 (outils), 329 (ateliers); ici, note 42. Un 
temps concerné, mais aussi face à la réputation d'habileté des métallurgistes gaulois ou la richesse légendaire de la Gaule en or ${ }^{37}$. Le pâle reflet des activités donné par ces témoignages est celui d'un artisanat réparti entre les grands centres urbains et les vici, ce qui est très logique.

Pour connaître les ateliers, on peut aussi noter les ressemblances de formes, décors ou techniques entre divers objets; la prudence, ici, s'impose, d'autant plus qu'il ne peut s'agir d'étude technique fondée sur des analyses, mais seulement de comparaisons stylistiques.

A. Un nombre assez important de bagues serpentiformes en argent a été retrouvé dans un rayon de 20 à $30 \mathrm{~km}$, entre Genève et Annecy (fig. $43,55.1)^{38}$; dix d'entre elles sont datées par la fouille du deuxième tiers du rII $\mathrm{s}$.; les ressemblances sont grandes dans la forme, le décor et aussi dans les irrégularités des molifs décoratifs.

Trois bagues d'argent (fig. 55.2) ${ }^{39}$ identiques proviennent de la même région; l'une d'entre elles est datée du deuxième tiers du $\mathrm{II}^{e} \mathrm{~s}$.

Deux bagues de la même région (fig. 55.3) ${ }^{40}$ en argent ont non seulement la même forme, mais aussi le même décor (rare) sous le doigt; l'une d'entre elles est datée du deuxième tiers du III $^{\mathrm{e}} \mathbf{s}$.

On peut donc raisonnablement croire à l'existence d'un atelier dans la région d'Annecy-Genève, entre 220 et 260 , ou d'un marchand se fournissant auprès.d'un atelier unique (carte fig. 55 ).

B. I'existence d'un atelier de bronzier à Mâlain (Côte-d'Or) est assurée par les résultats des fouilles; on y a trouvé, entre autres objets, une bague

artisanat peut se signaler aussi par un dépôt : découverte récente d'un dépôt d'artisan-orfèvre en Grande-Bretagne, en 1985 : T. W. Potter, A roman jeweller's hoard from Snettisham, Norfolk, Antiquily, 60, 1986, p. 137-139 (dépôt du milieu du II $^{\mathrm{e}} \mathrm{s}$.; sur 89 bagues, de nombreux exemplaires serpentiformes, 21 bagues de forme $2 c$ et une de forme $4 c$; renseignements aimablement fournis par C. Johns, du British Museum).

37 Pline, NH, XXXIV, 162 (étamage de l'argent à Alésia et en pays biturige), XXXVI, 194-195 (verrerie en Gaule); pour les divers textes sur la richesse en or de la Gaule : P.-M. Duval, La Gaule jusqu'au milieu du ve siècle. I, Les sources de l'histoire de France, Paris, 1971.

38 Bagues provenant des trésors de Cruseilles (HauteSavoie), de Saint-Genis (Ain) et d'une tombe des Fins d'Annecy (Haute-Savoie): W. Deonna, Les trésors galloromains d'orfèvrerie du Musée d'Art et d'Histoire de Genève, Revue Archéologique, 1921, p. 243-304; - Henkel, nos 336 et 335 , autres bagues; bagues de forme $7 \mathrm{c}$.

39 Anneau du trèsor de Cruseilles (cf. note précédente) et Henkel, nos 352,353 ; bagues de forme $2 \mathrm{~g}$.

40 Bague de forme $3 f$, tombe d'Annecy (cf. note 38 ) et HENKEL, no 454.

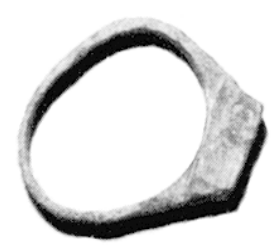

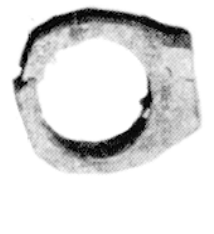

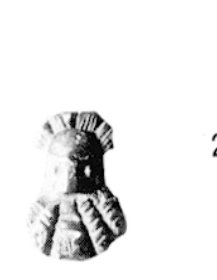

a
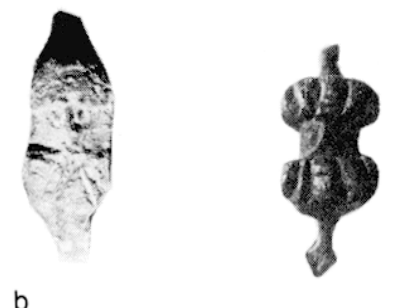

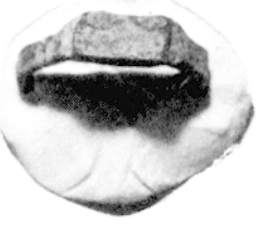

3

Fig. 56 -- Ateliers de Mâlain (Côte-d'Or);

1 , deux anneaux sortis du moule : bagues? vues de profil et de dessus;

2, bagues 4a, bronze. Détail du chaton :

a, bague terminée,

b, volume de la tête brut de fonte; sont ébauchés les ronds des yeux et sur le volume de la barbe quelques traits obliques; 3 , bague $4 a$, bronze; provenance: Virton, province du Luxembourg (Belgique) atelier inconnu; (Musée de Virton).

terminée et son ébauche (fig. 56); deux autres bijoux très proches sont connus, à Virton (Belgique) et à Londres; ont-ils pour origine le même atelier ${ }^{41}$ ? (carte fig. 57).

C. A Dalheim (carte fig. 57), un atelier a fonctionné à la fin du $I^{e} s$.; on peut réunir deux bagues terminées, identiques par la forme et le décor, trois autres à des stades différents de leur élaboration $^{42}$.

D. On peut observer une certaine concentration, dans la province de Belgique, d'un type rare de bague, monométallique, de forme $5 \mathrm{e}$; quatre bagues en or sont travaillées en opus interrasile et certaines portent des inscriptions; d'autres, en argent, ont une zone de dispersion un peu plus grande (fig. 58). Là, nous n'avancerons pas l'idée d'un atelier précis, mais au moins celle d'une zone de distribution de ce type, rare, de bijou ${ }^{43}$.

41 Virton: H. Guiraud, Bijoux d'époque romaine trouvés à Vertunum, Le Pays Gaumais, 42, 1981, p. 7-19, $n^{\circ}$ D 2; - Londres: R. Merrifield, The Roman City of London, Londres, 1965, p. 188, pl. 137(9). Bagues de bronze.

42 Henkel, nos 934, 935 (bagues de forme 3e) de Dalheim, nos 1780,1781 , ébauches de bagues, de Dalheim, $n^{\circ} 1858$, de Trèves, gravure sur le chaton non terminée.

43 Quatre bagues en or: M. E. MARIEn, op. cit., bagues provenant de Vechmaal, Herstal, Grimde et Simpelved ; autres 


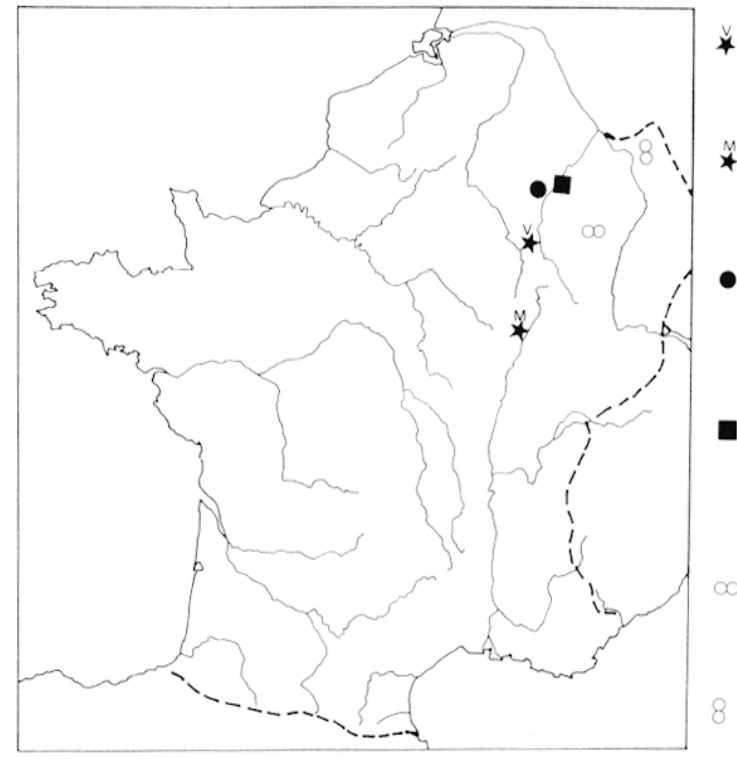

Virton

Mâlain

Dalheim



Trèves



Le Héraple

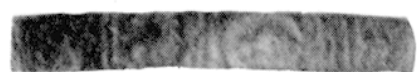

Heddernheim

Fig. 57 - Cartes de divers ateliers et répartition de bagues (voir paragraphes B, C, E et F).

1, bague $3 f$; or; provenance : région de Trèves. Voir Henkel, photo no 257.

2, bague-anneau $8 d$; provenance : Heddernheim (RFA). Voir Henkel, photo no 623.

E. Une bague du trésor de Beaurains (Pas-deCalais) est très proche d'une bague de la région de Trèves (fig. 57): inscription sur l'épaule soulignée par du nielle, forme de l'anneau, motifs de décor; un atelier commun semble plausible; à Trèves ${ }^{44}$ ?

F. Quatre anneaux de bronze ${ }^{45}$ présentent de grandes similitudes (groupe de traits verticaux séparant des zones avec des oiseaux); proviennent-ils d'un atelier commun à mi-chemin entre les deux lieux de provenance, Le Héraple (Moselle) et Heddernheim (Allemagne)? (carte fig. 57).

G. Trente et une bagues (fig. 55.4) de même forme $(2 \mathrm{~g})$, ornées du même type de décor (losange de

bagues de même forme, avec des variantes dans le décor ou le matériau : Ilrnkri, n" 92 (or, d'Augst), 93 (or, de la région de Trèves), 361 (argent, de Bonn), 1056 (bronze, de Mayence); bague en argent de Vertault (Côte-d'Or) (fig. 35). Pour cette forme assez. rare, voir aussi M. Hrenig, II. Chapman, A roman silver ring from London, The Antiquaries Journal, 65, 1985, p. 455-457 (les auteurs citent cinq exemplaires provenant de Bretagne et un de Dacie); et aussi, A. WARD et alii, The Ring from Anliquity to the Twenlieth Century, Fribourg, 1981, n" 68 (de Blagaj, Yougoslavie).

44 Bague $3 f$ en or de Beaurains: P. Bastien, C. Mrtzgra, Le trésor de Beaurains, Mémoires de la Commission départementale des Monuments historiques du Pas-de-Calais, 17,

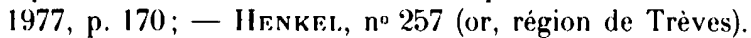

45 Anneaux du Mont Iléraple, Cocheren (Moselle), Musée d'Art et d'IIistoire, Metz, n* 3519, 3920; - E. IIurfar, Fouilles du Heraple, 1881-1904, Strasbourg, 1907-1908, no 402, 409 ; - Henkel, nos 623,624 (du fort du limes, Heddernheim, abandonné au milieu du $\mathrm{wI}^{\mathrm{s}} \mathrm{s}$.) en bronze. petits picots) ont été retrouvées dans des sites assez éloignés les uns des autres ${ }^{46}$. Ont-elles été offertes à la déesse de la Seine? A Étaples (Pas-de-Calais), estce le lot d'un marchand prêt à partir pour la Bretagne ... ou en revenant? Quel(s) atelier(s) a (ont) fabriqué ces petits objets? (carte, fig. 55 ).

On trouve aussi, sur certains sites, des bagues jumelles qui ont été faites dans le même atelier, puis vendues par le mème marchand, mais pour lesquelles on ne peut remonter plus haut dans leur histoire;

46 Bagues de bronze; six des Sources de la Seine (Côted'Or, Musée archéologique de Dijon; deux des Bolards (Côted'Or), Musée archéologique de Dijon, $n^{* 8} 7144,7140$ (bagues citées par M. de Lama fstre, Bijoux gallo-romains. Objels el représentations, mémoire de Maitrise, Université de Dijon, $\left.1980, n^{\prime *} 72-73\right)$; une de la région de Langres (Haute-Marne), Musée Saint-Didier, Langres; une de la région de Grand (Vosges), Musée départemental des Vosges, Épinal; une du Mont-Chyprès, Lacroix-Saint-Ouen (Oise), Musée des Antiquités nationales, Saint-Germain-en-Laye, no 14437; une de Virton (II. Guiraud, op. cit., n" C1); sept provenant d'Étaples (Pas-de-(ialais), Musée Quentovic, Etaples, $\mathrm{n}^{\circ \mathrm{5}}$ 50, 420, 561, $834,1122,825$, un fragment ; trois de Naintré (Vienne), Musée, Chàtellerault; les bagues des Bolards et de Naintré datent du II' $^{\circ}$. Autres bagues : Henkri, $n^{98} 877,878$ (de Dalheim), 879 (d'lleddernheim), 880, 881 (de la région de Mayence); on peut citer quatre exemplaires en Bretagne : deux de Verulamium, de la fin du jer $^{\text {s.: }}$ R. E. M. Wherier, T. E. Whenler, Verulamium. A Belgic and two Roman Cities, Oxford, 1936, p. 215 (fig. 47, no 81) et S. Frsar, Verulamium. Excavalions, Oxford, 1972, I, p. 120 (fig. 38b); M. Henig a bien voulu nous signaler la présence de deux autres bagues en Bretagne (sans référence), 


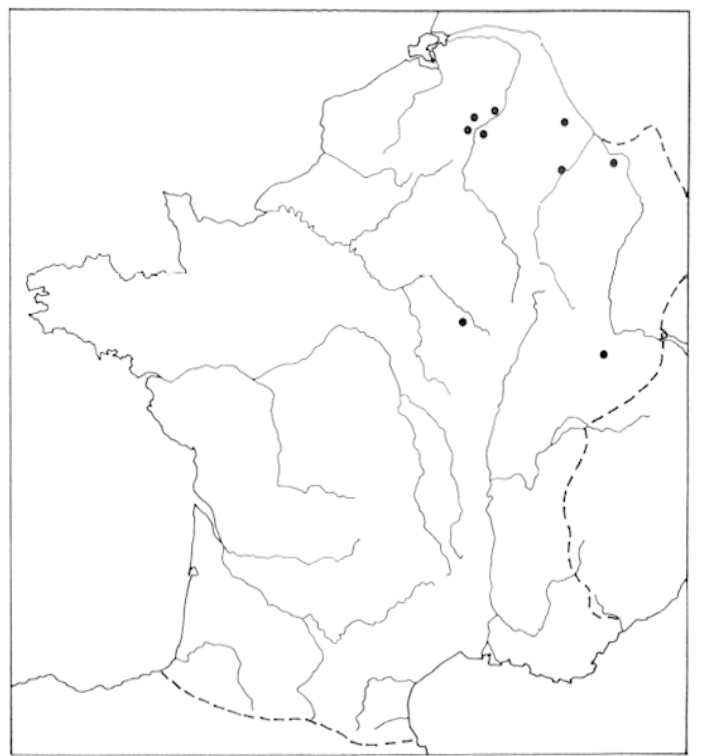

Fig. 58 - Carte de répartition des bagues monométalliques de forme $5 \mathrm{e}$.

c'est le cas à Lectoure (Gers) (deux bagues 3e), aux Bolards (Côte-d'Or) (fig. 59), à Chalain-d'Uzore (Loire) ${ }^{47}$. A Bonn, dans le quartier des canabae, on a retrouvé plus de cinquante bagues de bronze de même forme et portant des inscriptions variées mais, en grande majorité, témoignage d'affection ${ }^{48} ; \mathrm{y} \mathrm{a-t}$ il eu un même marchand? Ou plutôt un même atelier?

Ces divers exemples mettent en relief le secteur compris entre le Seuil de Bourgogne et les plaines du Nord, le long des rivières comme la Moselle ou la

47 Bagues des Bolards : M. de Lamanstre, op. cit., nos 76-77; un exemplaire de même décor à Alésia (Côte-d'Or), collection Pernet, Musée Alise-Sainte-Reine. Trésor de Chalain-d'Uzore: M. Frugrere, Le trésor de Chalain-d'Uzore (Loire), Cahiers archéologiques de la Loire, 4-5, 1984-85, p. 35-70, nos 16 et 17 , forme $3 e$ en argent, nos 27 et 28 , forme 3 a en argent (fig. 8.3 et 22 ).

48 Henkes, nos 813-873 (six d'entre elles ne proviennent pas de Bonn); type d'inscriptions : AMA ME ( $n^{\circ} 820$ ), AVE DULCIS (n० 823), MEMINI TUI (n० 846), AMA, AMO (n* 819); bagues de bronze de forme $2 \mathrm{~g}$.

49 Il n'était pas possible d'exploiter ici les résultats d'une recherche sur les possesseurs de ces bagues et anneaux. Les lieux de provenance apportent de précieuses indications, mais nous ne connaissons le nom que d'une dizaine de personnes et nous ne savons que peu de choses sur eux!
Fig. 59 - Bagues $4 \mathrm{~g}$; bronze; décor imitant une sandale ou une empreinte de pied;

provenance : Les Bolards,

Nuits-Saint-Georges

(Côte-d'Or);

(Musée archéologique,

Dijon, nos 7.142 et 7.143 ).
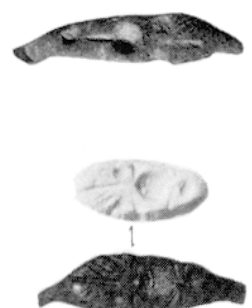

Meuse; sauf cas exceptionnel (Mâlain, Dalheim, Trèves), aucune certitude ne nous assure de la présence d'un atelier en un lieu précis, mais tant de points convergent vers cette région.

Des ateliers urbains de produits de luxe et de bijoux de pacotille ont fonctionné dans les grandes villes; de pelits ateliers onl fabriqué des objets modestes pour le marché local dans de petits centres commerciaux, des vici héritiers peut-être de la tradition celtique du travail métallurgique.

Les formes de bagues de type romain se sont répandues en Gaule sans hésitation. La clientèle, qui n'est pas connue individuellement sauf en de très rares $\operatorname{cas}^{49}$, a évolué en fonction de l'évolution de la Gaule elle-même; la richesse économique de la pax romana au II"s., puis les difficultés de Rome, sur le limes, en Gaule mème, au III's., l'arrivée des Barbares et les changements dans les centres actifs, tout cela peut se déchiffrer sur les cartes de répartition des bagues.

Hélène Guiraud

Abréviations des musées courammenl cités :

M.A..N. : Musée des Antiquités nationales, Saint-Germain-enLaye (Yvelines)

M.A.H. : Musée d'Art et d'Histoire, Genève (Suisse)

M.C.G.R., Lyon : Musée de la Civilisation gallo-romaine, Lyon (Rhône)

Siles archéologiques célèbres et leurs communes :

Alésia : Alise-Sainte-Reine (Côte-d'Or)

Boistray : Saint-Georges-de-Reneins (Rhône)

Cimiez: Nice (Alpes-Maritimes)

Les Bolards : Nuits-Saint-Georges (Côte-d'Or)

Sanctuaire des Sources de la Seine: Saint-Germain-SourceSeine (Côte-d'Or) 